\title{
Clinical and molecular genetic studies in hereditary syndromes featuring skin appendage tumors
}

Citation for published version (APA):

Parren, L. J. M. T. (2018). Clinical and molecular genetic studies in hereditary syndromes featuring skin appendage tumors. [Doctoral Thesis, Maastricht University]. Datawyse / Universitaire Pers Maastricht. https://doi.org/10.26481/dis.20181204lp

Document status and date:

Published: 01/01/2018

DOI:

10.26481/dis.20181204lp

Document Version:

Publisher's PDF, also known as Version of record

\section{Please check the document version of this publication:}

- A submitted manuscript is the version of the article upon submission and before peer-review. There can be important differences between the submitted version and the official published version of record.

People interested in the research are advised to contact the author for the final version of the publication, or visit the DOI to the publisher's website.

- The final author version and the galley proof are versions of the publication after peer review.

- The final published version features the final layout of the paper including the volume, issue and page numbers.

Link to publication

\footnotetext{
General rights rights.

- You may freely distribute the URL identifying the publication in the public portal. please follow below link for the End User Agreement:

www.umlib.nl/taverne-license

Take down policy

If you believe that this document breaches copyright please contact us at:

repository@maastrichtuniversity.nl

providing details and we will investigate your claim.
}

Copyright and moral rights for the publications made accessible in the public portal are retained by the authors and/or other copyright owners and it is a condition of accessing publications that users recognise and abide by the legal requirements associated with these

- Users may download and print one copy of any publication from the public portal for the purpose of private study or research.

- You may not further distribute the material or use it for any profit-making activity or commercial gain

If the publication is distributed under the terms of Article $25 \mathrm{fa}$ of the Dutch Copyright Act, indicated by the "Taverne" license above, 


\section{Clinical and molecular genetic studies in hereditary syndromes featuring skin appendage tumors}

\section{Lizelotte Parren}

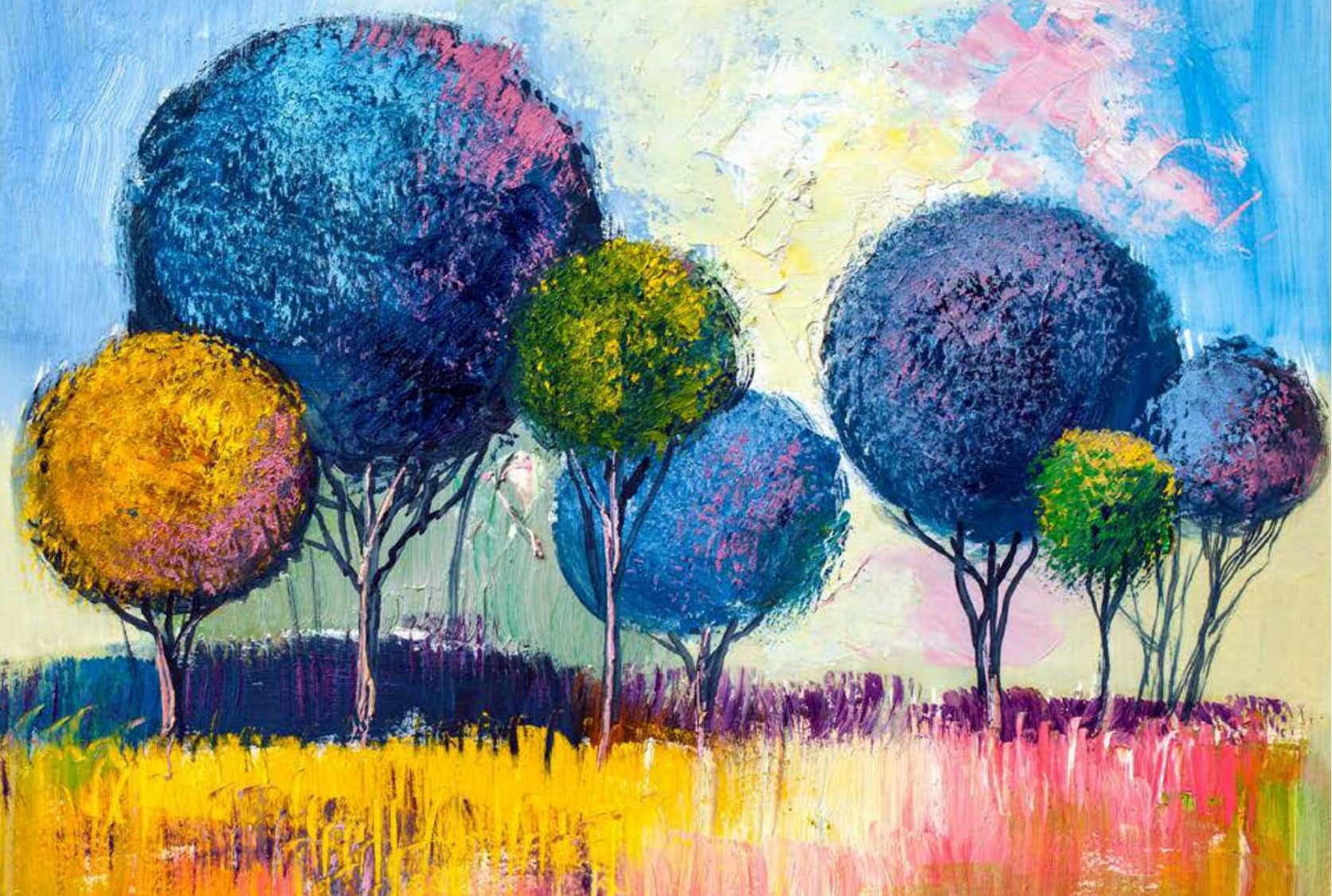




\title{
Clinical and molecular genetic studies in hereditary syndromes featuring skin appendage tumors.
}

\author{
PROEFSCHRIFT \\ ter verkrijging van de graad van doctor aan de Universiteit Maastricht \\ op gezag van Rector Magnificus, prof. dr. Rianne M. Letschert \\ volgens het besluit van het College van Decanen, \\ in het openbaar te verdedigen \\ op dinsdag 4 december 2018 om 14.00 uur \\ door \\ Lizelotte Johanna Maria Theresia Parren \\ Geboren te Sittard, 7 augustus 1983
}




\section{Promotores}

Prof. dr. P.M. Steijlen

Prof. dr. J. Frank (Universitair Medisch Centrum Göttingen, Duitsland)

\section{Copromotor}

dr. M. van Geel

\section{Beoordelingscommissie}

Prof. dr. A. zur Hausen (voorzitter)

dr. R. van Doorn (Leiden UMC)

Prof. dr. dr. P. van de Kerkhof (Radboud UMC)

dr. M. Vreeburg 
Aan mijn ouders 



\section{Contents}

Chapter 1 General introduction and aims of the thesis

Part $1 \quad$ Brooke-Spiegler syndrome

Chapter 2 Brooke-Spiegler syndrome complicated by unilateral hearing loss

Chapter 3 Molecular basis of Brooke-Spiegler syndrome

3.1

3.2

Novel splice site mutations differentially affect splicing and mRNA decay

Phenotypic variability in tumor disorders of the skin appendages

associated with mutations in the CYLD gene

3.3 Clustered unilateral trichoepitheliomas indicate type 1 segmental manifestation of multiple familial trichoepithelioma

Chapter 4 A novel therapeutic strategy for turban tumor: scalp excision and combined reconstruction with artificial dermis and split skin graft

\section{Part 2}

Bazex-Dupré-Christol syndrome

Chapter 5 Hereditary tumor syndromes featuring basal cell carcinomas

Chapter 6 Basal cell carcinoma and trichoepithelioma: a possible matter of confusion

Chapter 7 Multiple basal cell carcinomas in childhood: Bazex-Dupré-Christol syndrome

Chapter 8 Linkage refinement of Bazex-Dupré-Christol syndrome to an $11.4 \mathrm{Mb}$ interval on chromosome Xq25-27.1

Chapter 9 Discussion and valorisation

Summary

Samenvatting

List of abbreviations

Curriculum vitae 

Chapter 1

General introduction and aims of the thesis 
The skin appendages are derived from the embryonic ectoderm and are represented by the pilosebaceous unit, the eccrine sweat gland and the apocrine gland. ${ }^{1}$ The pilosebaceous unit is composed of the hair follicle, the sebaceous gland and the arrector pili muscle. ${ }^{2}$ The functions of the skin appendages include hair production, thermoregulation by sweat excretion, and producing sebum and scents.

Various tumors can arise from the skin appendages, including cylindromas, trichoepitheliomas, spiradenomas, and basal cell carcinomas.

\section{Cylindroma}

Cylindromas are benign slow-growing firm skin-colored to red nodules that can range in size from a few millimeters to several centimeters (Fig. 1a). The vast majority of cylindromas manifest on the scalp, and to a lesser extent on the trunk and extremities. Usually, these tumors occur solitary. For a time, it was debated whether cylindromas originate from eccrine or apocrine structures. Recently, however, it could be demonstrated that they presumably arise from hair follicle stem cells. ${ }^{3}$

Histologically, cylindromas consist of non-encapsulated irregularly shaped islands and lobuli of epithelial cells, which are surrounded by eosinophilic hyalinized material and are arranged in a "jigsaw puzzle" pattern (Fig. 1b). These islands are composed of larger, more differentiated cells with large pale nuclei in the center, and a palisade of smaller, less differentiated cells with dark nuclei at the periphery. ${ }^{3,4}$

Although cylindromas are benign, in rare cases malignant transformation has been described. ${ }^{5,6}$ Signs of malignant transformation include rapid growth, pain, ulceration and bleeding. Local infiltrative growth and metastasis, most often in lymph nodes, spinal bones and liver, has been reported. ${ }^{6}$
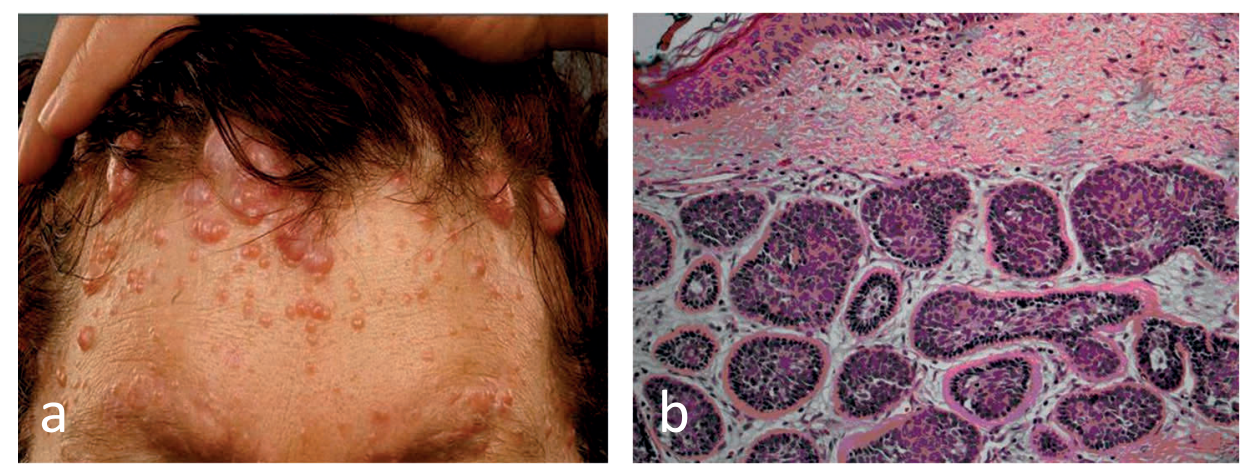

Figure 1

a. Clinical presentation of cylindromas on the head.

b. Histological signs of cylindroma: non-encapsulated irregularly shaped islands of epithelial cells that fit together like a "jigsaw puzzle", surrounded by eosinophilic hyalinized material. 


\section{Trichoepithelioma}

Trichoepitheliomas are benign small skin-colored papules with a diameter of 2-8 millimeters (Fig. 2a). Predilection sites are the nose, nasolabial folds, neck, and upper part of the trunk. Trichoepitheliomas originate from hair follicle cells. Histologically, a welldemarcated dermal tumor can be seen that consists of uniform basaloid cells with peripheral palisading. They are arranged in trabecular nests, which are surrounded by stroma containing fibroblasts (Fig. 2b). ${ }^{7,8}$ Both the clinical and histological presentation can resemble a basal cell carcinoma that can also arise from hair follicles. ${ }^{9}$ In comparison to trichoepithelioma, however, basal cell carcinomas tend to show more ulceration, peripheral palisading of basaloid keratinocytes, stromal edema, peritumoral mucin production and mitosis. Additional immunohistochemistry, in particular with androgen receptor and TGF- $\beta$, may be useful to differentiate the two entities. ${ }^{10}$
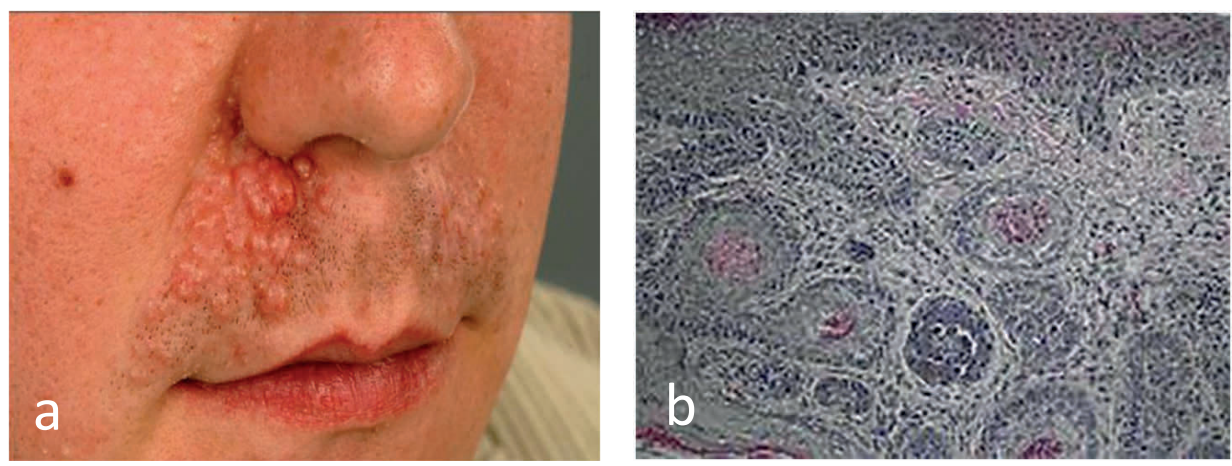

Figure 2

a. Clinical presentation of trichoepitheliomas on the upper lip.

b. Histology of trichoepitheliomas: trabecular nests of basaloid cells surrounded by stroma containing fibroblasts.

\section{Spiradenoma}

Spiradenomas are benign tumors presenting as solitary, painful, red or blue nodules on the trunk or upper extremities (Fig. 3a). Spiradenomas are derived from eccrine sweat glands. ${ }^{4}$ Histologically, spiradenomas are well-circumscribed nodules localized in the dermis and subcutaneaous fat, enclosed by fibrous material (Fig. 3b). In the center of the nodules large cells with round nuclei and pale cytoplasm can be found, whereas in the periphery of the nodules smaller cells with hyperchromatic nuclei and scant cytoplasm are located. ${ }^{4}$

Malignant transformation of spiradenomas is well known and is characterized by ulceration, rapid growth, pain and erythema. Metastasis to lymph nodes, bone, lung, liver and brain has been described. ${ }^{11,12}$ 

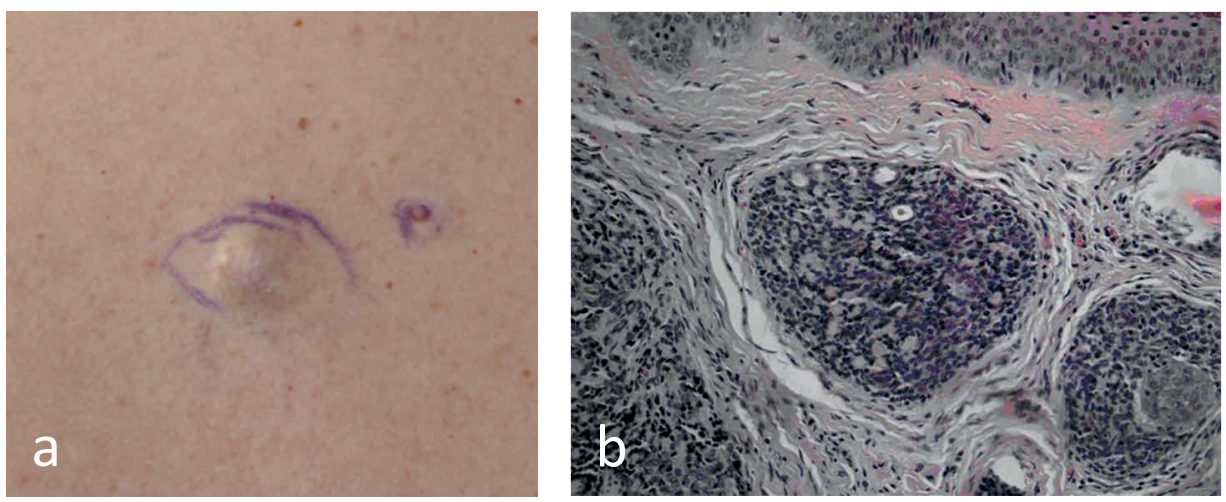

Figure 3

a. Clinical presentation of a spiradenoma.

b. Histological signs of spiradenoma: sharply circumscribed nodule in the dermis. Cells in the center have scant cytoplasm and round nuclei.

\section{Basal cell carcinoma}

Basal cell carcinomas are malignant tumors presenting as erythematous to skin-colored macules or plaques, often with a pearly border and telangiectasia (Fig. 4a). They mainly arise on the sun-exposed areas of the skin, most probably due to high cumulative exposure to ultraviolet radiation. Other risk factors for the development of these tumors include Fitzpatrick skin type 1 and 2, radiotherapy, immunosuppression, higher socioeconomic status, a previous basal cell carcinoma on the upper extremities, a relatively young age at first onset and genetic defects. ${ }^{13}$ Basal cell carcinomas are thought to be hair follicle tumors since they preferentially arise from stem cells located in the upper bulge, lower bulge, isthmus of the hair follicle and touch dome epithelia. ${ }^{14,15}$ Histologically, different types of basal cell carcinomas can be distinguished, including superficial, nodular, morpheaform (infiltrative) and basosquamous (metatypical) carcinomas. They are characterized by nests of basaloid cells in the dermis attached to the epidermis with peripheral palisading of basaloid keratinocytes and artificial retraction between the nests (Fig. 4b). ${ }^{16}$ 

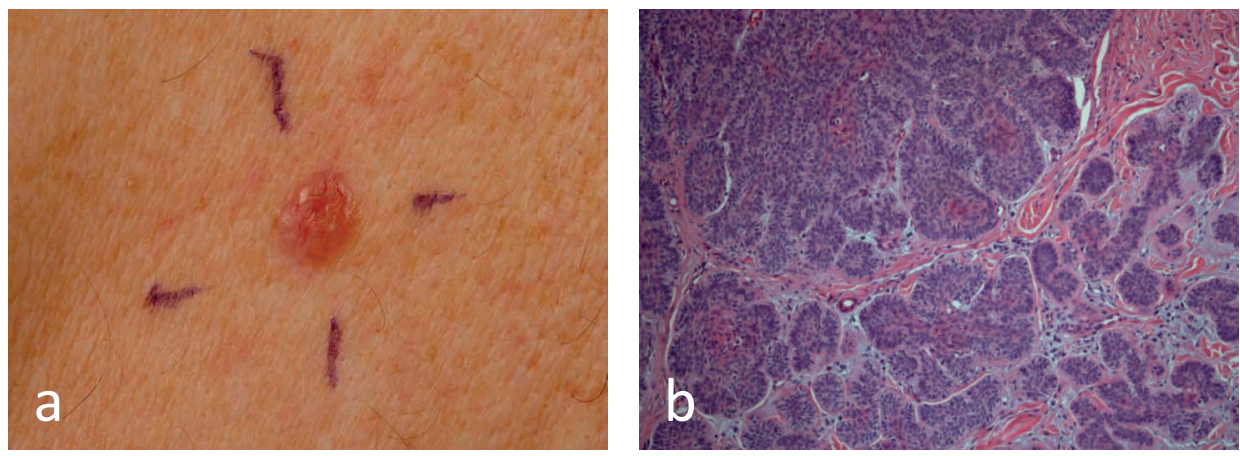

Figure 4.

a. Clinical presentation of a basal cell carcinoma on the back.

b. Histological signs of basal cell carcinoma: nests of basaloid cells in the dermis with peripheral palisading of basaloid keratinocytes and cleft formation.

\section{Hereditary syndromes associated with hair follicle tumors}

Cylindromas, trichoepitheliomas, spiradenomas and basal cell carcinomas can arise sporadically but can also be seen in the context of hereditary cutaneous tumor syndromes, such as Brooke-Spiegler syndrome (BSS) (OMIM 605041), familial cylindromatosis (OMIM 132700), multiple familial trichoepithelioma (OMIM 601606), Bazex-DupréChristol syndrome (BDCS) (OMIM 301845) and basal cell nevus syndrome (BCNS, Gorlin syndrome) (OMIM 109400).

\section{Brooke-Spiegler syndrome}

BSS is an autosomal dominant disorder characterized by the development of cylindromas, trichoepitheliomas and spiradenomas. In 1842, Ancell for the first time described "a remarkable case of tumours developed on the head and face with a similar disease in the abdomen" ${ }^{17}$ Originally, these tumors were called Ancell-Spiegler cylindromas and Brooke-Fordyce trichoepitheliomas. ${ }^{17-20}$ In 1968 , Welch et al. reported a patient with both cylindromas and trichoepitheliomas. This clinical observation led to speculations about the monogenetic origin of these two hair follicle tumors. ${ }^{21}$ In 1974, a patient was described who revealed both trichoepitheliomas and cylindromas in association with spiradenomas. ${ }^{22}$ In 2000, mutations in the CYLD gene were reported to cause all three forms of tumors in association with BSS. ${ }^{23}$ 


\section{Clinical presentation}

Cylindromas, trichoepitheliomas and/or spiradenomas in patients with BSS usually develop from the third decade onwards. Women are more frequently affected than men. ${ }^{24}$ During life, the tumors grow slowly and increase in size and number. Tumor size and distribution shows considerable intra- and interfamilial variability. In severe cases, cylindromas can coalesce to large masses that cover the whole scalp, so called turban tumors. This disfiguring phenotype can lead to cosmetic, mechanic, and psychological impairment. Complications include visual and hearing impairment by occlusive tumor growth, pain, and discomfort. Extracutaneous manifestations are rare, but cylindromas in the breast, lung and basal cell adenomas of the parotid glands have been described. ${ }^{25-28}$

Besides the aforementioned diffuse phenotype, a segmental or linear distribution of trichoepitheliomas or spiradenomas has been described, indicating mosaicism. ${ }^{29-35}$ In 1996 and 1997, Happle introduced two types of mosaic presentation of autosomal dominant disorders. In segmental type 1 mosaicism, a heterozygous de novo postzygotic somatic mutation in an otherwise healthy embryo causes a segmental presentation of the disease. A germline mutation is absent. ${ }^{36}$ The segmental type 2 manifestation is caused by a germline mutation in combination with loss of heterozygosity occurring at an early developmental stage. Clinically, the type 2 segmental manifestation is characterized by an area of more severe disease manifestation, usually occurring early in life, superimposed on the common diffuse and symmetric phenotype. ${ }^{37,38}$ Only few cases of type 1 and type 2 segmental trichoepitheliomas and spiradenomas have been described. To the best of our knowledge, however, none of these cases have been analyzed on the molecular genetic level. ${ }^{29-35}$

\section{Molecular genetic background}

In 1995, Biggs and colleagues reported linkage of BSS to chromosome $16 q 12-13 .{ }^{24}$ Five years later, the first germline mutations in the CYLD gene were detected in families with BSS. ${ }^{23}$ On the genomic level, the CYLD gene spans 56 kilobases and consists of 20 exons, of which the first three are non-coding (NCBI RefSeq: NM_015247.2). ${ }^{23}$ To date, CYLD seems to be the only gene involved in the formation of cylindromas and trichoepitheliomas in $\mathrm{BSS}^{39}$ It is thought to function as a tumor suppressor gene since $90 \%$ of the germline mutations are truncating; and in cylindromas and trichoepitheliomas loss of the wild-type allele was found. ${ }^{24,40}$

The CYLD gene encodes for the homonymous protein CYLD. Almost identical orthologues of the human CYLD protein have been identified in different species, including Drosophila melanogaster, Caenorhabiditis elegans, and mice, showing that CYLD is well conserved across evolution. ${ }^{23}$ The fact that human and mouse CYLD genes share 
95\% homology makes the CYLD knockout mouse a perfect model to study the clinical consequences of CYLD dysfunction. ${ }^{41}$ CYLD is expressed in fetal brain and skeletal muscle, and at lower levels in adult brain, leukocytes, liver, heart, kidney, spleen, ovary and lung. ${ }^{42}$ Interestingly, expression in the epithelium of human scalp hair follicles has been described as well. ${ }^{41}$

CYLD is a member of the ubiquitin-specific protease (USP) families of proteins and plays a central role in the nuclear factor-kappa B (NF-kB) pathway by acting as a deubiquitinating enzyme. CYLD consists of 956 amino acids and has a molecular weight of $107 \mathrm{kDa}$. It contains four groups of recognizable sequence motifs, which are three cytoskeleton-associated protein glycine-rich (CAP-GLY) domains and a ubiquitin C-terminal hydrolase (UCH) catalytic domain. ${ }^{23,43}$ The CAP-GLY domains are responsible for microtubule binding. The UCH catalytic domain, including a zinc-finger-like B-box domain, is involved in the de-ubiquitinating activity of CYLD.

Ubiquitination plays an important role in DNA repair, nuclear translocation, and endocytosis. ${ }^{40}$ This reversible process is characterized by binding the carboxy-terminal glycine of one ubiquitin to an internal lysine of another ubiquitin. ${ }^{43}$ Ubiquitination can be mediated through lysine-63 (K63)-linked chains or lysine-48 (K48)-linked chains. ${ }^{44}$ Whereas ubiquitination through K63-linked chains act as substrate for non-degradative functional properties of a modified protein, K48-linked chains promote proteasomal degradation. ${ }^{43,44}$ The ubiquitin reaction is catalyzed by three ubiquitin ligation enzymes (E1-E3). This process can be reversed by deubiquitinating enzymes (DUBs), such as CYLD. DUBs recognize specific ubiquitin chain linkages, e.g. CYLD is a K63-specific DUB which removes the K63-linked chains from tumor necrosis factor associated receptor 2 (TRAF2).${ }^{44}$ Through this mechanism CYLD plays an important role in the NF-kB signaling pathway.

\section{NF-kB signaling pathway}

The NF-kB signaling pathway is a cellular communication system. NF-kB is a transcription factor that was discovered in 1986 in the laboratory of D. Baltimore. ${ }^{45}$ It regulates expression of many genes, which are essential for the regulation of apoptosis, viral replication, tumorigenesis, inflammation and immune homeostasis. NF-kB is kept inactive in the cytoplasm by binding to the $\mathrm{IkB}$ complex. Two main pathways resulting in activation of NF-kB have been described; the canonical (classical) and non-canonical (alternative) pathway. ${ }^{46}$

The canonical pathway starts with a response to extracellular signals, which bind to a cell surface receptor. This receptor enlists adapters, for example TRAF2 to the cytoplasm of the cell. After self-ubiquitination, TRAF2 activates the IKappaB-kinase (IKK)complex, which consists of catalytic kinase subunits (IKKalpha and/or IKKbeta) and NF$\mathrm{kB}$ essential modulator (NEMO). Activation of the IKK-complex results in phosphoryla- 
tion of IkBalpha and degradation of IkB by the proteasome, which enables NF-kB to enter the nucleus, where it activates downstream target genes (Fig. 5). Normally, CYLD interacts in the canonical pathway by binding to and de-ubiquitinating NEMO, TRAF2 and TRAF6. ${ }^{47-50}$ CYLD dysfunction or knockdown leads to overactivation of TRAF2, which results in constitutive activation of NF-kB.

The non-canonical pathway differs from the canonical in that the activated IKK complex consists of 2 IKKalpha subunits and does not contain NEMO. In this pathway, receptor binding leads to activation of the NF-kB-inducing kinase (NIK). This in turn phosphorylates and activates an IKKalpha complex, resulting in activation of IkBalpha, which in turn enables NF-kB to enter the nucleus (Fig. 5). ${ }^{46,51}$ Massoumi and colleagues have shown in mouse models that CYLD interacts in the non-canonical pathway by affecting $\mathrm{Bcl}-3$. Bcl-3 is a coactivator of NF-kB that is present in the cytoplasm. Normally, CYLD blocks Bcl-3 by removing K63-linked polyubiquitin chains (de-ubiquitination) (Fig. 5). In case of deficiency of CYLD, Bcl-3 enters the nucleus and induces transcription of NF-kB target genes by activating NF-kB. ${ }^{52}$



Figure 5. A concise overview of the NF-kB signaling pathway.

In the canonical pathway, extracellular signals, such as TNF- $\alpha$ and bacterial lipopolysaccharide (LPS), bind to a cell surface receptor (TNF receptor and toll-like receptor (TLR)). This subsequently activates a cascade, in which eventually NF-kB is able to enter the nucleus where it activates downstream target genes.

In the non-canonical pathway, receptor binding leads to activation of NIK, thereby activating a cascade in which NF-kB can also enter the nucleus to activate downstream target genes.

CYLD interacts by binding to and de-ubiquitinating NEMO, TRAF2 and TRAF6. CYLD also blocks Bcl-3 by deubiquitination. 


\section{Genotype-phenotype correlation}

BSS shows considerable clinical overlap with multiple familial trichoepithelioma and familial cylindromatosis, in which either trichoepitheliomas or cylindromas arise solely. All three disorders are inherited in an autosomal dominant fashion and are caused by heterozygous mutations in the CYLD gene. Although these diseases have different OMIM numbers they seem to be allelic and, thus, might be a phenotypic variation of the same genetic disorder. ${ }^{40,53}$

To date, more than 100 mutations have been described in the CYLD gene, comprising splice site, frameshift, nonsense, missense mutations, and large genomic deletions. ${ }^{53-57}$ Still, no evident genotype-phenotype correlation could be established, which is supported by the fact that patients and families with the same CYLD germline mutation show inter- and intrafamilial phenotypic variability. ${ }^{53}$

\section{Treatment}

Currently, no curative therapy for BSS is available. Treatment of cylindromas, trichepitheliomas and/or spiradenomas in BSS can be challenging due to the localization and multitude of tumors. Many treatment options have been reported, including conventional surgery, electrosurgery, cryosurgery, Mohs' micrographic surgery, total scalp excision, dermabrasion, curettage, and ablative therapy with erbium:Yag or $\mathrm{CO}_{2}$ lasers. ${ }^{58,59} \mathrm{~A}$ disadvantage of these therapeutic modalities is scar formation and possible tumor recurrence. Currently, the therapy of first choice for cylindromas and trichoepitheliomas is excision of the tumors.

For BSS, a causal, pathway-based therapy would be desirable. In 2003, Brummelkamp and colleagues explored a pathway-based therapy for cylindromas consisting of topical treatment with $20 \%$ salicylic acid in unguentum lanette. ${ }^{60}$ Salicylic acid interferes with the NF-kB pathway by inhibiting IKK-gamma. Although this treatment was not curative, tumor growth could be slowed down or even completely blocked. ${ }^{61}$ Possibly, more specific and potent inhibitors of the NF-kB pathway will be necessary to halt growth or prevent the development of skin appendage tumors in patients with BSS.

\section{Bazex-Dupré-Christol syndrome}

BDCS is a rare X-linked hereditary disorder affecting the hair follicle. In 1964, the disease was described for the first time by Bazex, Dupré and Christol. ${ }^{62}$ 


\section{Clinical presentation}

BDCS is characterized by congenital hypotrichosis, follicular atrophoderma (affecting the dorsa of hands and feet, extensor surfaces of the elbows and/or knees, and face), and early onset of basal cell carcinomas. ${ }^{62}$ Other features that have been described are trichoepitheliomas, milia, hypohidrosis, facial hyperpigmentation, hair shaft abnormalities (trichorrhexis nodosa and pili torti) and pinched nose with hypoplastic nasal alae and prominent columella. ${ }^{63-66}$

\section{Molecular genetic background}

Until recently, the genetic defect underlying BDCS was not known. Since no male-tomale transmission in affected families had been described and almost all daughters of affected fathers were affected, an X-linked dominant inheritance mode was suspected. In line with this observation, Vabres and colleagues mapped the gene for BDCS to chromosome Xq24-q27.1 in 1995. ${ }^{67}$ Subsequently, we were able to refine the candidate region for BDCS to an 11.4 Mb interval on chromosome Xq25-27.1. Recently, Bal and colleagues described a germline mutation in the ACTRT1 gene in two families with BDCS (c.547_548insA) and germline mutations in noncoding sequences surrounding the ACTRT1 gene in four other families with BDCS. ${ }^{68}$ ACTRT1 encodes for actin-related protein T1 (ARP-T1). Loss of ARP-T1 leads to activation of the Hedgehog pathway, which is also activated in sporadic basal cell carcinomas and basal cell carcinomas in genetic syndromes such as BCNS. ${ }^{68-70}$

\section{Hedgehog signaling pathway}

The hedgehog signaling pathway is an important signal transduction pathway in embryonic development, cell proliferation, tissue regeneration and homeostasis maintenance. ${ }^{69,71}$ In adult tissues, the hedgehog signaling pathway is often silenced, because the 12-transmembrane protein receptor patched (PTCH1) inhibits the G-linked transmembrane receptor protein smoothened (SMO), leading to suppression of SMOinduced intracellular signaling. Hedgehog signaling is activated by binding of one of the hedgehog ligands (Sonic Hedgehog, Indian Hedgehog, and Desert Hedgehog) to PTCH1. This leads to the activation of SMO, resulting in an intracellular signal to the nucleus by transcription factors glioma-associated oncogene (GLI) 1 and GLI2, leading to transcriptional activation of intracellular target genes (Fig. 6). ${ }^{69-71}$

ARP-T1, which is involved in BDCS, interacts in the hedgehog signaling pathway by binding to the GLI1 promoter, thus inhibiting GLI1 expression. Loss of ARP-T1 leads to activation of the hedgehog signaling pathway. ${ }^{68}$ In $90 \%$ of sporadic basal cell carcino- 
mas, inactivating mutations In the PTCH1 gene are found, and $10 \%$ of sporadic basal cell carcinomas result from activating mutations in the SMO gene. Additionally, BCNS is caused by germline mutations in the PTCH1 gene. In both sporadic and syndromeassociated basal cell carcinomas, this leads to activation of the hedgehog signaling pathway.

A.

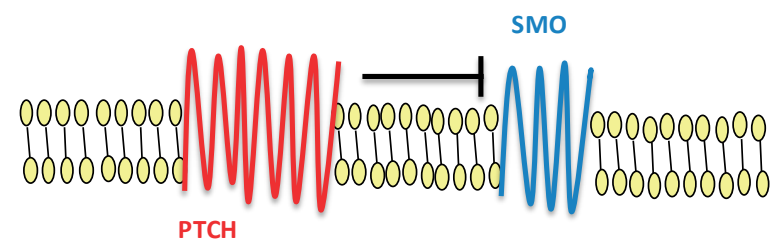

B.
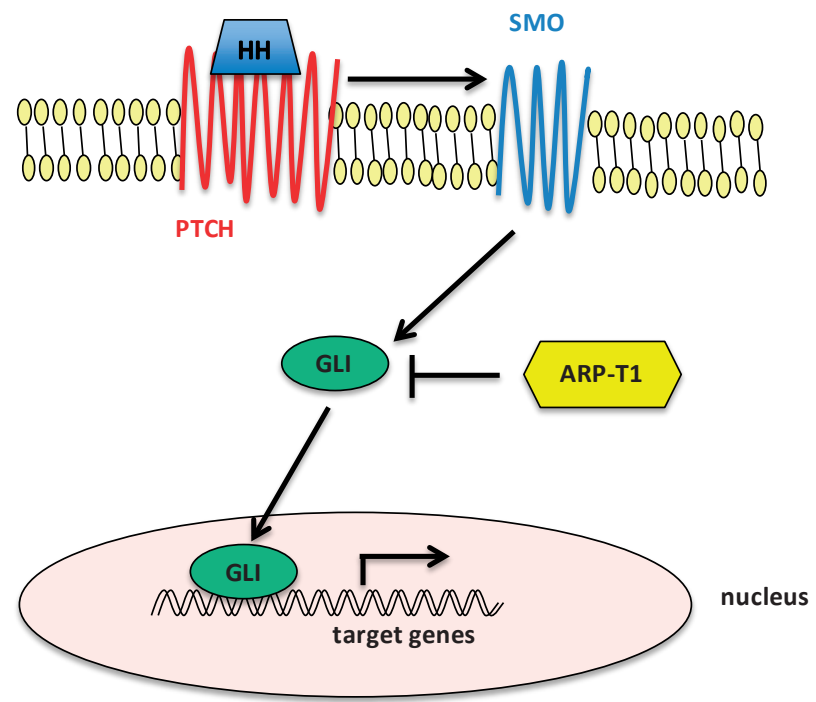

Figure 6. A concise overview of the hedgehog signaling pathway.

A. Membrane bound PTCH1 inhibits SMO.

B. When extracellular hedgehog ligands $(\mathrm{HH})$ bind to $\mathrm{PTCH} 1$, this inhibition is abolished, leading to activation of SMO. This in turn results in transcriptional activation of intracellular target genes. ARP-T1 inhibits the pathway by binding to the GLI1 promoter.

\section{Treatment}

Currently, no curative therapy for BDCS is available. The gold standard of treatment of basal cell carcinomas is surgical excision. Depending on, among others, histological subtype, localization and size of the tumor, primary or recurring basal cell carcinoma, and comorbidity, alternative treatment modalities such as Mohs' micrographic surgery, 
5-fluorouracil, imiquimod, and photodynamic therapy are available. As in BCNS, a pathway-based therapy for BDCS would be desirable.

\section{Aims and outline of this thesis}

BSS and BDCS are rare genetic disorders affecting the hair follicle.

BSS is caused by heterozygous mutations in the CYLD gene. Previous reports indicate both clinical and genetic heterogeneity in this disease. A genotype-phenotype correlation has not yet been demonstrated.

The genetic defect underlying BDCS has recently been reported, at least in a small subset of affected families described to date. In these families, mutations in the ACTRT1 gene have been identified. BDCS shows clinical heterogeneity.

The aim of this thesis was to gain deeper insights into clinic and molecular genetics of BSS and BDCS. In particular, we studied the following aspects of the diseases:

\section{Part 1. Brooke-Spiegler syndrome}

- Elucidation of the underlying CYLD gene defects in distinct families with BSS.

- Evaluation of putative genotype-phenotype correlations in BSS.

- Challenging the concept of segmental type 1 manifestation in multiple familial trichoepithelioma on the molecular genetic level.

- Exploration and evaluation of a novel therapeutic regimen for turban tumors.

\section{Part 2. Bazex-Dupré-Christol syndrome}

- Evaluation of immunohistochemical markers for the histopathological distinction between basal cell carcinomas and trichoepitheliomas.

- Characterization of frequent and infrequent symptoms in BDCS.

- Linkage confirmation and refinement in BDCS. 


\section{References}

1. Dubois A, Hodgson K, Rajan N. Understanding inherited cylindromas. Dermatol Clin. 2017;35:61-71.

2. Martel JL, Kornådorffer M. Anatomy Head, Hair, Follicle. StatPearls. Treasure Island (FL): StatPearls Publishing; 2017-.2017 Dec 4.

3. Massoumi R, Podda M, Fässler R, Paus R. Cylindroma as tumor of hair follicle origin. J Invest Dermatol. 2006;126:1182-1184.

4. Obaidat NA, Alsaad KO, Ghazarian D. Skin adnexal neoplasms-part 2: An approach to tumours of cutaneous sweat glands. J Clin Pathol. 2007;60:145-59.

5. Durani BK, Kurzen $H$, Jaeckel A, Kuner N, Naeher $H$, Hartschuh W. Malignant transformation of multiple dermal cylindromas. Br J Dermatol. 2001;145:653-6.

6. Gerretsen AL, van der Putte SC, Deenstra W, van Vloten WA. Cutaneous cylindroma with malignant transformation. Cancer. 1993;72:1618-23.

7. Alsaad KO, Obaidat NA, Ghazarian D. Skin adnexal neoplasms - part 1: An approach tot tumours of the pilosebaceous unit. J Clin Pathol. 2007;60:129-44.

8. Tellechea O, Cardoso JC, Reis JP, Ramor L, Gameiro AR, Coutinho I, Poiares A. Benign follicular tumors. An Bras Dermatol. 2015;90:780-98.

9. Kasper M, Jaks V, Hohl D, Toftgard R. Basal cell carcinoma - molecular biology and potential new therapies. J Clin Invest. 2012;122:455-63.

10. Arits AH, van Marion AM, Lohman BG, Thissen MR, Steijlen PM, Nelemans PJ, Kelleners-Smeets NW. Differentiation between basal cell carcinoma and trichoepithelioma by immunohistochemical staining of the androgen receptor: an overview. Eur J Dermatol. 2011;21:870-3.

11. Nyame TT, Mattos D, Lian CG, Granter SR, Laga AC, Caterson EJ. Malignant eccrine spiradenoma of the face. J Craniofac Surg. 2015;26:1711-2.

12. Andreoli MT, Itani KM. Malignant eccrine spiradenoma: a meta-analysis of reported cases. Am J Surg. 2011;201:695-9.

13. Kiiski V, Vries E de, Flohil SC, Bijl MJ, Hofman A, Stricker BH, Nijsten T. Risk factors for single and multiple basal cell carcinomas. Arch Dermatol. 2010;146:848-55.

14. Peterson SC, Eberl M, Vagnozzi AN, Belkadi A, Veniaminova NA, Verhagen ME, Bichakijan CK, Ward NL, Dlugosz AA, Wong SY. Basal cell carcinoma preferentially arises from stem cells within hair follicle and mechanosensory niches. Cell Stem Cell. 2015;16:400-12.

15. Wang GY, Wang J, Mancianti ML, Epstein EH Jr. Basal cell carcinomas arise from hair follicle stem cells in Ptch1(+/-) mice. Cancer Cell. 2011;19:114-24.

16. Crowson AN. Basal cell carcinoma: biology, morphology and clinical implications. Mod Pathol. 2006;19:S127-47.

17. Ancell $\mathrm{H}$. History of a remarkable case of tumours developed on the head and face; accompanied with a similar disease in the abdomen. Med Chir Trans. 1842;25:227-46.

18. Spiegler E. Ueber endoteliome der haut. AMA Arch Dermatol Syphilis. 1899;50:163-76.

19. Brooke H. Epithelioma adenoids cysticum. Br J Dermatol Syphilis. 1892;10:269.

20. Fordyce JA. Multiple benign cystic epithelioma of the skin. J Cutan. Dis. 1892;4:459

21. Welch JP, Wells RS, Kerr CB. Ancell-Spiegler cylindromas (turban tumours) and Brooke-Fordyce trichoepitheliomas: evidence for a single genetic entity. J Med Genet. 1968;5:29-35.

22. Gottschalk HR. Proceedings: dermal eccrine cylindroma, epithelioma adenoides cysticum of Brooke, and eccrine spiradenoma. Arch Dermatol. 1974;110:473-4.

23. Bignell GR, Warren W, Seal S, et al. Identification of the familial cylindromatoisis tumour-suppressor gene. Nat Genet. 2000;25:160-5.

24. Biggs PJ, Wooster R, Ford D, Chapman P, Mangion J, Quirk Y, Easton DF, Bum J, Stratton MR. Familial cylindromatosis (turban tumour syndrome) gene localised to chromosome 16q12-q13: evidence for its role as a tumour suppressor gene. Nat Genet. 1995;11:441-43. 
25. Nonaka D, Rosai J, Spagnolo D, Fiaccavento S, Bisceglia M. Cylindroma of the breast of skin adnexal type: a study of 4 cases. Am J Surg Pathol. 2004;28:1070-5.

26. Jungehülsing $M$, Wagner $M$, Damm M. Turban tumour with involvement of the parotid gland. J Laryngol Otol. 1999;113:779-83.

27. Vernon HJ, Olsen AE, Volmer RT. Autosomal dominant multiple cylindromas associated with solitary lung cylindroma. J Am Acad Dermatol. 1988;127:83-7.

28. Wang $\mathrm{N}$, Leeming R, Abdul-Karim FW. Fine needle aspiration cytology of breast cylindroma in a woman with familial cylindromatosis: a case report. Acta Cytol. 2004;48:853-8.

29. Rosales Santillan M, Atajnert K, Swaby MG, Migden MR, Silapunt S. Multiple eccrine spiradenomas in a zosteriform pattern. Dermatol Online J. 2017;23:13.

30. Gordon S, Styron BT, Haggstrom A. Pediatric segmental eccrine spiradenomas: a case report and review of the literature. Pediatric Dermatol. 2013;30:e285-6.

31. Englander L, Emer JJ, McClain D, Amin B, Turner RB. A rare case of multiple segmental eccrine spiradenomas. J Clin Aesthet Dermatol. 2011;4:38-44.

32. Geffner RE, Boslen B, Santa Cruz DJ. Linear and dermatomal trichoepitheliomas. J Am Acad Dermatol. 1986;14:927-30.

33. Chang YC, Colome-Grimmer M, Kelly E. Multiple trichoepitheliomas in the lines of Blaschko. Pediatr Dermatol. 2006;23:149-51.

34. Schirren CG, Worle B, Kind P, Plewig G. A nevoid plaque with histological changes of trichoepithelioma and cylindroma in Brooke-Spiegler syndrome. An immunohistochemical study with cytokeratins. J Cutan Pathol. 1995;22:563-9.

35. Oh DH, Lane AT, Turk AE, Kohler S. A young boy with a large hemifacial plaque with histopathologic features of trichoepithelioma. J Am Acad Dermatol. 1997;37:881-3.

36. Happle R. A rule concerning the segmental manifestation of autosomal dominant skin disorders: Review of clinical examples providing evidence for dichotomous types of severity. Arch Dermatol. 1997;133:1505-9.

37. Happle R. Segmental forms of autosomal dominant skin disorders: different types of severity reflect different states of zygosity. Am J Med Genet. 1996;66:241-2.

38. Happle R. Type 2 segmental trichoepitheliomatosis: a genetic concept that may explain congenital multiple trichoepitheliomas in the lines of Blaschko. Pediatric Dermatol. 2007;24:448-9.

39. Biggs PJ, Chapman P, Lakhani SR, Burn J, Stratton MR. The cylindromatosis gene (cyld1) on chromosome $16 q$ may be the only tumour suppressor gene involved in the development of cylindromas. Oncogene. 1996;12:1375-7.

40. Blake PW, Toro JR. Update of cylindromasosis gene (CYLD) mutations in Brooke-Spiegler syndrome: novel insights into the role of deubiquitination in cell signalling. Hum Mutat. 2009;30:1025-36.

41. Massoumi R, Paus R. Cylindromatosis and the CYLD gene: new lessons on the molecular principles of epithelial growth control. Bioessays. 2007;29:1203-14.

42. Kovalenko A, Chable-Bessia C, Cantarella G, Israel A, Wallach D, Courtois G. The tumour suppressor CYLD negatively regulates NF-kB signalling by deubiquitination. Nature. 2003;424:801-5.

43. Sun SC. CYLD: a tumor suppressor deubiquitinase regulating NF-kB activation and diverse biological processes. Cell Death and Differentiation. 2010;17:25-34.

44. Massoumi R. Ubiquitin chain cleavage: CYLD at work. Trends Biochem Sci. 2010;35:392-9.

45. Sen R, Baltimore D. Multiple nuclear factors interact with the immunoglobulin enhancer sequences. Cell. 1986;46:705-16.

46. Gilmore TD. Introduction to NF-kB: players, pathways, perspectives. Oncogene. 2006;25:6680-4.

47. Ikeda F, Dikic I. CYLD in ubiquitin singaling and tumor pathogenesis. Cell. 2006: 125: 643-645.

48. Trompouki E, Hatzivassiliou E, Tsichritzis T, Farmer $\mathrm{H}$ et al. CYLD is a deubiquitinating enzyme that negatively regulates NF-kB activation by TNFR family members. Nature. 2003;424:793-6.

49. Brummelkamp TR, Nijman SMB, Dirac AMG, Bernards R. Loss of the cylindromatosis tumour suppressor inhibits apoptosis by activating NF-kappaB. Nature. 2003;424:797-801. 
50. Regamey A, Hohl D, Liu JW, Roger T, Kogerman P, Toftgard R, Huber M. The tumor suppressor CYLD interacts with TRIP and regulates negatively nuclear factorB activation by tumor necrosis factor. J Exp Med. 2003;198:1959-64.

51. Courtois G, Gilmore TD. Mutations in the NF-kB signaling pathway: implications for human disease. Oncogene. 2006;25:6831-43.

52. Massoumi R, Chmielarska K, Hennecke K, Pfeifer A, Fassler R. Cyld inhibits tumor cell proliferation by blocking Bcl-3-dependent NF-kB signaling. Cell. 2006;125:665-77.

53. Nagy N, Farkas K, Kemeny L, Szell M. Phenotype-genotype correlations for clinical variants caused by CYLD mutations. Eur J Med Genet. 2015;58:271-8.

54. Guardoli D, Arganziano G, Ponti G, Nasti S, Zalaudek I, Moscarella E, Lallas A, Piana S, Specchio F, Martinuzzi C, Raucci M, Pellacani G, Longo C. A novel CYLD germline mutation in Brooke-Spiegler syndrome. J Eur Acad Dermatol Venereol. 2015;29:457-62.

55. Tancheva-Poor I, Vanecek T, Lurati MC, Rychly B, Kempf W, Michal M, Kazakov DV. Report of three novel germline CYLD mutations in unrelated patients with Brooke-Spiegler syndrome, including classic phenotype, multiple familial trichoepitheliomas and malignant transformation. Dermatology. 2016;232:30-7.

56. Fujii A, Matsuyama K, Mizutani Y, Kanoh H, Nakano h, Seishima M. Multiple familial trichoepithelioma with a novel mutation of the CYLD gene. J Dermatol. 2017;44:e228-9.

57. Shiver M,Hughes M, Naylor M, McLarney B, Stolle C, Shalin S, Gao L. A novel CYLD gene mutation and multiple basal cell carcinomas in a patient with Brooke-Spiegler syndrome. Clin Exp Dermatol. 2016;41:98-100.

58. Richard A, Chevalier JM, Verneuil L, Sergent B, Tesnière A, Dolfus C, Labbé D, Bénateau H,Dompmartin A. CO2 laser treatment of skin cylindromas in Brooke-Spiegler syndrome. Ann Dermatol Venereol. 2014;141:346-53.

59. Rajan N, Trainer AH, Burn J, Langtry JAA. Familial cylindromatosis and Brooke-Spiegler syndrome: a review of current therapeutic approaches and the surgical challenges posed by two affected families. Dermatol Surg. 2009:35;845-52.

60. Brummelkamp TR, Nijman AMB, Dirac AMG, Bernards R. Loss of the cylindromatosis tumour suppressor inhibits apoptosis by activating NF-kB. Nature. 2003;424:797-801.

61. Oosterkamp HM, Neering H, Nijman SM, Dirac AM, Mooi WJ, Bernards R, Brummelkamp TR. An evaluation of the efficacy of topical application of salicylic acid for the treatment of familial cylindromatosis. $\mathrm{Br} \mathrm{J}$ Dermatol. $2006 ; 155: 182-5$.

62. Bazex A, Dupre A, Christol B. Génodermatose complexe de type indéterminé associant une hypotrichose, un état atrophodermique généralisé et des dégénérescences cutanées multiples (épithéliomasbasocellulaires). Bull Soc Franc Derm Syph. 1964;71:206.

63. Goeteyn M, Geerts ML, Kint A, de Weert J. The Bazex-Dupré-Christol syndrome. Arch Dermatol. 1994;130:337-42.

64. Gambichler T, Hoffjan S, Altmeyer P, Bechara FG. A case of sporadic Bazex-Dupré-Christol syndrome presenting with scarring folliculitis of the scalp. Br J Dermatol. 2007;156:184-6.

65. Torrelo A, Sprecher E, MEdiero IG, Bergman R, Zombrano A. What syndrome is this? Bazex-Dupre-Christol syndrome. Pediatr Dermatol. 2006;23:286-90.

66. Kidd A, Carson L, Gregory DW, de Silva D, Holmes J, Dean JC, Haites N. A Scottish family with Bazex-DupréChristol syndrome: follicular atrophoderma, congenital hypotrichosis, and basal cell carcinoma. J Med Genet. 1996;33:493-7.

67. Vabres P, Lacombe D, Rabinowitz LG, Aubert G, Anderson CE, Taieb A, Bonafe JL, Hors-Cayla MC. The gene for Bazex-Dupré-Christol syndrome maps to chromosome Xq. J Invest Dermatol. 1995;105:87-91.

68. Bal E, Park HS, Belaid-Choucair Z, Kayserili H, Naville M, MAdrange M, Chiticariu E, Hajd-Rabia S, Cagnard N, Kuonen F, Bachmann D, Huber M, Le Gall C, Cote F, Hanein S, Rosti RO, Aslanger AD, Waisfisz Q, Bodemer C, Hermine O, Morice-Picard F, Labeille B, Caux F, Mazereeuw-Hautier J, Philip N, Levy N, Taieb A, Avril MF, Headon DJ, Gyapay G, Magnaldo T, Fraitag S, Crollius HR, Vabres P, Hohl D, Munnich A, Smahi A. Mutations in ACTRT1 and its enhancer RNA elements lead to aberrant activation of Hedgehog signalling in inherited and sporadic basal cell carcinomas. Nat Med. 2017;23:1226-33. 
69. Abe Y, Tanaka N. Roles of the hedgehog signaling pathway in epidermal and hair follicle development, homeostasis, and cancer. J Dev Biol. 2017;5:E12.

70. Epstein EH. Basal cell carcinomas: attack of the hedgehog. Nat Rev Cancer. 2008;8:743-54.

71. McMillan R, Matsui W. Molecular pathway: the hedgehog signaling pathway in cancer. Clin Cancer Res. 2012;18:4883-8. 


\section{Part 1}

\section{Brooke-Spiegler syndrome}





\section{Chapter 2}

\section{Brooke-Spiegler syndrome complicated by unilateral hearing loss}

Parren LJMT, Bauer B, Hamm H, Frank J. Brooke-Spiegler syndrome complicated by unilateral hearing loss. Int J Dermatol. 2008;47(Suppl 1):56-9. 


\section{Abstract}

Brooke-Spiegler syndrome is an autosomal dominant tumor predisposition disorder. The disease is characterized by the occurrence of multiple skin appendage tumors, including cylindroma, trichoepithelioma, and spiradenoma. In some patients, tumors cover the entire head circumference, thereby causing disfigurement and other complications. Here, we report on a man with multiple cylindroma that were distributed in a turban tumor-like fashion. One of these neoplasms arose in the meatus externus of the right ear leading to unilateral hearing loss, a complication that has been documented only on few occasions in this disease. 


\section{Introduction}

Brooke-Spiegler syndrome (BSS) (OMIM 605041), also known as familial cylindromatosis (OMIM 132700), is an autosomal dominantly inherited tumor predisposition disorder that was reported for the first time in 1842 by Ancell. ${ }^{1}$ The disease is characterized by the development of multiple benign skin appendage neoplasms, including cylindroma, trichoepithelioma, and spiradenoma. ${ }^{1-4}$

Clinically, the different types of tumor mostly adhere to specific predilection sites on the body. Trichoepitheliomas are commonly encountered on the central face in the perinasal area, whereas spiradenomas usually develop on the upper trunk. Cylindromas mostly manifest on the head and neck as firm, pink-reddish nodules that range in size from a few millimeters to several centimeters. These tumors can fuse into large masses that cover the whole scalp, referred to as turban tumor. ${ }^{5}$

The histopathology can be variable, sometimes making it difficult to clearly differentiate cylindroma from either trichoepithelioma or spiradenoma.

Although already described in 1842, it was not until more than 150 years later that Biggs et al. found a linkage of familial cylindromatosis to chromosome $16 q 12-13 .{ }^{6}$ In 2000, the first mutations in the CYLD gene were reported in patients with multiple hereditary cylindromas and trichoepitheliomas. ${ }^{7}$ To date, approximately 50 CYLD mutations have been detected in BSS and the allelic diseases familial cylindromatosis and multiple familial trichoepitheliomas (OMIM 601606), which show overlapping phenotypes. $^{7-24}$

In this article, we report a patient with the characteristic phenotype of turban tumor syndrome and unilateral hearing loss caused by tumor growth in the ear. This complication has only been documented on a few occasions in BSS. ${ }^{25-28}$

\section{Case Report}

A 37-year-old white German man with known BSS presented with a 4-week history of pain in the right external acoustic meatus and ipsilateral progressive hearing loss over approximately 4 years. He was the only family member affected by the disorder and his further medical history was unremarkable.

At the age of 9 years, he started to develop small, skin-colored, centrofacial papules, predominantly in the nasolabial folds. In June 1989, a biopsy from one of the papules revealed a trichoepithelioma. Over the following 12 years, several trichoepitheliomas were treated with repeated dermabrasion and, later, by ablative CO2 laser therapy. Since the age of 21 years, he had also manifested multiple, skin-colored tumors on the forehead, scalp, right upper maxilla, and right meatus externus, showing the histopathologic characteristics of cylindroma. During the course of the disease, several of these tumors were surgically excised. In 1997, histopathologic examination of a tumor 
excised from the right infraclavicular region showed an eccrine spiradenoma. On visiting our clinic in October 2004, almost the entire circumference of his head was covered with large, partly confluent, skin-colored to pink tumors that were distributed in a turban-like fashion (Fig. 1). One tumor of approximately $1 \mathrm{~cm}$ in size had grown into the right meatus externus, thereby causing an almost complete obstruction that was responsible for the steadily increasing hearing loss confirmed by audiometry.

Subsequently, the tumor was radically excised and histopathology showed a cylindroma. After tumor resection, the patient's hearing difficulties resolved completely and have not reoccurred since. A recently initiated therapeutic attempt with topically applied $20 \%$ salicylic acid in an elastic collodion base did not yield any improvement.
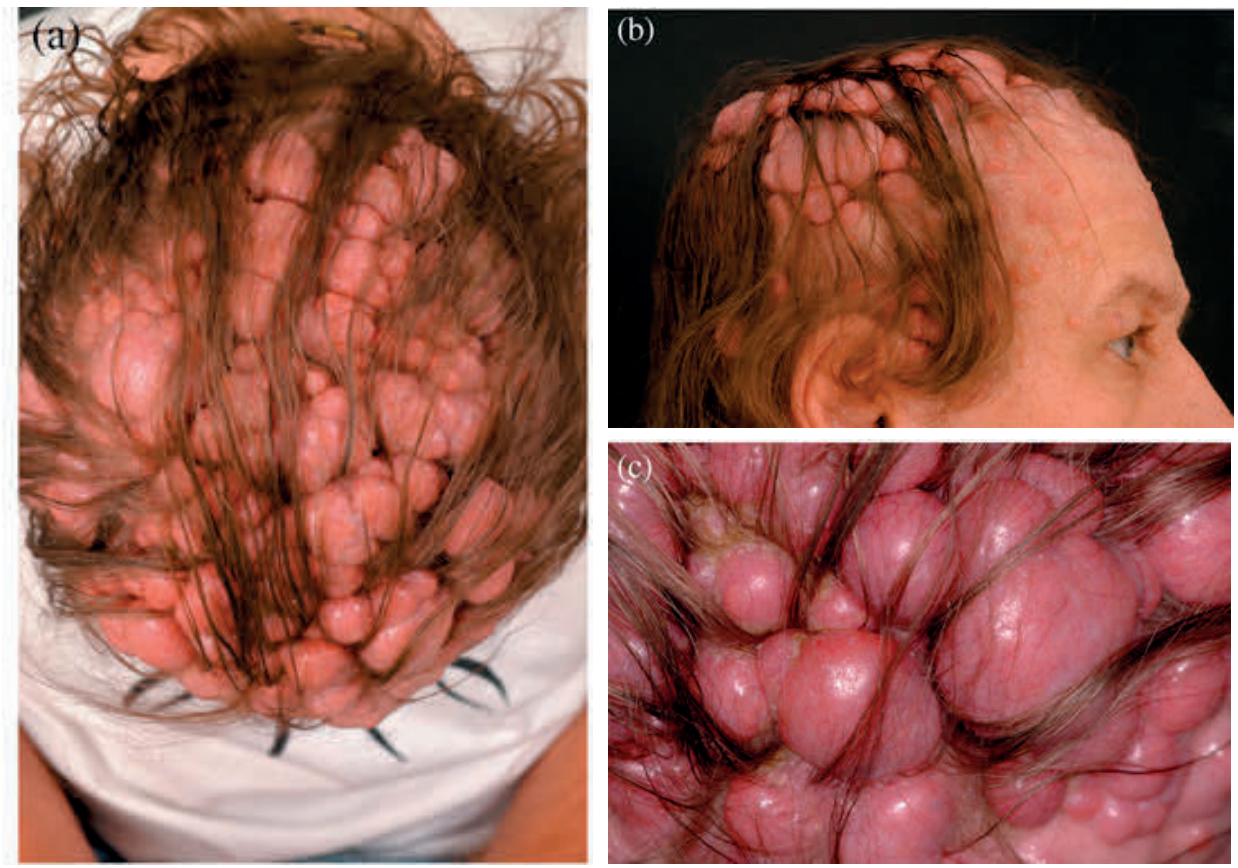

Figure 1. Clinical manifestation of Brooke-Spiegler syndrome in a 37-year-old man. Multiple skin-colored to reddish tumors with partial confluence are distributed in a turban-like fashion on the scalp. (a) Cranial view on the vertex. (b) View from the right side. (c) Detailed view of several coalescing tumors of variable size on the right aspect of the vertex.

\section{Discussion}

Although the exact incidence and prevalence of the disease are unknown, BSS is considered to be a rare disorder. To date, no racial or gender preponderance has been described. Clinically, at least three different variants of the disease can be distinguished: (i) familial trichoepithelioma, in which only trichoepitheliomas are encountered; (ii) famili- 
al cylindromatosis, which is characterized by the occurrence of cylindromas exclusively; and (iii) BSS, in which three different tumor types have been described: cylindroma, trichoepithelioma, and spiradenoma. Although the clinical manifestations may vary, it has recently been demonstrated that all three variants arise from heterozygous mutations in the CYLD gene, and thus represent phenotypic variations of a single genetic defect. $^{7-24}$ To date, the specific mechanisms governing the development of one or more of these histopathologically distinct tumors have not been unraveled.

Cylindromas most commonly manifest on the head and neck. Less than $10 \%$ of patients develop such neoplasms on other sites of the body, e.g. the trunk. Of these tumors, approximately $6 \%$ are reported to involve the ear, as in our patient. ${ }^{25,28}$ In exceptional cases, cylindromas can also occur in even more unusual locations, such as the lung or the breast. ${ }^{29,30}$

In BSS, different tumor growth and distribution patterns can be observed. Although spiradenomas usually manifest as solitary, reddish-to-pink nodules on the trunk, both cylindroma and trichoepithelioma rarely present as solitary neoplasms, but rather in groups of partly coalescing and confluent tumors. The growth pattern observed in the patient presented here is also referred to as turban tumor syndrome, and is considered to be the full-blown and clinically most disfiguring form of BSS which, fortunately, is seldom observed.

This phenotypic variant of BSS is more frequently associated with complications that are hardly ever seen in solitary tumors, including unpleasant fetor, ulceration, secondary infection, and anemia caused by chronic bleeding. Sometimes, a solitary cylindroma, or groups, can cover the eyes. ${ }^{25,31}$ Furthermore, discomfort, pain, hearing loss, and deafness may be the result of tumor growth into the external ear, with occlusion of the auditory canal, as observed in our patient. ${ }^{25-28}$ As described previously in other patients, the unilateral hearing loss resolved after surgical excision of the cylindroma occluding the meatus externus in the external auditory canal.

Although the underlying genetic defect in BSS has been known since 2000, no curative therapy is yet available for multiple cylindromas and trichoepitheliomas. Therefore, all current treatment options merely aim to improve the cosmetic aspects and to prevent or resolve the complications, such as the hearing loss encountered in our patient. Currently, surgical excision or laser ablation is the treatment of first choice in multiple cylindromas and trichoepitheliomas, ${ }^{31,32}$ not solely with regard to tumor mass reduction, but also considering the small, but non-negligible chance of malignant transformation. ${ }^{33,34}$ Although not considered as a treatment option in our patient, total scalp and forehead excision with coverage by skin grafts has been described in patients with turban tumors. ${ }^{31}$ Recently, a therapeutic attempt has been made to treat single cylindroma in BSS with topically applied salicylic acid at varying concentrations. Salicylic acid acts by interfering with the NF-KB signaling pathway and, thereby, is thought to be capable of blocking tumor progression and/or reducing the size of existing tumors. The results of this therapeutic approach are rather discouraging, however, probably be- 


\section{Chapter 2}

cause salicylic acid is a rather weak and nonspecific blocker of NF-kB activation. In line with these observations, a therapeutic attempt with $20 \%$ salicylic acid in a topical formulation did not lead to tumor size reduction or prevention of tumor progression in our case. Thus, our own and previous data suggest that salicylic acid is not sufficiently potent to inhibit tumor growth. ${ }^{35}$

In summary, BSS is a complex disease that can present with a variable clinical and histopathologic pattern. Turban-like tumor growth can lead to a broad spectrum of complications, and patients with this rare phenotypic variant should be treated and followed up in an interdisciplinary setting to provide the best possible care. The treatment of rapidly growing tumors should preferably consist of surgical excision at an early stage to prevent complications such as those encountered in the patient described here. 


\section{References}

1. Ancell $\mathrm{H}$. History of a remarkable case of tumours developed on the head and face; accompanied with a similar disease in the abdomen. Med Chir Trans. 1842;25:227-46.

2. Spiegler E.Ueber endoteliome der haut. AMA Arch Dermatol Syphil. 1899;50:163-76.

3. Brooke H. Epithelioma adenoids cysticum. Br J Dermatol Syphil. 1892;10:459-73.

4. Fordyce J. Multiple benign cystic epithelioma of the skin. J Cutan Dis. 1892;10:459-73.

5. Lee DA, Grossman ME, Schneiderman P, et al. Genetics of skin appendage neoplasms and related syndromes. J Med Genet. 2005;42:811-9.

6. Biggs PJ, Chapman P, Lakhani SR, et al. The cylindromatosis gene (cyld1) on chromosome $16 q$ may be the only tumour suppressor gene involved in the development of cylindromas. Oncogene. 1996;12:1375-7.

7. Bignell GR, Warren W, Seal S, et al. Identification of the familial cylindromatosis tumour-suppressor gene. Nat Genet. 2000;25:160-5.

8. Bowen S, Gill M, Lee DA, et al. Mutations in the CYLD gene in Brooke-Spiegler syndrome, familial cylindromatosis, and multiple familial trichoepithelioma: lack of genotype-phenotype correlation. J Invest Dermatol. 2005;124:919-20.

9. Zhang GL, Huang YJ, Yan KL, et al. Diverse phenotype of Brooke-Spiegler syndrome associated with a nonsense mutation in the CYLD tumor suppressor gene. Exp Dermatol. 2006;15:966-70.

10. Zhang XJ, Liang YH, He PP, et al. Identification of the cylindromatosis tumor suppressor gene responsible for multiple familial trichoepithelioma. J Invest Dermatol. 2004;122:658-64.

11. Scheinfeld N, Hu G, Gill M, et al. Identification of a recurrent mutation in the CYLD gene in BrookeSpiegler syndrome. Clin Exp Dermatol. 2003;28:539-41.

12. Hu G, Onder M, Gill M, et al. A novel missense mutation in CYLD in a family with Brooke-Spiegler syndrome. J Invest Dermatol. 2003;121:732-4.

13. Zheng G, Hu L, Huang W, et al. CYLD mutation causes multiple familial trichoepithelioma in three Chinese families. Hum Mutat. 2004;23:400.

14. Salhi A, Bornholdt D, Oeffner F, et al. Multiple familial trichoepithelioma caused by mutations in the cylindromatosis tumor suppressor gene. Cancer Res. 2004;64:5113-7.

15. Liang YH, Gao M, Sun LD, et al. Two novel CYLD gene mutations in Chinese families with trichoepithelioma and a literature review of 16 families with trichoepithelioma reported in China. $\mathrm{Br} J$ Dermatol. 2005;153:1213-5.

16. Young AL, Kellermayer R, Szigeti R, et al. CYLD mutations underlie Brooke-Spiegler, familial cylindromatosis, and multiple familial trichoepithelioma syndromes. Clin Genet. 2006;70:246-9.

17. Heinritz W, Grunewald S, Strenge S, et al. A case of Brooke-Spiegler syndrome with a new mutation in the CYLD gene. Br J Dermatol. 2006;154:992-4.

18. Oiso N, Mizuno N, Fukai K, et al. Mild phenotype of familial cylindromatosis associated with an R758X nonsense mutation in the CYLD tumour suppressor gene. Br J Dermatol. 2004;151:1084-6.

19. Poblete Gutierrez P, Eggermann T, Holler D, et al. Phenotype diversity in familial cylindromatosis: a frameshift mutation in the tumor suppressor gene CYLD underlies different tumors of skin appendages. J Invest Dermatol. 2002;119:527-31.

20. Almeida S, Maillard C, Itin P, et al. Five new CYLD mutations in skin appendage tumors and evidence that aspartic acid 681 in CYLD is essential for deubiquitinase activity. J Invest Dermatol. 2008;128:587-93.

21. Zuo YG, Xu Y, Wang B, et al. A novel mutation of $C Y L D$ in a Chinese family with multiple familial trichoepithelioma and no CYLD protein expression in the tumour tissue. Br J Dermatol. 2007;157: 818-21.

22. Espana A, Garcia-Amigot F, Aguado L, et al. A novel missense mutation in the CYLD gene in a Spanish family with multiple familial trichoepithelioma. Arch Dermatol. 2007;143:1194-6.

23. Lv HL, Huang YJ, Zhou D, et al. A novel missense mutation of CYLD gene in a Chinese family with multiple familial trichoepithelioma. J Dermatol Sci. 2008;50:143-6.

24. Saggar S, Chernoff KA, Lodha S, et al. CYLD mutations in familial skin appendage tumors. J Med Genet. 2008;45:298-302. 


\section{Chapter 2}

25. Balkom IDC, van Hennekam RCM. Dermal eccrine cylindromatosis. J Med Genet. 1994;31:321-4.

26. Sharma HS, Meorkamal MZ, Zainol H, et al. Eccrine cylindroma of the ear canal - report of a case. J Laryngol Otol. 1994;108:706-9.

27. Wilson RS, Johnson JT. Benign eccrine cylindroma of the external auditory canal. Laryngoscope. 1980;90:379-82.

28. Wolf BA, Gluckman JL, Wirman JA. Benign dermal cylindroma of the external auditory canal: a clinicopathological report. Am J Otolaryngol. 1985;6:35-8.

29. Vernon HJ, Olsen AE, Volmer RT. Autosomal dominant multiple cylindromas associated with solitary lung cylindroma. J Am Acad Dermatol. 1988;127:83-7.

30. Wang N, Leeming R, Abdul-Karim FW. Fine needle aspiration cytology of breast cylindroma in a woman with familial cylindromatosis: a case report. Acta Cytol. 2004;48:853-8.

31. Freedman AM, Woods JE. Total scalp excision and auricular resurfacing for dermal cylindroma (turban tumor). Ann Plast Surg. 1989;22:50-7.

32. Martins C, Bartolo E. Brooke-Spiegler syndrome: treatment of cylindromas with CO2 laser. Dermatol Surg. 2000;26:877-82.

33. De Francesco V, Frattasio A, Pillon B, et al. Carcinosarcoma arising in a patient with multiple cylindromas. Am J Dermatopathol. 2005;27:21-6.

34. Mashkevich G, Undavia S, lacob C, et al. Malignant cylindroma of the external auditory canal. Otol Neurotol. 2005;27:97-101.

35. Brummelkamp TR, Nijman AMB, Dirac AMG, et al. Loss of the cylindromatosis tumour suppressor inhibits apoptosis by activating NF-kB. Nature. 2003;424:797-801. 


\section{Chapter 3}

\section{Molecular basis of Brooke-Spiegler syndrome}

Parren LJMT, Baron JM, Joussen S, Marquardt Y, Hanneken S, van Steensel MAM, Steijlen PM, Frank J. CYLD mutations differentially affect splicing and mRNA decay in Brooke-Spiegler syndrome. J Eur Acad Dermatol Venereol. 2018; accepted.

Parren LJMT, Giehl K, van Geel M, Frank J. Phenotype variability in tumor disorders of the skin appendages associated with mutations in the CYLD gene. Arch Dermatol Res. 2018;310(7):599-606.

Parren LJMT, Munte K, Winnepenninckx V, van Geel M, Steijlen PM, Frank J, van Steensel MAM. Clustered unilateral trichoepitheliomas indicate type 1 segmental manifestation of multiple familial trichoepithelioma. Clin Exp Dermatol. 2016;41(6):682-4. 

Chapter 3.1

Novel splice site mutations differentially affect splicing and mRNA decay 


\section{Abstract}

\section{Background}

Mutations in the CYLD gene underlie Brooke-Spiegler syndrome, an autosomal dominantly inherited cutaneous tumor disorder characterized by cylindromas, trichoepitheliomas, and spiradenomas. To date, however, the consequences of CYLD splice site mutations have not yet been assessed.

\section{Objectives}

To identify CYLD mutations in BSS patients and study the consequences of CYLD splice site mutations on the cDNA and mRNA level.

\section{Methods}

We performed mutation analysis in three patients with Brooke-Spiegler syndrome and assessed the expression of CYLD in normal human epidermal keratinocytes, leukocytes, and peripheral blood mononuclear cells by quantitative reverse transcriptase-PCR. The consequences of the mutations detected were studied by both reverse transcriptase PCR and quantitative reverse transcriptase PCR.

\section{Results}

We detected two novel and one recurrent CYLD splice site mutations, designated c. $2108+1 G>A, c .2242-2 A>G$, and c.2109-2A>C. We show that CYLD is expressed in peripheral blood mononuclear cells, which facilitated assessing the consequences of the mutations. In two of the patients, the mutations resulted in exon skipping and premature termination codons whereas in the third one, aberrant splicing was not detectable.

\section{Conclusion}

Our data suggest that CYLD splice site mutations differentially affect splicing and mRNA degradation. 


\section{Introduction}

Brooke-Spiegler syndrome (BSS; OMIM 605041), also known as familial cylindromatosis (OMIM 132700) or turban tumor syndrome, is an autosomal dominant disorder characterized by the occurrence of multiple benign skin adnexal tumors, including cylindromas, trichoepitheliomas, and spiradenomas. ${ }^{1}$ These tumors predominantly develop in the first or second decade of life on the head and neck. Malignant transformation is apparently rare. ${ }^{2}$

After Biggs and colleagues demonstrated linkage of BSS to chromosome 16q12$q 13,{ }^{3}$ Bignell et al. in 2000 reported the first mutations in the CYLD gene underlying the disorder. The gene consists of 20 exons and functions as a tumor suppressor. ${ }^{4}$ Although Welch et al. already suggested in 1968 that a mutation in one gene only may be responsible for the different tumors observed in $\mathrm{BSS}^{5}{ }^{5}$ it was not until 2002 that a single DNA alteration in the CYLD gene was indeed shown to give rise to both cylindromas and multiple trichoepitheliomas. ${ }^{6}$

To date, different mutations in the CYLD gene have been reported, most of them resulting in a premature termination codon. ${ }^{7}$ Among these, thirteen splice site mutations have been described. ${ }^{4,8-17}$ However, it remains elusive how such mutations affect splicing. ${ }^{7}$

Here, we detected three distinct splice site mutations in three unrelated patients with BSS. After first analysing CYLD expression in blood and skin cells in order to select appropriate tissues for RNA studies, we assessed the consequences of the mutations on splicing and mRNA decay.

\section{Material and methods}

\section{Patients}

We studied three Caucasian individuals with BSS, two of Dutch, and one of German origin. The initial diagnosis was based on the characteristic clinical manifestation and confirmed by histopathology (Table 1). All participants provided informed consent in accordance with the declaration of Helsinki and guidelines set forth by the local institutional review board.

Table 1. CYLD splice site mutations in this study, associated phenotypes as well as the structural and functional consequences of these mutations.

\begin{tabular}{llll}
\hline Mutation & Phenotype & Consequence of splicing defect & Levels of mRNA \\
\hline c.2108+1G>A & $\begin{array}{l}\text { Cylindromas and } \\
\text { trichoepitheliomas }\end{array}$ & Exon skipping & Normal \\
c.2242-2A $>\mathrm{G}$ & $\begin{array}{l}\text { Cylindromas and } \\
\text { trichoepitheliomas }\end{array}$ & Exon skipping & Normal \\
c.2109-2A>C & Cylindromas & Nonsense-mediated mRNA decay & 40\% of normal \\
\hline
\end{tabular}




\section{Mutation analysis and paternity analysis}

We collected EDTA blood by venipuncture. DNA and RNA were isolated from peripheral blood leucocytes according to standard techniques ${ }^{18}$; and with the Nucleospin ${ }^{\circledR}$ RNA kit, respectively, according to the manufacturer's instructions (Machery-Nagel GmbH \& Co.KG, Düren, Germany). We amplified by PCR all coding regions and exon-intronjunctions of the CYLD gene (primer sequences and amplification conditions available upon request). PCR products were directly sequenced using an ABI 3730 DNA Analyser (Applied Biosystems, Foster City, CA, USA). Sequence analysis was performed with the software tools Phred, Phrap and Consed.

To verify paternity in the first Dutch patient, haplotypes were derived using the microsatellite markers D16S500, D16S409, D16S3136, CDRP40, D16S3117, D16S416, D16S3034, and D16S3066. Fragment sizing was performed on an ABI 3730 DNA analyser (Applied Biosystems, Foster City, CA, USA) and analyzed with peakscanner V1.0 (Applied Biosystems, Foster City, CA, USA).

\section{CYLD expression in blood and normal skin}

We assessed the expression of CYLD in normal human epidermal keratinocytes (NHEK), leukocytes and peripheral blood mononuclear cells (PBMC) by quantitative reverse transcriptase (qRT)-PCR. Total RNA from patient PBMCs was isolated using the high pure RNA isolation kit from Roche (Roche Diagnostics $\mathrm{GmbH}$, Mannheim, Germany), accor-ding to the manufacturer's recommendations, including the DNAse digestion step. Equal amounts of purified RNA were reverse transcribed using the TaqMan Reverse Transcription Reagent Kit (Applied Biosystems, Foster City, CA, USA) with random hexamers as primers. For the real time PCR experiments we utilized Assay-on-Demand gene expression products (Applied Biosystems, Foster City, CA, USA). The target transcripts of CYLD were normalised to 18S rRNA (Hs99999901) as an internal reference. All sequences were amplified in triplicate in separate reaction wells and the relative differences between CYLD expression in normal PBMCs and patient PBMCs were calculated using the mathematical $\triangle \triangle C T$ method developed by Pfaffl. ${ }^{19}$

\section{Reverse transcriptase PCR (RT-PCR)}

RNA was reverse transcribed into cDNA using the SuperScript First-Strand Synthesis System (Invitrogen, Carlsbad, CA, USA), following the manufacturer's instructions. RTPCR was performed using primers located in exon 14 and 18 of the CYLD gene, RT-14F 5'-AAGGTGGAGGCTGCATCAGG-3' and RT-18R 5'-CAGCTGAGATGTCCGGATCG-3'. After horizontal gel electrophoresis and visualisation of the bands the smaller-sized PCR products were cut out of the gel, purified, subcloned and automatically sequenced, respectively. 
mRNA levels in affected individuals

In all patients, residual mRNA levels were measured in RNA specimens derived from whole blood using PAXgene collection tubes. The PAXgene Blood RNA system (PAXgene Blood RNA Tubes and PAXgene Blood RNA Kit, PreAnalytiX GmbH, Hombrechtikon, Switzerland) stabilises intracellular RNA and, thus, provides accurate detection and purification of gene transcripts. We used the tubes and kit according to the manufacturer's instruction. Amounts of total RNA were measured using the Nanodrop system (NanoDrop Technologies, Rockland, Delaware, USA) and equal RNA concentrations of each sample were used for RT-PCR.

\section{Results}

We detected three single nucleotide substitutions in different CYLD splice sites, respectively (Table 1). In the first patient the mutation consisted of a G-to-A transition at the splice donor site of intron 15, designated c.2108+1G>A (Fig. 1A). This mutation was not detectable in either parent. Paternity was confirmed by haplotype analysis (data not shown). The second patient had an A-to-G transition at the splice acceptor site of intron 16, designated c.2242-2A>G (Fig. 1B). In the third patient we detected a mutation at the splice acceptor site of intron 15 consisting of an A-to-C transversion, designated c.2109-2A>C (Fig. 1C). Absence of all mutations in the ExAC (Exome Aggregation Consortium) database, dbSNP, exome variant server and gnomeAD, excluded the possibility of polymorphisms. 

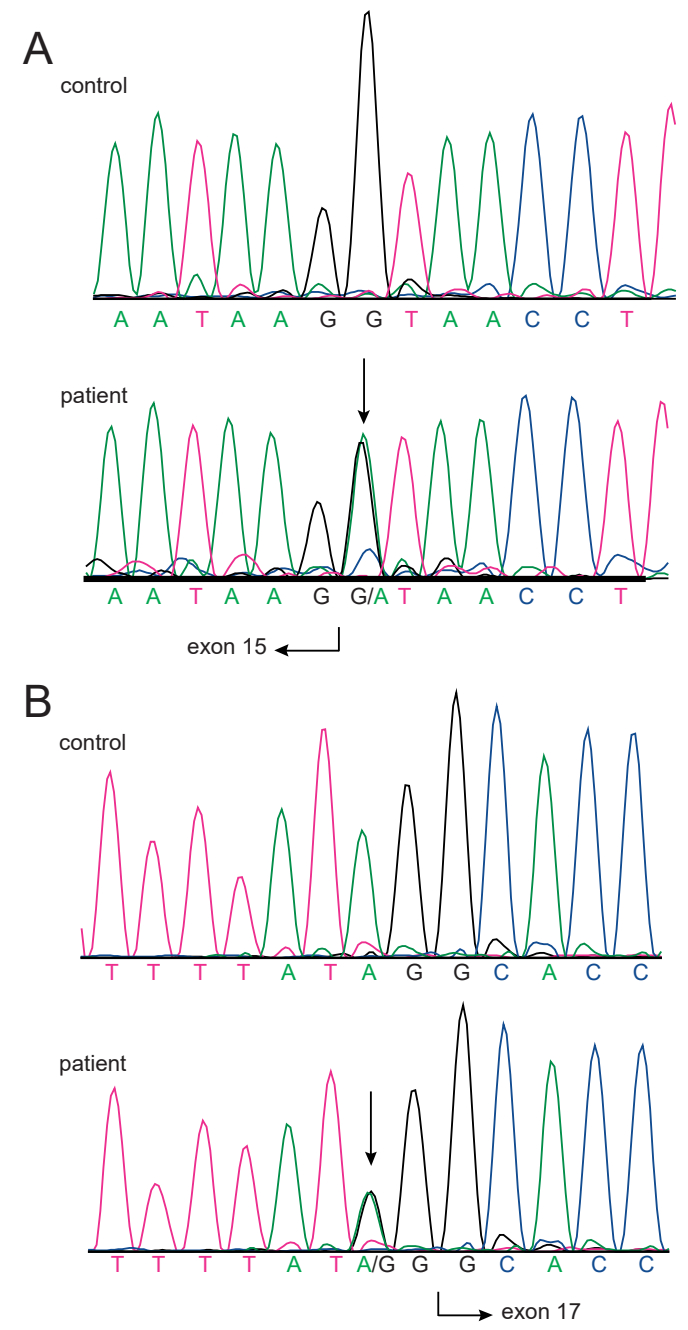

C
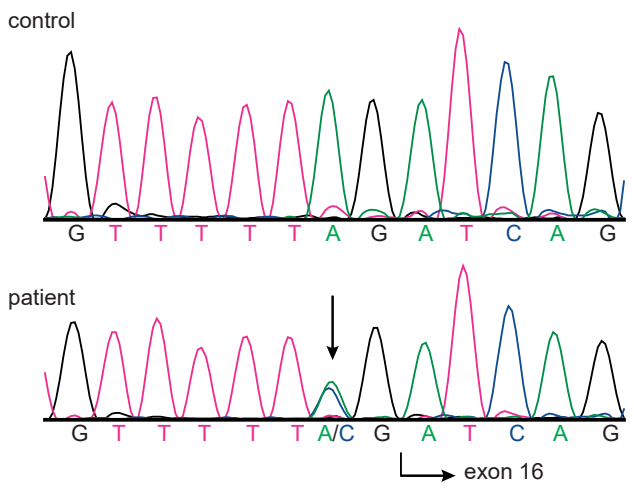

Figure 1. Splice site mutations detected in this study. A. c. $2108+1 G>A ;$ B. c.2242-2A>G; C. c.2109-2A>C. 


\section{CYLD expression and consequences of splice site mutations}

Comparison of mRNA expression by RT-PCR revealed that CYLD is expressed at almost equal levels in NHEK, leukocytes and PBMC (Fig. 2). In the patients carrying mutations c. $2108+1 G>A$ and c.2242-2A $>G, R T-P C R$ on RNA derived from PBMCs revealed the wildtype product containing 430 base pairs (bp) and two smaller additional bands of 363 and $321 \mathrm{bp}$, respectively. Automated DNA sequencing showed that the smaller bands represented fragments excluding exons 15 and 17, respectively. By contrast, in the third patient carrying c.2109-2A>C, we only found the wild-type PCR product and no additional band (data not shown).

In all patients, residual CYLD mRNA levels were measured in RNA specimens derived from whole blood. Whereas mutations c. $2108+1 G>A$ and c. $2242-2 A>G$ do not result in a significant decrease of mRNA levels, mutation c.2109-2A>C is associated with approximately $60 \%$ mRNA decay when compared to a control (Fig. 3).

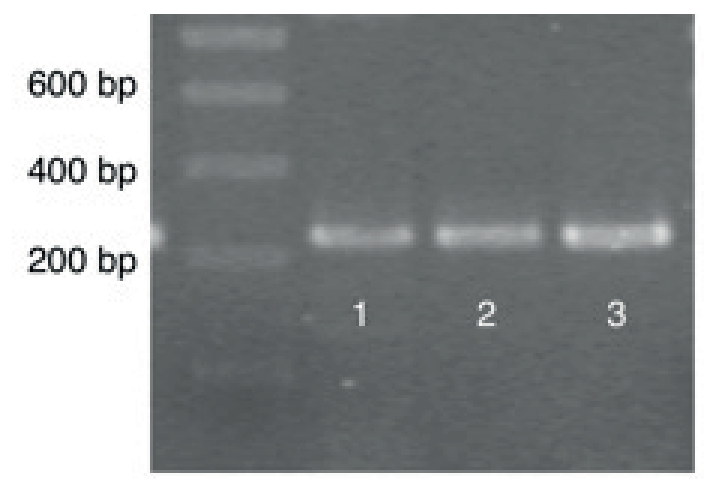

Figure 2. Results of RT-PCR with primers spanning exons 14-18 of the CYLD cDNA.

Lane 1: PBMCs of a healthy control. Lanes 2 and 3: Commercially available leukocyte and keratinocyte RNA, respectively.

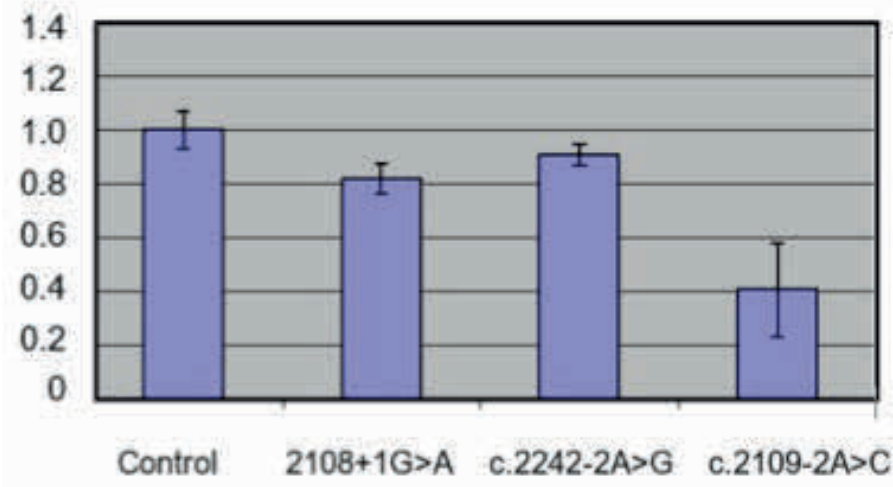

Figure 3. Quantitative real-time PCR shows that mutations C.2108+1G>A and C.2242-2A>G are not associated with relevant mRNA decay. By contrast, mutation C.2109-2A>C leads to substantial mRNA decay. 


\section{Discussion}

The CYLD gene codes for the homonymous protein CYLD. This protein plays an important role in the nuclear factor-kappaB (NF-kB) signaling pathway that regulates, among others, apoptosis and tumorigenesis. ${ }^{20}$ Massoumi et al. showed in a mouse model that negative regulation of CYLD governs proliferation and tumor growth. ${ }^{21}$

Previous reports suggested that CYLD is ubiquitously expressed. ${ }^{22,23}$ Our expression studies in NHEK, leukocytes and PBMC show that in these cells, CYLD is expressed at almost equal levels (Fig. 2). Knowledge on the cell-type specific expression of CYLD should facilitate the functional assessment of splice site mutations in the future.

In one Dutch family studied here, only the index patient showed clinically overt BSS and was shown to carry a CYLD mutation, designated c. $2108+1 G>A$. Because BSS is believed to have a complete penetrance, we clinically examined both her parents but did not find any tumors. This raised the possibility that the mutation detected arose de novo. Haplotype analysis confirmed paternity in this family. Subsequent mutation screening showed that neither parent carried the mutation. Thus, to the best of our knowledge, c. $2108+1 G>$ A represents the first de novo mutation reported in BSS.

Generally, splice site mutations can cause intron retention, exon skipping, cryptic splicing and combinations thereof, resulting in in-frame or out-of-frame translation. Out-of-frame translation generally leads to the occurrence of a premature termination codon (PTC), as do nonsense mutations. ${ }^{24}$ Such PTCs can either result in the formation of a truncated protein ${ }^{25}$ or lead to degradation and elimination of mutated transcripts by nonsense-mediated mRNA decay. ${ }^{24}$

By RT-PCR, we ascertained that two of the splice site mutations, c. $2108+1 G>A$ and c. $2242-2 A>G$, result in skipping of exons 15 and 17, respectively (data not shown). Both exon skipping events lead to putative out-of-frame translation and generation of a PTC. For mutation c. $2108+1 \mathrm{G}>\mathrm{A}$ the PTC is located 30 codons downstream of the mutation site (p.Pro682Gln31fs*) and for c.2242-2A>G, 47 codons downstream of the mutation (p.Ala748Leufs48*). Interestingly, we did not detect an aberrant splicing pattern for c.2109-2A>C. This finding suggested that the transcript of the mutated allele is subject to nonsense-mediated mRNA decay.

To study the role of nonsense-mediated mRNA decay in the three splice site mutations detected here, we measured CYLD mRNA expression in peripheral blood leukocytes by qRT-PCR. Of note, only mutation c.2109-2A>C is associated with evident mRNA decay (Fig. 3), consistent with the findings of our RT-PCR experiments. By contrast, mutations c. $2108+1 G>A$ and c.2242-2A $>G$ only lead to negligible mRNA decay (Fig. 3), indicating that transcription from these mutant alleles might result in the formation of truncated and dysfunctional proteins.

The patient harbouring mutation c.2109-2A>C studied here presented with cylindromas exclusively. Thus, our data suggest that the residual amounts of CYLD mRNA seem to be unrelated to the distinct phenotypes of individuals with this CYLD splice site 
defect, since mutation c.2109-2A $>C$ has been previously reported in a family with trichoepitheliomas only. ${ }^{16}$ To date, fifteen splice site mutations have been reported to underlie different phenotypes, comprising Brooke-Spiegler syndrome (30\%), familial cylindromatosis (35\%), and multiple familial trichoepithelioma (35\%) (Table 2). ${ }^{4,8-17}$ These previous reports and our own data confirm the previous notion that there is no apparent genotype-phenotype correlation in diseases caused by CYLD mutations. ${ }^{7}$ Possibly, as of yet unknown environmental factors, modifier genes or epigenetic events could contribute to the different phenotypes observed. ${ }^{26,27}$

Table 2. Splice site mutations in the CYLD gene and the associated phenotypes reported to date.

\begin{tabular}{|c|c|c|}
\hline Mutation & Phenotype & Publication \\
\hline c. $1518+2 C>T$ & Brooke-Spiegler syndrome & Ly et al. 2004 \\
\hline c. $1684+1 G>A$ & $\begin{array}{l}\text { Brooke-Spiegler syndrome } \\
\text { Brooke-Spiegler syndrome }\end{array}$ & $\begin{array}{l}\text { Kazakov et al. } 2010 \\
\text { Kazakov et al. } 2011\end{array}$ \\
\hline c. $1826+1 G>A$ & Multiple familial trichoepithelioma & Huang et al. 2009 \\
\hline c. $1826+1 G>T$ & Multiple familial trichoepithelioma & Kazakov et al. 2011 \\
\hline c. $1826+2 T>G$ & Multiple familial trichoepithelioma & Liang et al. 2005 \\
\hline c.1950_1953-1delGATA & Familial cylindromatosis & Nasti et al. 2009 \\
\hline c. $1950-2 A>T$ & Familial cylindromatosis & Nasti et al. 2009 \\
\hline c. $2041+G>T$ & Familial cylindromatosis & Kacerovska et al. 2013 \\
\hline c. $2042-1 G>C$ & Multiple familial trichoepithelioma & Malzone et al. 2015 \\
\hline c. $2018+1 G>A$ & Brooke-Spiegler syndrome & Parren et al., this study \\
\hline c. $2109-2 A>C$ & $\begin{array}{l}\text { Multiple familial trichoepithelioma } \\
\text { Familial cylindromatosis }\end{array}$ & $\begin{array}{l}\text { Duparc et al. } 2013 \\
\text { Parren et al., this study }\end{array}$ \\
\hline c. $2241-1 \mathrm{G}>\mathrm{A}$ & Multiple familial trichoepithelioma & Fujii et al. 2017 \\
\hline c. $2242-2 A>G$ & Brooke-Spiegler syndrome & Parren et al., this study \\
\hline c. $2350+5 G>A$ & Familial cylindromatosis & Bignell et al. 2000 \\
\hline c. $2469+1 G>A$ & Familial cylindromatosis & Bignell et al. 2000 \\
\hline
\end{tabular}

In conclusion, we detected two novel and one recurrent CYLD splice site mutations and assessed their consequences on mRNA splicing and degradation. Our data contribute to the growing number of CYLD splice site defects and confirm that there is no obvious genotype-phenotype correlation in BSS. 


\section{References}

1. Ancell $\mathrm{H}$. History of a remarkable case of tumours developed on the head and face; accompanied with a similar disease in the abdomen. Med Chir Trans. 1842;25:227-46.

2. Tripathy SM, Somu TN, Sundaram M, Sahiya S. Malignant cylindroma of post aural region involving the temporal bone. J Clin Diagn Res. 2015;9:MD01-2.

3. Biggs PJ, Wooster R, Ford D, et al. Familial cylindromatosis (turban tumour syndrome) gene localized to chromosome 16q12-13: evidence for its role as a tumour suppressor gene. Nat Genet. 1995;11:441-3.

4. Bignell GR, Warren W, Seal S, et al. Identification of the familial cylindromatosis tumour-suppressor gene. Nat Genet. 2000;25:160-5.

5. Welch J, Wells R, Kerr C. Ancell-Spiegler cylindromas (turban tumours) and Brooke-Fordyce trichoepitheliomas: evidence for a single genetic entity. J Med Genet. 1968;5:29-35.

6. Poblete Gutierrez P, Eggermann T, Holler D, et al. Phenotype diversity in familial cylindromatosis: a frameshift mutation in the tumor suppressor gene CYLD underlies different tumors of skin appendages. J Invest Dermatol. 2002;119:527-31.

7. Nagy N, Farkas K, Kemény K, Széll M. Phenotype-genotype correlations for clinical variants caused by CYLD mutations. Eur J Med Genet. 2015;58:271-8.

8. Malzone MG, Campanile AC, Losito NS, et al. Brooke-Spiegler syndrome presenting multiple concurrent cutaneous and parotid gland neoplasms. Diagn Cytopathol. 2015;43:654-8.

9. Ly H, Black MM, Robson A. Case of the Brooke-Spiegler syndrome. Australas J Dermatol. 2004;45:220-2.

10. Kazakov DV, Schaller J, Vanecek T, Kacerovska D, Michal M. Brooke-Spiegler syndrome: a report of a case with a novel mutation in the CYLD gene and different types of somatic mutations in benign and malignant tumors. J Cutan Pathol. 2010;37:886-90.

11. Kazakov DV, Vanecek T, Zelger B, et al. Multiple (familial) trichoepitheliomas: a clinicopathological and molecular biological study, including CYLD and PTCH gene analysis, of a series of 16 patients. Am J Dermatopathol. 2011;33:251-65.

12. Huang TM, Chao SC, Lee JY. A novel splicing mutation of the CYLD gene in a Taiwanese family with multiple familial trichoepithelioma. Clin Exp Dermatol. 2009;34:77-80.

13. Liang YH, Gao M, Sun LD, et al. Two novel CYLD gene mutations in Chinese families with trichoepithelioma and a literature review of 16 families with trichoepithelioma reported in China. Br J Dermatol. 2005;153:1213-5.

14. Nasti S, Pastorino L, Bruno $W$, et al. Five novel germline function-imparing mutations of CYLD in Italian patients with multiple cylindromas. Clin Genet. 2009;76:481-5.

15. Kacerovska D, Szep Z, Kollarikova L, et al. A novel germline mutation in the CYLD gene in a Slovak patient with Brooke-Spiegler syndrome. Cesk Pathol. 2013;49:89-92.

16. Duparc A, Lasek-Duriez A, Wiart T, Duban-Bedu B, Gosset P, Modiano P. Multiple familial trichoepithelioma: a new CYLD gene mutation. Ann Dermatol Venereol. 2013;140:274-7.

17. Fujii A, Matsuyama K, Mizutani Y, Kanoh H, Nakona H, Sishima M. Multiple familial trichoepithelioma with a novel mutation of the CYLD gene. J Dermatol. 2017;44:e228-9.

18. Sambrook J, Fritsch EF, Maniatis T. Molecular Cloning: a laboratory manual. Cold Spring Harbor, 13. NY: Cold Spring Harbor Laboratory Press, 1989.

19. Pfaffl MW. A new mathematical model for relative quantification in real-time RT-PCR. Nucleic Acids Res. 2001;29:e45.

20. Rajan N, Ashworth A. Inherited cylindromas: lessons from a rare tumour. Lancet Oncol. 2015;16:460-9.

21. Massoumi R, Paus R. Cylindromatosis and the CYLD gene: new lessons on the molecular principles of epithelial growth control. Bioessays. 2007;29:1203-14.

22. Blake PW, Toro JR. Update of cylindromatosis gene (CYLD) mutations in Brooke-Spiegler syndrome: novel insights into the role of deubiquitination in cell signaling. Hum Mutat. 2009;30:1025-36.

23. Reiley W, Zhang M, Wu X, Granger E, Sun SC. Regulation of the deubiquitinating enzyme CYLD by IkappaB kinase gamma-dependant phosphorylation. Mol Cell Biol. 2005;25:3886-95. 
24. Hentze MW, Kulozik AE. A perfect message: RNA surveillance and nonsense-mediated decay. Cell. 1999;96:307-10.

25. Frio TR, Civic N, Ransijn A, Beckmann JS, and Rivolta C. Two trans-acting eQTLs modulate the penetrance of PRPF31 mutations. Hum Mol Genet. 2008;17:3154-65.

26. Massoumi R. Ubiquitin chain cleavage: CYLD at work. Trends Biochem Sci. 2010;35:392-9.

27. Iliopoulos D, Jaeger SA, Hirsch HA, Bulyk ML, Struhl K. STAT3 activation of miR-21 and miR-181b-1 via PTEN and CYLD are part of the epigenetic switch linking inflammation to cancer. Mol Cell. 2010;39:493506. 

Chapter 3.2

Phenotypic variability in tumor disorders of the skin appendages associated with mutations in the CYLD gene 


\section{Abstract}

Mutations in the tumor suppressor gene CYLD underlie phenotypically heterogeneous hereditary tumor disorders of the skin appendages. These diseases are inherited autosomal dominantly and include Brooke-Spiegler syndrome (BSS; OMIM 605041), familial cylindromatosis (FC; OMIM 132700) and multiple familial trichoepithelioma (MFT; OMIM 601606). Clinically, cylindromas, trichoepitheliomas and spiradenomas can be found in affected individuals.

We sought to elucidate the molecular genetic basis in individuals with newly diagnosed cylindromas, trichoepitheliomas and/or spiradenomas. Mutation analysis using polymerase chain reaction (PCR)-based techniques was performed in seven German patients and one Turkish patient. We detected two missense, two nonsense, two deletion and two duplication mutations in the CYLD gene, of which seven have not yet been reported. No genotype-phenotype correlation was detected amongst the patients. Our data provide additional information on the clinical and molecular genetic heterogeneity of disorders associated with CYLD mutations. 


\section{Introduction}

Brooke-Spiegler syndrome (BSS, OMIM 605041) is a hereditary disorder predisposing to tumor formation, which was first described in $1842 .{ }^{1}$ Clinically, the disease is characterized by the development of multiple skin appendage neoplasias, including cylindromas, trichoepitheliomas, and spiradenomas. Originally, the tumors were referred to as Ancell-Spiegler cylindromas and Brooke-Fordyce trichoepitheliomas. ${ }^{1-4}$ After observation of a patient with both cylindromas and trichoepitheliomas, Welch and colleagues suggested in 1968 that they might have an identical genetic basis. ${ }^{5}$ Eventually, spiradenomas were added to the spectrum of BSS in $1974 .{ }^{6}$

Recently, it has been shown that these tumors are mainly derived from the hair follicle. ${ }^{7}$ They can occur from the first decade onwards and show a slow but progressive growth pattern. Although the tumors are primarily benign, malignant transformation has been reported. Clinical signs of malignant transformation comprise pain, ulceration, and rapid growth. ${ }^{8-10}$

In 1995, Biggs et al. reported linkage of BSS to chromosome $16 q 12-q 13 .{ }^{11}$ SubsequentIy, germline mutations in the CYLD gene were detected in families affected by the disorder. ${ }^{12}$ The CYLD gene is located on chromosome $16 q 12-q 13$ and contains 20 exons, of which 17 are coding (NCBI RefSeq: NM_015247.2). It encodes for the homonymous protein CYLD, which consists of 956 amino acids (aa) and has a molecular weight of 107 kDa. The protein comprises i) three cytoskeleton-associated protein glycine-rich (CAP-GLY) domains (aa 127-203; 232-303; 472-540), which are responsible for microtubule binding; ii) proline rich repeats (aa 388-413; 446-471); iii) four Cys-X-X-Cys pairs (between aa 788 and 856); and iv) an ubiquitin C-terminal hydrolase (UCH) catalytic domains (aa 593-948). CYLD is involved in deubiquitination processes within the NF-kB signaling route and also has an important function in the JNK, RIG-I/IRF, and the Cyclin pathways. ${ }^{12,13}$

Here, we studied seven German patients and one Turkish patient with multiple cylindromas, trichoepitheliomas, and/or spiradenomas. Sequencing analysis revealed two missense, two nonsense, two deletion and two duplication mutations in the CYLD gene.

\section{Material and methods}

\section{Patients and control individuals}

The index patients (BSS1 - BSS8 in Table 1) studied here were unrelated individuals of German or Turkish origin with BSS (for detailed patient information see Table 1). In all patients, the clinical diagnosis of cylindromas, trichoepitheliomas and/or spiradenomas was confirmed by histopathology. All participants provided informed consent for inclusion in this study, in accordance with the declaration of Helsinki principles and guidelines set forth by the local institutional review board. 
Table 1. Clinical and genetic characteristics of the patients studied.

\begin{tabular}{|c|c|c|c|c|c|}
\hline Family & Ethnic origin & Mutation CYLD gene & Exon & Protein change & Phenotype \\
\hline BSS1 & Turkish & c. $2261 \mathrm{~T}>\mathrm{G}$ & 17 & p.(Ile754Ser) & Trichoepitheliomas \\
\hline BSS2 & German & c. $2581 T>G$ & 19 & p.(Leu861Val) & Trichoepitheliomas \\
\hline BSS3 & German & c. $2409 C>A$ & 18 & p.(Tyr803*) & Cylindromas \\
\hline BSS4 & German & c. $2540 \mathrm{G}>\mathrm{A}$ & 19 & p. $\left(\operatorname{Trp} 847^{*}\right)$ & $\begin{array}{l}\text { Cylindromas, } \\
\text { trichoepitheliomas and } \\
\text { spiradenoma }\end{array}$ \\
\hline BSS5 & German & c.2081del & 15 & p.(Leu694*) & $\begin{array}{l}\text { Cylindromas, } \\
\text { trichoepitheliomas and } \\
\text { spiradenomas }\end{array}$ \\
\hline BSS6 & German & c.822del & 6 & p.(Asn275Thrfs*36) & $\begin{array}{l}\text { Cylindromas, } \\
\text { trichoepitheliomas and } \\
\text { spiradenomas }\end{array}$ \\
\hline BSS7 & German & c.2649dup & 19 & p.(Ala884Cysfs*6) & Trichoepitheliomas \\
\hline BSS8 & German & c.588_591dup & 5 & p.(Ala198Cysfs*12) & Trichoepitheliomas \\
\hline
\end{tabular}

DNA isolation, polymerase chain reaction (PCR) and sequence analysis

Genomic DNA was isolated from peripheral blood collected in tubes containing ethylenediamine tetraacetic acid, according to standard techniques. ${ }^{14}$

All coding regions and adjacent splice sites of the CYLD gene were amplified by PCR using specific primer pairs (primer sequences and amplification conditions are available from the authors upon request) and sequenced directly on an ABI 3730 DNA analyzer (Applied Biosystems Inc.), using the BigDye deoxy terminator V3.1cycle sequencing kit (Applied Biosystems, Foster City, CA, USA). Sequence analysis was performed with the software tools Phred, Phrap and Consed. ${ }^{15,16}$ Sequence deviations were detected by visual inspection.

\section{Results}

Our study revealed one recurrent and seven novel mutations in the CYLD gene (Table 1). Mutation nomenclature is based on NCBI RefSeq NM_015247.2 and according to the recommendations of the Human Genome Variation Society (HGVS) version 15.11. All mutations were classified as likely pathogenic (class 4, the missenses) or pathogenic (class 5, all others) according to the guidelines of the Associations for Clinical Genetic Science, the Dutch Society of Clinical Genetic laboratory Specialists and the American College of Medical Genetics and Genomics. ${ }^{17,18}$ Phenotypic features of the patients are summarized in Table 1.

In individuals BSS1 and BSS2, we detected two novel missense mutations, designated c.2261T>G (p.(lle754Ser)) and c.2581T>G (p.(Leu861Val)), respectively (Fig. 1a and 1b). In patients BSS3 and BSS4 we identified two nonsense mutations not described 
previously, comprising C-to-A transversion, designated c.2409C>A (p.(Tyr803*)), and c.2540G >A (p.(Trp847*)), respectively (Fig. 1c and 1d). In patients BSS5-8, we found two deletion and two duplication mutations, all leading to premature stop codons. The mutation in patient BSS5 has been reported previously and consisted of a single nucleotide deletion c.2081del (p.(Leu694*)) (Fig. 1e). ${ }^{19}$ In patients BSS6-BSS8 we detected a single nucleotide deletion c.822del (p.(Asn275Thrfs*36)), a single nucleotide duplication c.2649dup (p.(Ala884Cysfs*6)), and a TGTT-duplication c.588-591dup (p.(Ala198Cysfs*12)), respectively (Fig. 1f-h).

Absence of all mutations in the ExAC (Exome Aggregation Consortium) database, $\mathrm{dbSNP}$, exome variant server and gnomeAD, excluded the possibility of polymorphisms.

(a) control

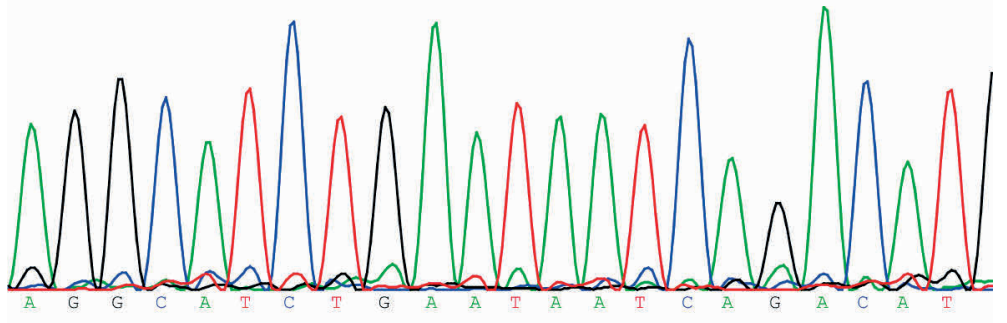

patient

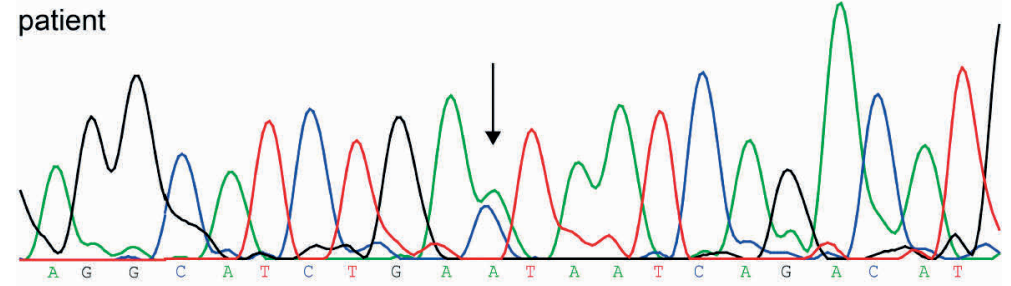

(b) control

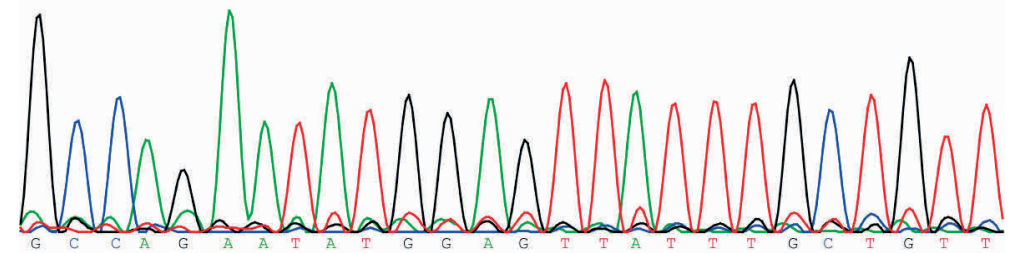

patient

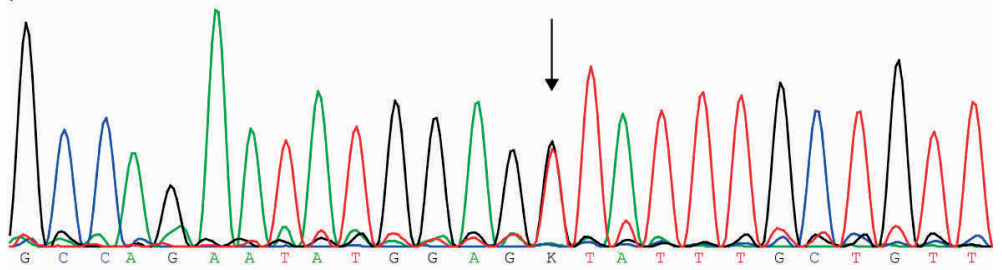


Chapter 3.2

(c) control
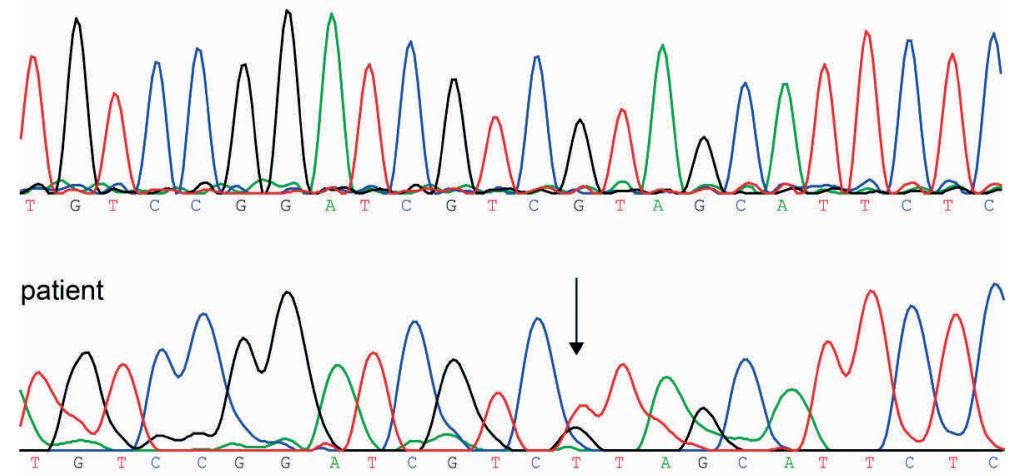

(d) control
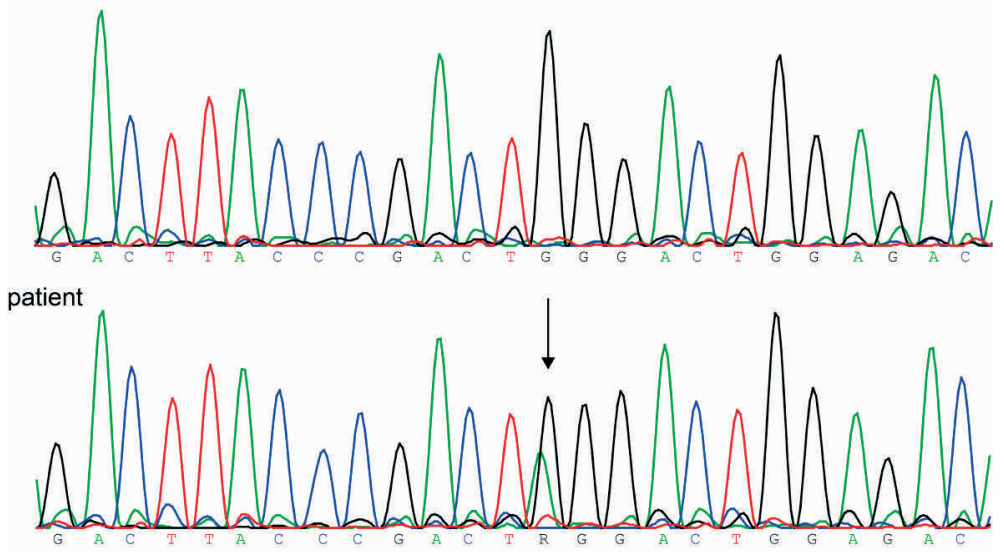

(e) control
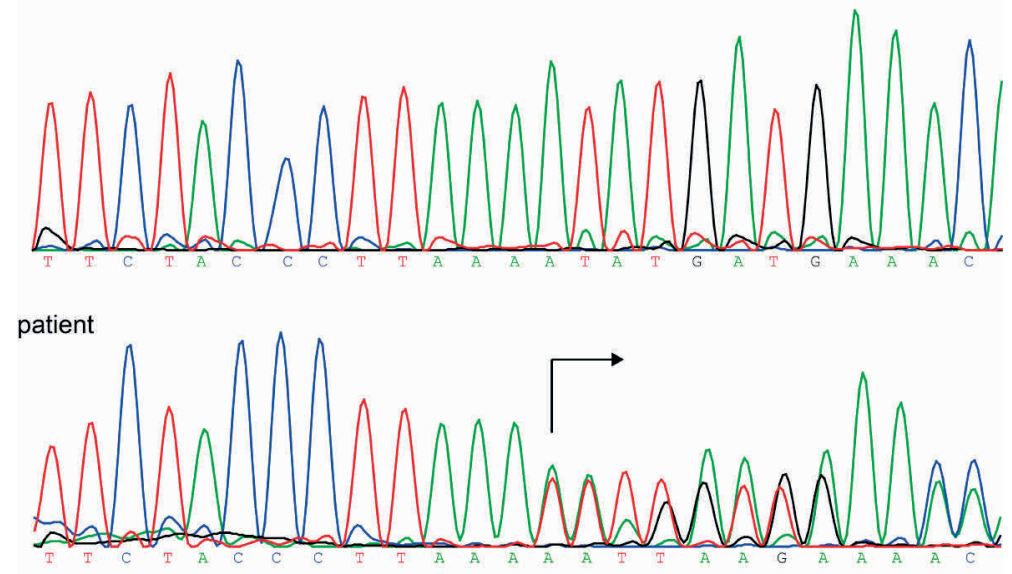
(f) control
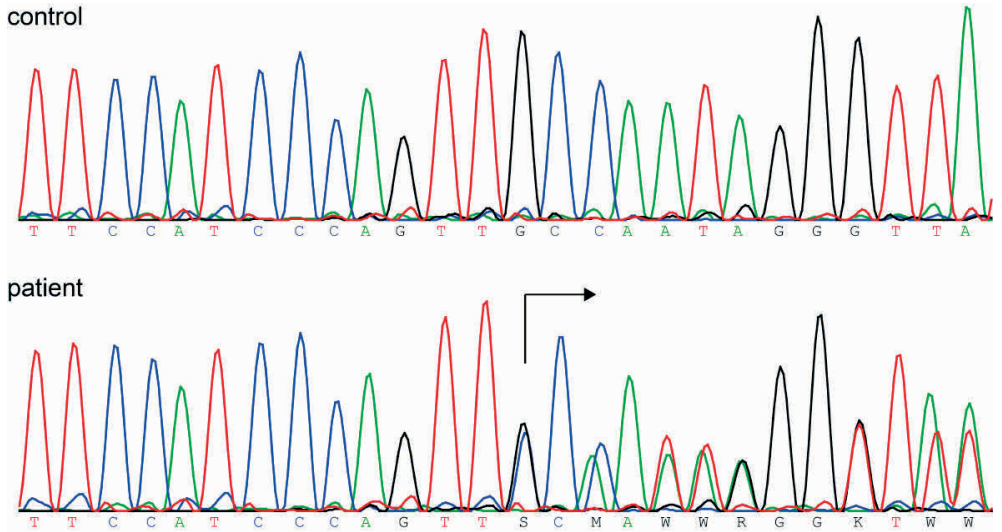

(g) control
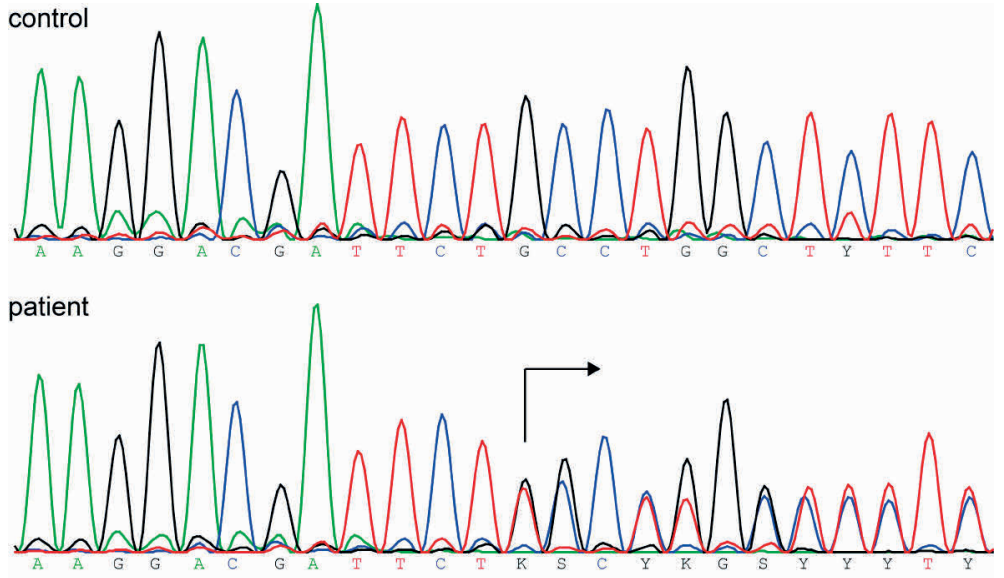

(h) control
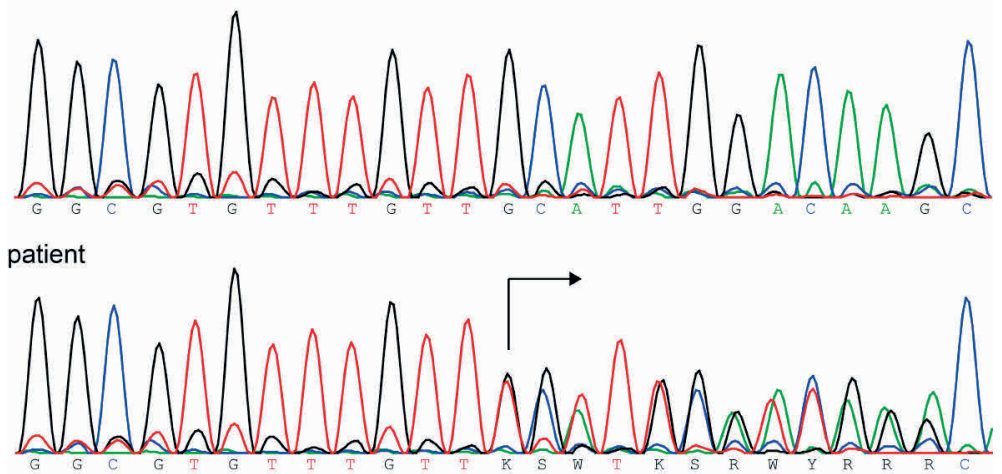

Figure 1. Mutations detected in this study. a. c.2261T>G (reverse strand orientation); b. c.2581T>G; c. c.2409C>A (reverse strand orientation); d. c.2540G>A; e. c.2081del (reverse strand orientation); f. c.822del; g. c. 2649dup; h. c.588_591dup. Mutation nomenclature based on NCBI RefSeq NM_015247.2. 


\section{Discussion}

BSS has a variable phenotype and shows considerable clinical overlap with multiple familial trichoepithelioma (MFT; OMIM 601606) and familial cylindromatosis (FC; OMIM 132700), in which trichoepitheliomas can occur either solely or in combination with cylindromas. ${ }^{20}$ All three disorders are inherited in an autosomal dominant fashion and are caused by heterozygous mutations in the CYLD gene, thus representing different ends of genetically allelic diseases. ${ }^{13,21}$

To date, more than 100 unique CYLD mutations have been reported, comprising 13 missense (12\%), 22 nonsense (20\%), 55 frameshift (50\%), 16 splice site mutations (15\%) and 3 large genomic deletions (3\%). ${ }^{21-24}$ More than $97 \%$ of these sequence deviations are located in exons 9-20, while, until 2009, no mutations had been reported in exon 48 (Fig. 2). ${ }^{25}$ Currently, there is little if any evidence for a genotype-phenotype correlation in any of the disorders caused by CYLD mutations. This is mainly because there is considerable intra- and interfamilial phenotypic variability, even within patients/families carrying the same germline mutation. ${ }^{21}$

Our study adds seven novel mutations to this database, the majority of them also located in exons 9-20. Of note, we did not find any splice site mutation.

The two missense mutations detected here have not yet been reported and are located in exons 17 (p.(Ile754Ser)) and 19 (p.(Leu861Val)) (Fig. 2). Both mutations are associated with a phenotype of MFT (Table 1). In this context it should be pointed out that $50 \%$ of the missense mutations reported previously cause MFT, thus perhaps suggesting at least a certain degree of genotype-phenotype correlation after all.

Our study revealed two novel nonsense mutations, p.(Tyr803*) and p.(Trp847*) located in exons 18 and 19, respectively (Table 1; Fig. 2). Whereas mutation p.(Trp847*) was associated with BSS, p.(Tyr803*) results in FC. Both mutations lead to null alleles, which depending on their exonic context, can exert their pathogenic effects through rapid degradation of the encoded protein by nonsense-mediated mRNA decay. ${ }^{26,27}$

We found two deletions and two duplication mutations, p.(Ala198Cysfs*12), p.(Asn275Thrfs*36), p.(Leu694*) and p.(Ala884Cysfs*6), located in exons 5, 6, 15 and 19, respectively (Fig. 2). Mutation p.(Leu694*) has already been reported and was associated with BSS. ${ }^{19}$ While p.(Asn275Thrfs*36) was also associated with BSS the other two mutations cause MFT. All four mutations lead to a premature termination codon and will give rise to either a truncated and thus dysfunctional protein or result in degradation of the transcript by nonsense-mediated mRNA decay. ${ }^{27}$

To date, 55 frameshift mutations have been identified in the CYLD gene. ${ }^{15,28,29}$ These mutations are mainly located in exons 9-20 (Fig. 2). Of note, the novel four-basepairduplication detected here (c.588_591dup) is located in exon 5. Only one other CYLD mutation has been identified in this exon to date. ${ }^{25}$ For the first time we detected a mutation located in exon 6, c.822del. 


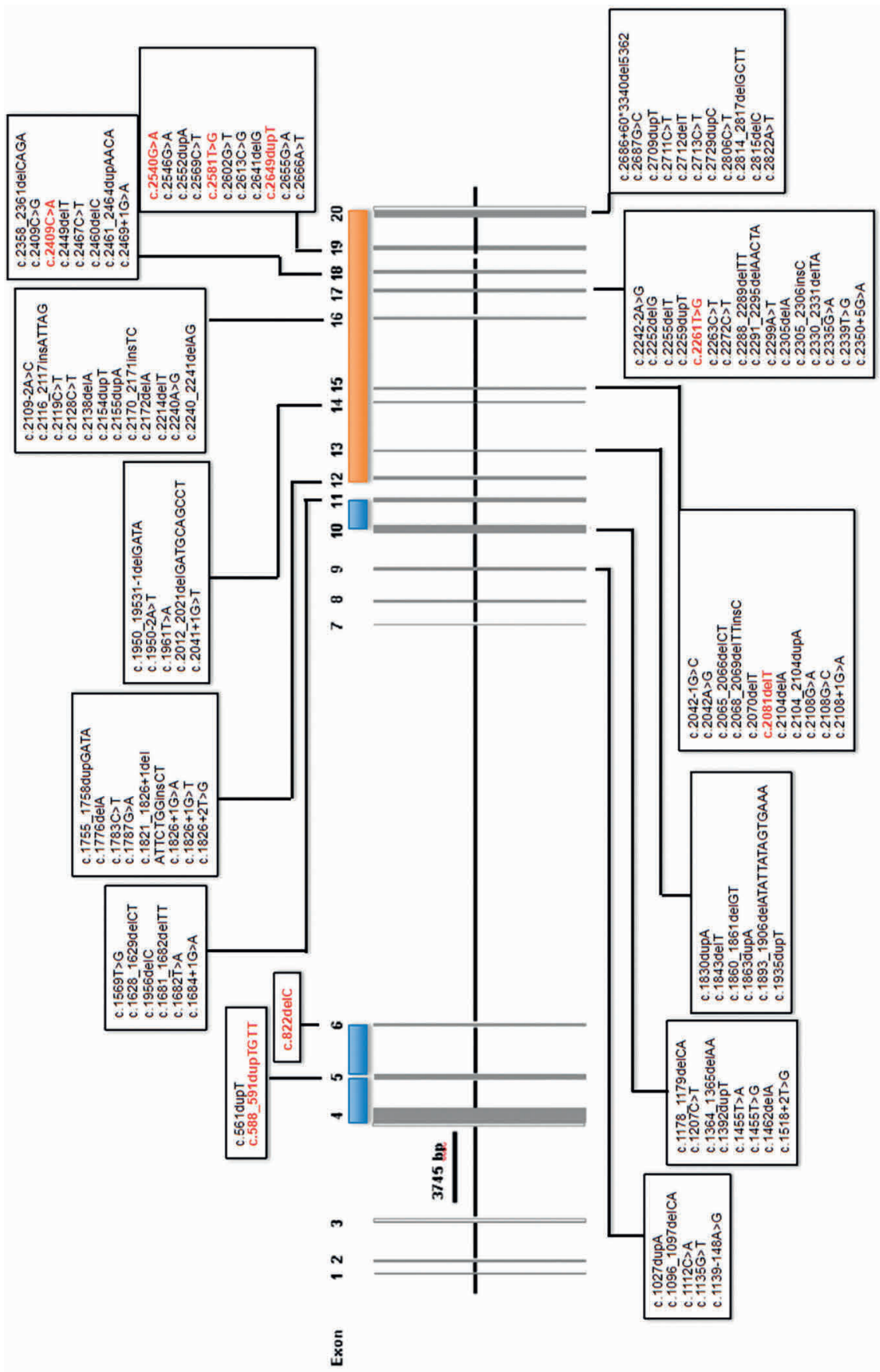

Figure 2. Mutations in the CYLD gene reported to date in relationship to the functional domains of the encoded CYLD protein. CYLD contains three CAP-GLY domains (amino acids 127-203, 232-303, 472-540; depicted as blue boxes) and an UCH catalytic domain (amino acids 593-948); based on NCBI number NP_056062.1. The mutations detected in this study are depicted in red. 
Currently, it is not well understood why mutations in the CYLD gene are associated with at least three different phenotypes, BSS, MFT, and FC. Likewise, family members harboring an identical mutation exhibiting distinct different phenotypes, is puzzling. Apart from yet unknown environmental factors and the involvement of modifying genes, epigenetic mechanisms, such as e.g. promoter hypermethylation, might play a role. ${ }^{30,31}$ The latter mechanism has been observed in sporadic forms of cancer and could silence the function of CYLD as a tumor suppressor. ${ }^{30,32}$

In summary, our results expand the database of CYLD mutations associated with the clinically variable skin appendage tumor syndromes BSS, MFT and FC. Further studies on the molecular mechanisms modifying disease expression may be helpful in the development of targeted and causal therapeutic strategies. 


\section{References}

1. Ancell $\mathrm{H}$. History of a remarkable case of tumours developed on the head and face; accompanied with a similar disease in the abdomen. Med Chir Trans. 1842;25:227-46.

2. Brooke H. Epithelioma adenoids cysticum. Br J Dermatol Syphilis. 1892;10:459-73.

3. Fordyce J. Multiple benign cystic epithelioma of the skin. J Cutan Dis. 1892;10:459-73.

4. Spiegler E. Ueber endoteliome der haut. AMA Arch Dermatol Syphilis. 1899;50:163-76.

5. Welch J, Wells R, Kerr C. Ancell-Spiegler cylindromas (turban tumours) and Brooke-Fordyce trichoepitheliomas: evidence for a single genetic entity. J Med Genet. 1968;5:29-35.

6. Gottschalk HR. Proceedings: dermal eccrine cylindromas, epithelioma adenoides cysticum of Brooke, and eccrine spiradenoma. Arch Dermatol. 1974;110:473-4.

7. Sellheyer K. Spiradenoma and cylindroma originate from the hair follicle bulge and not from the eccrine sweat gland: an immunohistochemical study with CD200 and other stem cell markers. J Cutan Pathol. 2015;42:90-101.

8. Nyame TT, Mattos D, Lian CG, Granter SR, Laga AC, Caterson EJ. Malignant eccrine spiradenoma of the face. J Craniofac Surg. 2015;26:1711-2.

9. Samaka RM, Bakry OA, Seleit I, Abdelwahed MM, Hassan RA. Multiple familial trichoepithelioma with malignant transformation. Indian J Dermatol. 2013;58:409.

10. Tripath SM, Somu TN, Sundaram M, Sahiya S. Malignant cylindroma of post aural region involving the temporal bone. J Clin Diagn Res. 2015;9:MD01-2.

11. Biggs PJ, Wooster R, Ford D, Chapman P, Mangion J, Quirk Y, Easton DF, Burn J, Stratton MR. Familial cylindromatosis (turban tumour syndrome) gene localized to chromosome 16q12-13: evidence for its role as a tumour suppressor gene. Nat Genet. 1995;11:441-3.

12. Bignell GR, Warren W, Seal S, Takahashi M, Rapley E, Barfoot R, Green H, Brown C, Biggs PJ, Lakhani SR, Jones C, Hansen J, Blair E, Hofmann B, Siebert R, Turner G, Evans DG, Schrander-Stumpel C, Beemer FA, van den Ouweland A, Halley D, Delpech B, Cleveland MG, Leigh I, Leisti J, Rasmussen S. Identification of the familial cylindromatosis tumour-suppressor gene. Nat Genet. 2000;25:160-5.

13. Blake PW, Toro JR. Update of cylindromatosis gene (CYLD) mutations in Brooke-Spiegler syndrome: novel insights into the role of deubiquitination in cell signalling. Hum Mutat. 2009;30:1025-36.

14. Sambrook J, Fritsch EF, Maniatis T. Molecular Cloning: A Laboratory Manual. Cold Spring Harbor, 13. NY: Cold Spring Harbor Laboratory Press, 1989.

15. Ewing B, Hillier L, Wendl MC, Green P. Base-calling of automated sequencer traces using phred. I. Accuracy assessment. Genome Res. 1998;8:175-85.

16. Gordon D, Abajian C, Green P. Consed: a graphical tool for sequence finishing. Genome Res. 1998;8:195202.

17. Richards S, Aziz N, Bale S, Bick D, Das S, Gastier-Foster J, Grody WW, Hegde M, Lyon E, Spector E, Voelkerding K, Rehm HL; ACMG Laboratory Quality Assurance Committee. Standards and guidelines for the interpretation of sequence variants: a joint consensus recommendation of the American College of Medical Genetics and Genomics and the Association for Molecular Pathology. Genet Med. 2015;17:405-24.

18. Wallis Y, Payne S, McAnulty C, Bodmer D, Sistermans E, Robertson K, Moore D, Abbs S, Deans Z, Devereau A. Practice guidelines for the evaluation of pathogenicity and the reporting of sequence variants in clinical molecular medicine. Association for Clinical Genetic Science (ACGS), Dutch Society of Clinical Laboratory Specialists (VKGL), 2013.

19. Almeida S, Maillard C, Itin P, Hohl D, Huber M. Five new CYLD mutations in skin appendage tumors and evidence that aspartic acid 681 in CYLD is essential for deubiquitinase activity. J Invest Dermatol. 2008;128:587-93.

20. Kazakov DV. Brooke-Spiegler syndrome and phenotypic variants: an update. Head Neck Pathol. 2016;10:125-30.

21. Nagy N, Farkas K, Kemeny L, Szell M. Phenotype-genotype correlations for clinical variants caused by CYLD mutations. Eur J Med Genet. 2015;58:271-8. 
22. Guardoli D, Arganziano G, Ponti G, Nasti S, Zalaudek I, Moscarella E, Lallas A, Piana S, Specchio F, Martinuzzi C, Raucci M, Pellacani G, Longo C. A novel CYLD germline mutation in Brooke-Spiegler syndrome. J Eur Acad Dermatol Venereol. 2015;29:457-62.

23. Rajan N, Ashworth A. Inherited cylindromas: lessons from a rare tumour. Lancet Oncol. 2015;16:e460-9.

24. Tancheva-Poor I, Vanecek T, Lurati MC, Rychly B, Kempf W, Michal M, Kazakov DV. Report of three novel germline CYLD mutations in unrelated patients with Brooke-Spiegler syndrome, including classic phenotype, multiple familial trichoepitheliomas and malignant transformation. Dermatology. 2016;232:30-7.

25. Nasti S, Pastorino L, Bruno W. Five novel germline function impairing mutations of CYLD in Italian patients with multiple cylindromas. Clin Genet. 2009;76:481-5.

26. Karousis ED, Nasif S, Muhlemann O. Nonsense-mediated mRNA decay: novel mechanistic insights and biological impact. Wiley Interdiscip Rev RNA. 2016;7:661-82.

27. Kurosaki T, Maquet LE. Nonsense-mediated mRNA decay in humans at a glance. J Cell Sci. 2016;129:461-7.

28. Oiso N, Mizuno N, Fukai K, Nakagawa K, Ishii M. Mild phenotype of familial cylindromatosis associated with an R758X nonsense mutation in the CYLD tumour suppressor gene. Br J Dermatol. 2004;15:1084-6.

29. Zhang G, Huang Y, Yan K, Li W, Fan X, Liang Y, Sun L, Li H, Zhang S, Gao M, Du W, Yang S, Liu J, Zhang X. Diverse phenotype of Brooke-Spiegler syndrome associated with a nonsense mutation in the CYLD tumor suppressor gene. Exp Dermatology. 2006;15:966-70.

30. Iliopoulos D, Jaeger SA, Hirsch HA, Bulyk ML, Struhl K. STAT3 activation of miR-21 and miR-181b-1 via PTEN and CYLD are part of the epigenetic switch linking inflammation to cancer. Mol Cell. 2010;39:493506.

31. Massoumi R. Ubiquitin chain cleavage: CYLD at work. Trends Biochem Sci. 2010;35:392-9.

32. Jones PA, Baylin SB. The fundamental role of epigenetic events in cancer. Nat Rev Genet. 2002;3:415-28. 
Chapter 3.3

Clustered unilateral trichoepitheliomas indicate type 1 segmental manifestation of multiple familial trichoepithelioma 


\begin{abstract}
Trichoepitheliomas are benign hair follicle tumors. They can arise sporadically, or in the context of the monogenetic disorder multiple familial trichoepithelioma (MFT; OMIM \#601606). This disease is caused by mutations in the CYLD gene. Here, we report a woman who at the age of 19 developed multiple trichoepitheliomas on her shoulder, following a Blaschko line. We considered this presentation to be suggestive of type 1 somatic mosaicism. We analyzed the coding regions and adjacent splice sites of the CYLD gene in peripheral blood and in a tissue biopsy to screen for germline and somatic mutations, respectively. No mutations were found. We suggest that the present case could represent a type 1 segmental manifestation of MFT due to either an exonic CYLD insertion, deletion or rearrangement, a mutation outside the coding regions of the CYLD gene, or a genetic defect other than a CYLD mutation.
\end{abstract}




\section{CORRESPONDENCE}

Trichoepitheliomas are benign hair follicle tumors, which can arise sporadically or in the context of an underlying genetic disorder, such as the monogenetic disorder multiple familial trichoepithelioma (MFT; OMIM \#601606). MFT is caused by heterozygous mutations in the CYLD gene. ${ }^{1}$

We report the case of a woman who developed multiple trichoepitheliomas on her shoulder, following a Blaschko line.

A 24-year-old white woman presented with a 5-year history of skin-colored papules on her right shoulder in a segmental distribution, following the lines of Blaschko (Fig. 1a). The rest of her skin was not affected. Her parents were unrelated, and neither they nor the patient's monozygotic twin sister had any similar lesions. Histopathological examination of a papule showed a sharply demarcated lesion in the dermis consisting of nests of small basaloid cells with peripheral palisading cells (Fig. 1b). Considering the clinical and histological findings, we diagnosed segmental trichoepitheliomas.


Figure 1. (a) Multiple small skin-colored papules in a segmental manifestation on the patient's right shoulder; (b) trichoepithelioma, showing nests of small basaloid cells with peripheral palisading cells (haematoxylin and eosin, original magnification $\times 100)$.

The local institutional review board approved a genetic study, and the patient provided written informed consent. Genomic DNA was isolated from peripheral blood according to standard techniques. ${ }^{2}$ A biopsy was taken from a clinically evident trichoepithelioma and frozen in liquid nitrogen. DNA from this fresh-frozen tissue was isolated (Nucleospin Tissue XS kit (Macherey-Nagel GmbH \& Co. K., Düren, Germany) according to the manufacturer's recommendations. The blood and tissue were used for screen for germline ans somatic mutations, respectively. All coding exons and exon-intron boundaries of the CYLD gene were amplified with PCR, and analyzed by direct sequencing (ABI 3730 DNA Analyzer; Applied Biosystems, Foster City, CA, USA) (primer sequences and reaction conditions are available upon request). Sequences were screened by visual inspection. We found no CYLD mutations in peripheral blood or in the affected tissue.

We considered this presentation to be suggestive of Type 1 somatic mosaicism. 
A linear manifestation of multiple trichoepitheliomas, suggestive of a genetic mosaicism, is very rare. Two types of mosaic presentations of autosomal dominant disorders are known. In Type 1, a heterozygous de novo postzygotic somatic mutation causes a segmental presentation of the disease. There is no germline mutation. ${ }^{3}$ The Type 2 manifestation is caused by a germline mutation in combination with a postzygotic somatic mutation. Clinically, a Type 2 mosaic is characterized by a diffuse phenotype with a superimposed area of more severe disease manifestation. ${ }^{4}$

Because we did not find a germline or somatic mutation in the CYLD gene, and considering the fact that the monozygotic twin sister was not affected, we hypothesize that our patient's phenotype reflects a Type 1 segmental manifestation of MFT. Possible explanations for not detecting a somatic CYLD mutation include: (i) involvement of other genes in the formation of trichoepitheliomas, (ii) location of the mutation in the promoter or deep intronic regions of the CYLD gene, (iii) exonic duplication/deletion or a large genomic rearrangement in the CYLD gene, (iv) insufficient number of mutated cells in the biopsy to reach the detection threshold of Sanger sequencing, or ( $v$ ) epigenetic events, for instance promoter hypermethylation, that silence the function of CYLD in this segmental form of trichoepitheliomas; a mechanism that is often seen in sporadic forms of cancer. ${ }^{5}$

In conclusion, we suggest that our case could represent a Type 1 segmental manifestation of MFT caused either by an exonic CYLD insertion, deletion or rearrangement; a mutation outside the coding regions of the CYLD gene; or a genetic defect other than a CYLD mutation. To our knowledge, this is the first time that the molecular genetics of a segmental manifestation of trichoepithelioma has been analyzed. 


\section{References}

1. Nagy N, Farkas K, Kemény L, Széll M. Phenotype-genotype correlations for clinical variants caused by CYLD mutations. Eur J Med Genet. 2015;58:271-8.

2. Sambrook J, Fritsch EF, Maniatis T. Molecular Cloning: A Laboratory Manual. Cold Sporing Harbor, NY: Cold Spring Harbor Laboratory Press, 1989.

3. Happle R. A rule concerning the segmental manifestation of autosomal dominant skin disorders: Review of clinical examples providing evidence for dichotomous types of severity. Arch Dermatol. 1997;133:1505-9.

4. Happle R. Segmental forms of autosomal dominant skin disorders: different types of severity reflect different states of zygosity. Am J Med Genet. 1996;66:241-2.

5. Jones PA, Baylin SB. The fundamental role of epigenetic events in cancer. Nat Rev Genet. 2002;3:415-28. 



\section{Chapter 4}

\section{A novel therapeutic strategy for turban tumor: scalp excision and combined reconstruction with artificial dermis and split skin graft}

Parren LJMT, Ferdinandus P, van der Hulst R, Frank J, Tuinder S. A novel therapeutic strategy for turban tumor: scalp excision and combined reconstruction with artificial dermis and split skin graft. Int J Dermatol. 2014;53(2):246-9. 


\section{Abstract}

\section{Background}

Brooke-Spiegler syndrome is a hereditary tumor predisposition disorder characterized by the development of cylindromas, trichoepitheliomas, and spiradenomas. Predilection sites of the disease are hair follicles and sweat glands of the head and neck. In some patients the tumors can coalesce to so-called turban tumors, which then usually cause cosmetic, psychological, and functional impairment.

A curative therapy is not yet available and, thus total scalp excision followed by split skin graft is evolving as a frequently applied therapy. However, this treatment can lead to the formation of a thin and vulnerable skin, which hampers wearing a wig. Therefore, a more robust and functional solution is preferable. Here, we report on a woman with a turban tumor who suffered enormously from the disease and had secluded herself from social life.

\section{Methods}

We treated her with a total scalp excision down to the periosteum, followed by sequential combined reconstruction with an artificial dermal template and split skin grafts.

\section{Results}

The treatment resulted in formation of a robust and flexible skin.

\section{Conclusions}

Treatment of turban tumor is a challenge considering the localization and the extensiveness of the tumor masses. This novel therapy for turban tumor leads to a very good cosmetic and functional outcome. 


\section{Introduction}

Brooke-Spiegler syndrome (BSS; OMIM 605041), also known as familial cylindromatosis, is a rare genetic tumor disease that is characterized by the occurrence of multiple benign tumors of skin appendages from the second decade onwards, including cylindromas, trichoepitheliomas, and spiradenomas. ${ }^{1}$ Cylindromas and trichoepitheliomas originate from eccrine hair follicle structures, whereas spiradenomas derive from sweat glands. Cylindromas predominantly occur on the head and neck. Trichoepitheliomas most often arise in the face, in particular in the perinasal area, preauricularly, and around the eyebrows. In exceptional cases, both cylindromas and trichoepitheliomas can enlarge dramatically and coalesce. This formation of big tumor masses, which can cover the entire circumference of the head, is distinguished as turban tumor. In contrast, spiradenomas are most frequently found on the trunk.

In 1968, Welch and colleagues suggested that one single genetic defect was responsible for the development of cylindromas and trichoepitheliomas. ${ }^{2}$ It was not until 2000 though that the first mutations in the CYLD gene, localized on chromosome 16q12-13, were reported to underlie the disorder. ${ }^{3}$ Since then, more than 50 mutations have been reported in $\mathrm{BSS} .{ }^{4}$ The $C Y L D$ gene encodes for the eponymous protein CYLD that plays an important role in the nuclear factor-kappaB (NF-kB) pathway.

BSS and, in particular, turban tumor frequently leads to disfigurement. Since a curative treatment is not yet available, the first choice therapy in patients with few, solitary tumors is surgical excision. In patients with turban tumor, however, total scalp excision may be indicated. Because this usually constitutes a reconstructive challenge we describe a novel therapeutic strategy for this variant of BSS that resulted in a solid and functional outcome.

\section{Case report}

In our outpatient clinic we saw a 48-year old Caucasian woman who was born to nonconsanguineous, healthy parents of Dutch origin. At the age of 12 years, she developed papules and nodules on her head and face. Histopathological examination showed cylindromas on the scalp and trichoepitheliomas in the face. Her further medical history was unremarkable. After giving birth to her first child in 1986, she rapidly developed more cylindromas and trichoepitheliomas, eventually resulting in turban tumor formation (Fig.1a).

Previous therapeutic attempts in our patient consisted of dermabrasion, trichloroacetic acid, electrocoagulation, intralesional infiltration with triamcinolonacetonide, topical phenol, both topically applied and systemic acetyl salicylic acid, and surgical excision of single tumors. However, all these treatments were unsatisfactory, leading to psychological impairment and social isolation in our patient. In order to hide the tumors 
and improve her cosmetic aspect she tried to wear a wig. Unfortunately though, this was not possible due to the extensiveness of the tumor masses.

In an interdisciplinary approach, we therefore performed a total scalp excision down to the periosteum, followed by coverage of the periost with an artificial dermal template (Integra LifeSciences Corp., Plainsboro, NJ) (Fig. 1b and 1c). Histopathological examination of the excised tumors showed cylindromas and spiradenomas (data not shown). Three weeks later we covered the artificial dermis with split skin grafts $(0.3$ millimeters) from the upper legs, which resulted in formation of a robust and flexible skin (Fig.1d). As postoperative treatment, we applied a compression therapy with a silicon coated cap for scar management (Fig. 1e). Four months after the surgery she was able to wear a wig with a good aesthetic result and, as a consequence, a higher selfesteem (Fig. 1f).

\section{Comment}

To date, the development of turban tumor in patients with BSS has been reported in approximately 30 individuals. Although the tumors associated with BSS usually develop in the skin, extracutaneous manifestations also have been described, including involvement of the parotid gland. ${ }^{5}$ Turban tumor may cause bone destruction by locally invasive growth. Furthermore, cylindroma, trichoepithelioma, and spiradenoma can show malignant transformation, which is reflected clinically by pain, ulceration, and rapid growth. $^{6}$

Turban tumor constitutes an aesthetic burden that usually leads to considerable psychological distress and social isolation, as in our patient. Further, cylindromas can block the auditory channel leading to hearing loss and deafness. ${ }^{7}$ Coalescing tumors are prone to bleeding and ulceration. Other possible complications include secondary infection, pain, and ocular occlusion by multiple cylindromas.

To date, a curative therapy for BSS or turban tumor is not available and treatment may be difficult depending on the localization and expansion of the tumors. Possible therapeutic options that have been reported previously include, e.g. conventional surgery, electrosurgery, cryosurgery, Mohs' micrographic surgery, dermabrasion, curettage, and topical $5 \%$ imiquimod cream. ${ }^{8}$ For trichoepitheliomas, ablative therapy with the erbium:Yag or $\mathrm{CO}_{2}$ laser might also be suitable. ${ }^{9}$ However, most of the aforementioned therapies can lead to scar formation and lesions may recur. In 2006, a non-invasive therapeutic approach was reported. Oosterkamp et al. suggested topical treatment with $20 \%$ salicylic acid in unguentum lanette. ${ }^{10}$ Although this therapy is not curative, tumor growth may be slowed down or even completely blocked. Our patient, however, did not show any response to either topically applied salicylic acid or systemic treatment with acetyl salicylic acid. 

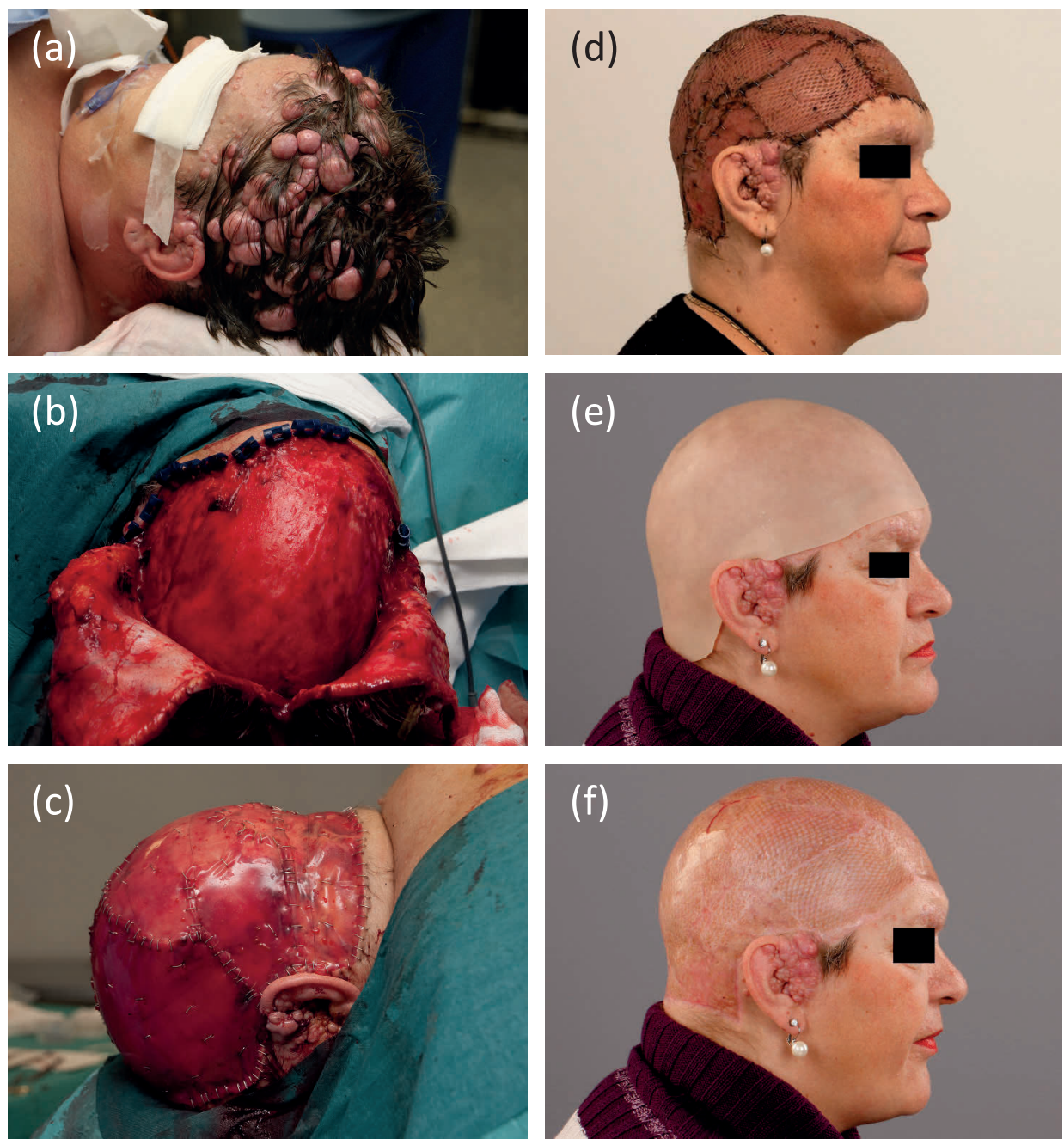

Figure 1. a) 48-year old woman with a turban tumor. b) Intra-operative view on total scalp excision. c) Coverage of the periost by artificial dermis (Integra 'LifeSciences Corporation, Plainsboro, NJ). d) Placement of split skin grafts onto the artificial dermis five days after surgery. e) Compression therapy with a silicon coated cap postoperative. f) Aesthetic outcome four months after surgery.

Treatment of turban tumor is an interdisciplinary challenge, in particular considering its localization and the enormous extent these tumor masses may reach. The chance of malignant transformation and the frequently observed improvement of hygiene, cosmesis, and psychological well-being after surgery makes broad removal of tumor tissue the first choice treatment. Over the last years, total scalp excision followed by reconstruction with a split skin graft is evolving as a frequently applied therapy in turban tumors. ${ }^{11}$ However, this intervention can lead to the formation of a fragile and vulnerable skin with an increased risk of wound development after friction or pressure, e.g. 
while wearing a wig. Hence, a therapeutic approach would be desirable that, after scalp removal, results in formation of a robust and flexible skin. In our opinion, the depth of the excision is another important aspect. Both trichoepithelioma and cylindroma are hair follicle tumors and have their origin deep in the deep dermal layers. Therefore, excision of the entire skin down to the periosteum is recommendable to minimize the risk of recurrence of the tumors.

Here, we applied a novel therapeutic strategy for turban tumor. After removal of the entire skin of the head circumference down to the periosteum the wounds were covered in a first step with an artificial dermis (Integra ${ }^{\circ}$ ) followed by split thickness skin grafting. It is already known that artificial dermal templates like the one applied by us can be used for the successful reconstruction of complex scalp defects following extensive tumor resection, thereby providing minimal donor-site morbidity and expedient operative time. ${ }^{12}$ Further, coverage of periost or calvarial defects with artificial dermis usually results in a more solid outcome compared to application of split skin only. ${ }^{12}$ Recently, a patient with various cutaneous malignancies on the head was treated with radical excision of the tumors followed by reconstruction of the resulting defects with a split skin graft only on one operation site and with the combination of artificial dermis and an additional split skin graft on the other operation site. Direct comparison of the two healed wounds showed a much thicker and healthier result on the latter site when compared to the thin and vulnerable coverage on the former site. ${ }^{13}$ In line with this report, the combined reconstructive approach chosen in our patient resulted in a firm and resistant coverage with a very good functional and aesthetic outcome so that she was able to wear a wig without complications.

The treatment of turban tumor can be complex and in these patients, we recommend a multidisciplinary approach in which, e.g. dermatologists, plastic surgeons, otorhinolaryngologists, and psychologists can combine their expertise to warrant the best therapeutic outcome for the patient. Since the genetic defect in BSS is ubiquitously expressed, a thorough follow-up of our patient will show if total scalp removal can prevent tumor recurrence in the long run. 


\section{References}

1. Ancell $\mathrm{H}$. History of a remarkable case of tumours developed on the head and face; accompanied with a similar disease in the abdomen. Med Chir Trans. 1842;25;227-46.

2. Welch J, Wells R, Kerr C. Ancell-Spiegler cylindromas (turban tumours) and Brooke-Fordyce trichoepitheliomas: evidence for a single genetic entity. J Med Genet. 1968;5:29-35.

3. Bignell GR, Warren W, Seal S, et al. Identification of the familial cylindromatosis tumour-suppressor gene. Nat Genet. 2000;25:160-5.

4. Blake PW, Toro JR. Update of cylindromatosis gene (CYLD) mutations in Brooke-Spiegler syndrome: novel insights into the role of deubiquitination in cell signalling. Hum Mutat. 2009;30:1025-36.

5. Jungehulsing $M$, Wagner M, Damm M. Turban tumour with involvement of the parotid gland. J Laryngol Otol. 1999;113;779-83.

6. Kuklani RM, Glavin FL. Malignant Cylindroma of the Scalp Arising in a Setting of Multiple Cylindromatosis: A Case Report. Head Neck Pathol. 2009;3;315-9.

7. Parren LIMT, Bauer B, Hamm H, Frank J. Brooke-Spiegler syndrome complicated by unilateral hearing loss. Int J Dermatol. 2008;47;56-9.

8. Rajan N, Trainer AH, Burn J, Langtry JAA. Familial cylindromatosis and Brooke-Spiegler syndrome: a review of current therapeutic approaches and the surgical challenges posed by two affected families. Dermatol Surg. 2009;35;845-52.

9. Retamar RA, Stengel F, Saadi, ME, et al. Brooke-Spiegler syndrome - report of four families: treatment with CO2 laser. Int J Dermatol. 2007;46;583-6.

10. Oosterkamp HM, Neering $\mathrm{H}$, Nijman SMB, et al. An evaluation of the efficacy of topical application of salicylic acid for the treatment of familial cylindromatosis. Br J Dermatol. 2006;155;82-5.

11. O'Blenes CAE, Lee JP, Walsh NMG, Morris SF. An unusual case of turban tumor syndrome treated with total scalp excision and advancement flap and skin graft reconstruction. Ann Plast Surg. 2010;65;107-9.

12. Komorowska-Timek E, Gabriel A, Bennett DC, et al. Artificial dermis as an alternative for coverage of complex scalp defects following excision of malignant tumors. Plast Reconstr Surg. 2005;115:1010-7.

13. Wain RA, Shah SH, Senarath-Yapa K, Laitung JK. Dermal substitutes do well on dura: comparison of split skin grafting+/-artificial dermis for reconstruction of full-thickness calvarial defects. J Plast Reconstr Aesthet Surg. 2010;63:826-8. 



\section{Part 2}

\section{Bazex-Dupré-Christol syndrome}





\section{Chapter 5}

\section{Hereditary tumor syndromes featuring basal cell carcinomas}

Parren LJMT, Frank J. Hereditary tumour syndromes featuring basal cell carcinomas. Br J Dermatol. 2011;165(1):30-4. 


\begin{abstract}
Basal cell carcinoma (BCC) is the most frequent cutaneous malignancy worldwide. This skin tumor is characterized by a broad phenotypic variability and distinct histopathological subtypes. It shows slow, locally invasive growth and only rarely metastasises. BCCs can occur either sporadically or in the context of genetic syndromes, including Gorlin syndrome, Bazex-Dupré-Christol syndrome, Rombo syndrome, Oley syndrome, and Xeroderma pigmentosum. Different genes and signaling routes have been shown to play an important role in the development and growth of these tumors, including the hedgehog and Wnt/beta-catenin pathway. In some of the aforementioned hereditary disorders, the underlying genetic defect is still unknown whereas in others several genes have been demonstrated to be involved. Currently, most therapeutic approaches are based on surgical measures. In the case of superficial BCCs, photodynamic therapy, 5-fluorouracil cream, imiquimod or radiotherapy also may be an option. Elucidation of the molecular mechanisms governing the manifestation of BCCs in monogenetically inherited tumor syndromes will not only contribute to a better understanding of the complex pathogenesis of these tumors but might pave the way to the development of non-invasive, specific and molecule-based therapeutic strategies in the near future.
\end{abstract}




\section{Introduction}

Basal cell carcinoma (BCC) is the most frequent malignancy of the skin in the white population. With an overall annual increase worldwide, the incidence of BCC in the southern part of the Netherlands is approximately 165 per 100,000 men and 190 per 100,000 women $^{1}$, as compared to 1041 per 100,000 men and 745 per 100,000 women in Australia. ${ }^{2}$

Usually, the primary lesion is a red-brownish, flat to slightly elevated papule of variable size with an elevated, sometimes pearly border and telangiectasias. Other clinical variants comprise superficial, morphoeic, and pigmented BCCs. If left untreated, tumors may appear eroded or ulcerated.

Although most BCCs are diagnosed clinically, confirmation by histopathologic examination is mandatory to choose the least invasive therapy. Histologically, superficial, nodular, infiltrative or mixed BCCs can be differentiated. ${ }^{3}$

Both solitary and multiple sporadic BCCs commonly arise in the sun-exposed areas of the body, most probably due to high cumulative exposure to ultraviolet radiation. Other known risk factors for the development of these tumors include Fitzpatrick skin type 1 and 2, radiotherapy, immunosuppression, higher socioeconomic status, one or more previous BCCs in the medical history, a positive family history, and genetic defects. ${ }^{4,5}$

In particular patients fulfilling one ore more of the latter three criteria are at higher risk of developing multiple and recurrent BCCs. The manifestation of these tumors already in childhood or adolescence is always suspicious for a hereditary tumor predisposition syndrome, including basal cell naevus syndrome (BCNS), Bazex-Dupré-Christol syndrome (BDCS), Rombo syndrome, Oley syndrome, and Xeroderma pigmentosum (XP).

Here, we give an overview on hereditary syndromes associated with BCCs and particularly focus on the genetic basis and underlying pathogenetic mechanisms driving tumor development in these disorders.

\section{Hereditary tumor syndromes featuring basal cell carcinomas}

\section{Basal cell naevus syndrome}

BCNS (OMIM 109400), also known as Gorlin or Gorlin-Goltz syndrome, is an autosomal dominant disorder with complete penetrance that was described for the first time in $1960 .^{6}$ The prevalence varies from 1 per 56.000 to 1 per $164.000,{ }^{7}$ and approximately $0.4 \%$ of individuals with multiple BCCs are thought to have BCNS. ${ }^{8}$ Males and females are equally affected. ${ }^{9}$ 
The clinical spectrum of the disease is variable both within the same family and between unrelated affected individuals (Table 1). Still, most patients with BCNS have a characteristic phenotype comprising macrocephaly, frontal bossing, hypertelorism, skeletal defects, and palmar pits. ${ }^{6}$ Predilection sites of BCCs, which evolve from childhood onwards and grow locally invasive, are the head, neck, and trunk (Figure 1). Pulmonary and bone metastases have been described only rarely. ${ }^{10}$

Table 1. Cutaneous and extracutaneous signs encountered in basal cell naevus syndrome

\begin{tabular}{ll}
\hline Organ/anatomical site & Clinical signs \\
\hline Skin & Basal cell carcinomas; epidermal cysts; palmar and plantar pits; facial milia \\
Head and brain & Macrocephaly; frontal bossing; cleft lip and/or palate; jaw cysts; \\
& medullablastoma; lamellar calcification of the falx; calcification of tentorium \\
& cerebelli; cerebral cysts \\
& Congenital cataract; microphtalmia; orbital cysts; coloboma of the iris, \\
cyes & poroid and optic nerve; strabismus; nystagmus; keratin-filled cysts on the \\
& palpebral conjunctivae \\
Skeleton & bifida; polydactyly of hands or feet, syndactyly \\
& Ovarian fibromas; mesenteric cysts; fetal rhabdomyoma; kidney anemalies; \\
Other & hypogonadotropic hypogonadism; cardiac fibromas
\end{tabular}

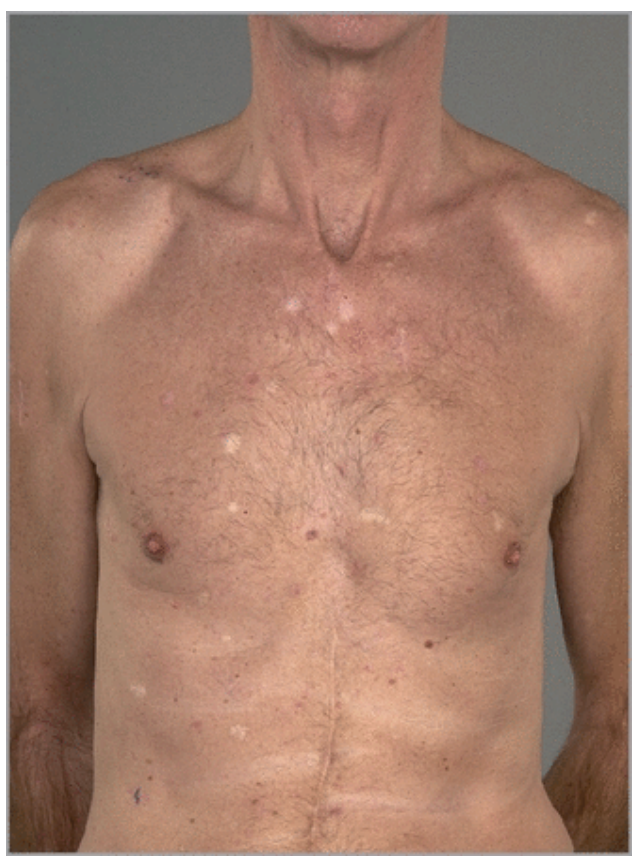

Figure 1. Multiple superficial and nodular basal cell carcinomas and hypopigmented scars on the trunk of a patient with basal cell naevus syndrome (Picture courtesy of drs Kelleners-Smeets, Mosterd and Thissen, Departement of Dermatology, Maastricht University Medical Centre, the Netherlands) 
In 1996, germline mutations in the patched (PTCH) gene on chromosome 9q22.3 were found to underlie BCNS and it was also demonstrated that somatic $P T C H$ mutations are present in sporadic BCCs. ${ }^{11,12}$ The PTCH gene codes for the eponymous transmembrane protein receptor PTCH that plays an important role in the Sonic hedgehog $(\mathrm{SHH})$ signaling pathway and acts as a tumor suppressor. Normally, SHH ligand interacts at the cell membrane with PTCH and the G-linked receptor protein smoothened (SMO). In the absence of SHH, PTCH inhibits SMO, leading to suppression of SMO-induced intracellular signaling. However, when SHH binds to PTCH, the inhibitory function gets lost and $\mathrm{SMO}$ is activated, resulting in an intracellular signal to the nucleus by the zinc finger transcription factors glioma-associated oncogene (GLI) 1 and GLI2. This leads to transcriptional activation of intracellular target genes. When $\mathrm{PTCH}$ is mutated, $\mathrm{SHH}$ is no longer able to bind to PTCH and SMO cannot be repressed. This results in activation of the hedgehog signaling pathway and, eventually, in the development of BCCs.

In affected individuals, a broad range of mutations has been detected, including insertions, deletions, missense, nonsense, and splice site mutations. To date, there is no evidence for genotype-phenotype correlations. ${ }^{9}$ In patients with BCNS, different in vivo mechanisms of PTCH inactivation exist, as demonstrated in different tumors from the same patient, which either showed loss of the wild-type allele or a second hitmutation. ${ }^{13}$

\section{Bazex-Dupré-Christol syndrome}

Bazex, Dupré and Christol described in 1964 a hereditary tumor syndrome affecting the hair follicle, which is nowadays referred to as Bazex-Dupré-Christol syndrome (OMIM 301845). Until now, approximately 20 patients and families have been reported. ${ }^{14}$

The disorder is characterized by hypotrichosis, follicular atrophoderma, BCCs, and milia. ${ }^{15}$ Other clinical signs that have been described are hypohidrosis, facial hyperpigmentation, and trichoepitheliomas, reflecting the intra- and interfamilial phenotypic variation of the disease (Table 2). ${ }^{14,16}$ Most symptoms manifest during childhood. Hypotrichosis is usually the first clinical finding that can often be appreciated already after birth. BCCs may develop from the first decade onwards, the youngest patient hitherto reported being three years old. ${ }^{14}$

The genetic defect underlying BDCS is not yet known. Due to absence of male-tomale transmission in affected families an X-linked dominant inheritance mode was proposed. ${ }^{16-18}$ In supported of this notion, Vabres et al. mapped the gene for BDCS to chromosome Xq24-q27. ${ }^{19}$ In a very recent study, we were able to confirm these data and further refine the critical region to an 11.4 Mb interval on Xq25-27.1. ${ }^{20}$

\section{Rombo syndrome}

In 1981, Michaelsson et al. ${ }^{21}$ reported on a family with vermiculate atrophoderma, milia, hypotrichosis, trichoepitheliomas, BCCs, and peripheral vasodilation with cyanosis 
(Table 2, Fig.2). Since then, two other cases of the so-called Rombo syndrome (OMIM 180730) have been described. ${ }^{22,23}$ The first clinical signs are follicular atrophy of the sun-exposed skin and a cyanotic redness, which evolve in childhood. BCCs develop from the fourth decade onwards. ${ }^{21}$

Evidently, the phenotypes of Rombo syndrome and BDCS show a high degree of overlap. Still, there are two apparent differences, (i) the follicular atrophoderma in Rombo syndrome is seen on the elbows and cheeks, whereas in BDCS it is mainly localized on the dorsa of the hands; and (ii) patients with Rombo syndrome exhibit a reddening of the skin that has not yet been described in BDCS. ${ }^{14,23}$ Further, in the family described by Michaelsson and colleagues there was male-to-male transmission, suggesting an autosomal dominant inheritance mode. ${ }^{21,23}$ BDCS, in contrast, is inherited as an X-linked dominant trait. ${ }^{19.2}$

Table 2. Comparative overview of clinical characteristics and inheritance pattern in Bazex-Dupré-Christol, Rombo, and Oley syndromes.

\begin{tabular}{lll}
\hline Disease & Clinical signs & Inheritance \\
\hline Bazex-Dupré-Christol syndrome & Basal cell carcinomas & X-linked dominant \\
& Hypotrichosis & \\
& Follicular atrophoderma & \\
& Milia & \\
& Hypohidrosis & \\
& Facial hyperpigmentation & \\
Trichoepitheliomas & Autosomal dominant \\
Rombo syndrome & Vermiculate atrophoderma & \\
& Milia & \\
& Hypotrichosis & \\
& Trichoepitheliomas & \\
& Basal cell carcinomas & \\
& Peripheral vasodilation & \\
& Cyanosis & Unknown \\
& Basal cell carcinomas & \\
& Coarse sparse hair & \\
\hline
\end{tabular}




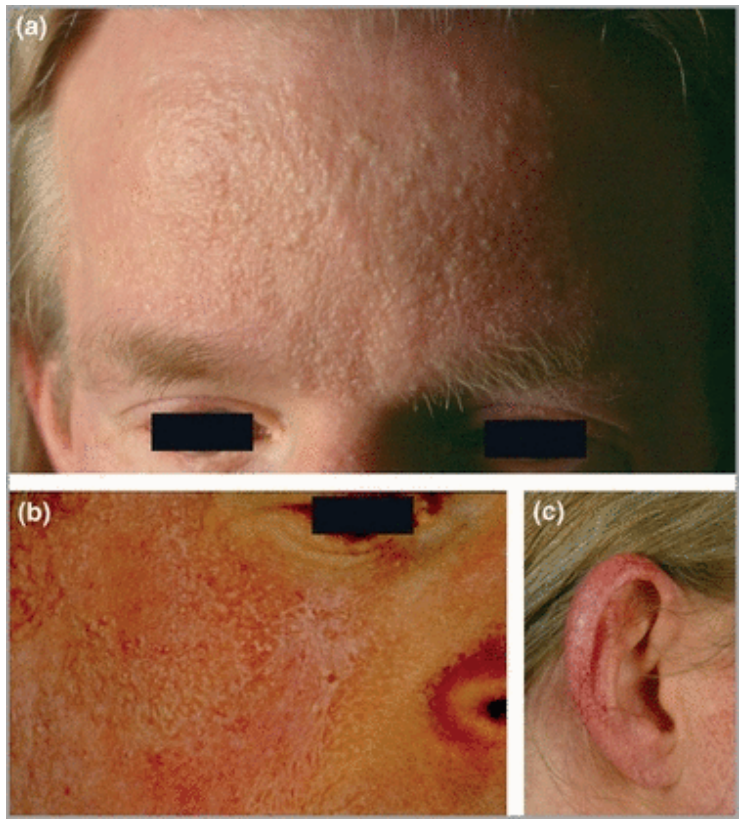

Figure 2. Clinical signs in a patient with Rombo syndrome, including (a) multiple aggregated milia on the forehead, (b) atrophoderma vermiculatum and milia on an erythematous background on the right cheek and (c) telangiectasias and erythema on the right ear (pictures courtesy of Prof. Dr van Steensel and Prof. Dr Steijlen, Departement of Dermatology, Maastricht University Medical Centre, the Netherlands)

\section{Oley syndrome}

In 1992, Oley et al. described a family with coarse sparse hair, milia, and BCCs (Table 2). ${ }^{24}$ Affected individuals had similar clinical signs as patients with BDCS but, in contrast to the latter disorder, these symptoms spontaneously regressed during adolescence. Because of the apparent clinical overlap, Adreani et al. suggested in 2000 that Oley syndrome and BDCS may be two variants of the same disease. ${ }^{25}$ To date, the inheritance mode and causative genetic defect of Oley syndrome have not been elucidated.

\section{Xeroderma pigmentosum}

Xeroderma pigmentosum (OMIM 278700) is an autosomal recessive tumor predisposition disorder that was first recognized by Hebra and Kaposi in $1874 .{ }^{26}$ The incidence is approximately 1 per 250.000 newborns. ${ }^{27}$

Clinically, XP is characterized by photosensitivity of sun-exposed tissues, premature skin ageing, development of cutaneous neoplasms including BCCs, photophobia, and pigmentary changes (Fig. 3). Beside the cutaneous signs, various extracutaneous manifestations may arise (Table 3). ${ }^{28}$ The skin seems to be normal at birth. From childhood onwards, however, affected individuals develop multiple BCCs, squamous cell carcinomas and melanomas, most probably as the result of repeated exposure to UV radiation. 
Overall, the incidence of skin cancer in these patients is 1000 times higher than in normal individuals. ${ }^{29}$

Eight XP genes have been identified thus far, subdivided into XPA-XPG and XP variant, respectively. The first seven (XPA-XPG) are involved in nucleotide excision repair whereas XP variant is responsible for replication of damaged DNA on the leading strand. In patients with mutations in any of these genes DNA damage due to UV radiation cannot be repaired appropriately, leading to cutaneous malignancies and ocular and neurological complications (Table 3). ${ }^{27,28}$

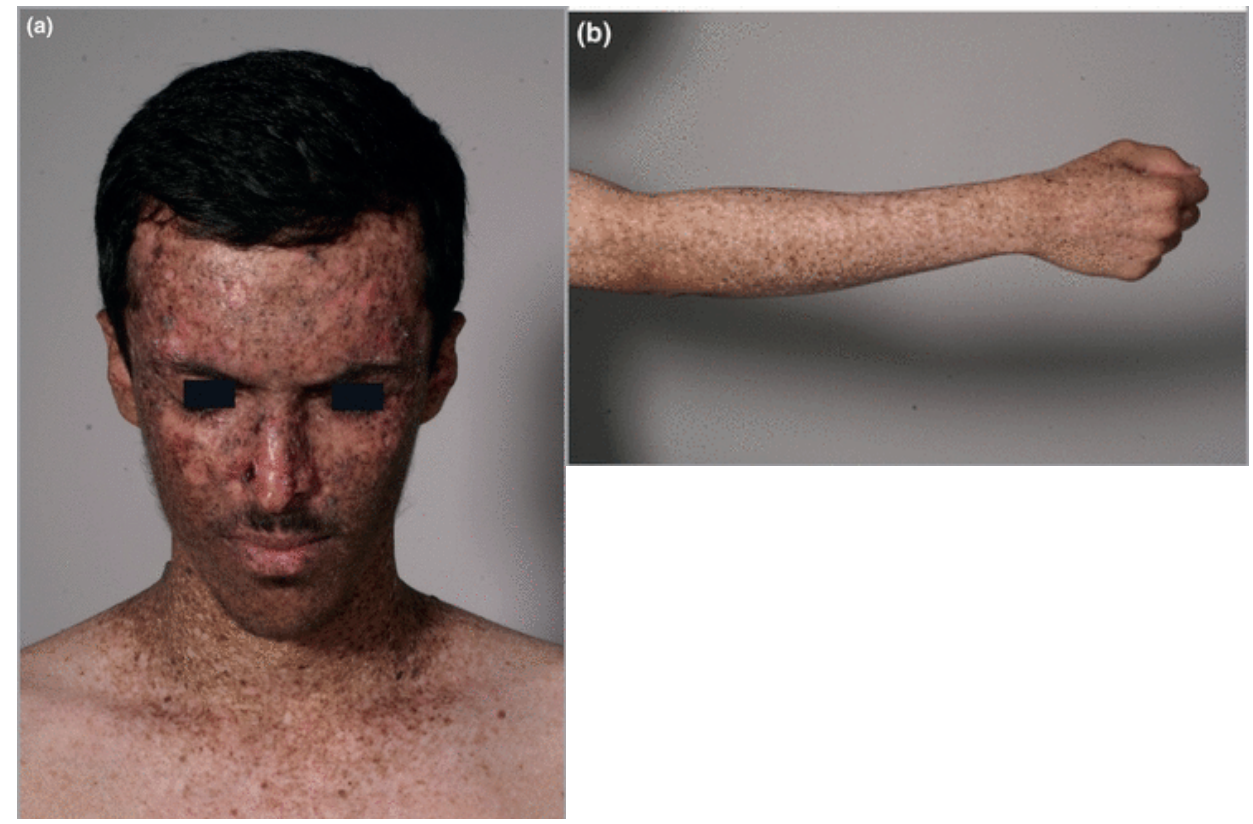

Figure 3. Cutaneous changes in xeroderma pigmentosum, including (a) numerous freckle-like hyperpigmented macules, actinic keratoses, basal cell and squamous carcinomas in the face and (b) pigmented macules of varying size and intensity and scattered achromic areas on the right arm (pictures courtesy of Prof. Dr Berneburg, Department of Dermatology, University of Tubingen, Germany)

Table 3. Selected cutaneous and extracutaneous clinical signs often encountered in xeroderma pigmentosum

\begin{tabular}{ll}
\hline Cutaneous symptoms & Extracutaneous symptoms \\
\hline Premature skin ageing & Eyes \\
Neoplasm development & Photophobia \\
Photosensitivity of sun-exposed tissues & Keratosis \\
Pigmentary changes & Corneal opacification \\
& Ectropion \\
& Nervous system \\
& Microcephaly \\
& Cognitive impairment \\
& Hearing loss \\
\hline
\end{tabular}




\section{Current therapeutic options and future prospects}

At present, different treatment modalities for BCCs are available. The individual therapeutic choice depends on, for example the histological subtype, tumor localisation, patient-adherent relevant concomitant diseases and whether it is a primary or recurrent BCC. ${ }^{30}$ The standard therapy for BCCs consists of surgical excision allowing for confirmation of radical tumor removal by histopathological examination. In recurrent BCCs, Mohs' micrographic surgery may be preferable.

Non-invasive therapies including photodynamic therapy, 5-fluorouracil cream or imiquimod, were found to be effective in the treatment of superficial BCCs. These treatment modalities have reasonable cure rates and result in highly acceptable cosmetic outcomes. ${ }^{30}$ Radiotherapy might be a good alternative when the patient is in a bad general health state, has cognitive impairment or if surgical excision would bear the risk of cosmetic or functional impairment. ${ }^{31}$

Beyond the aforementioned therapeutic measures, dermatologic and genetic counselling of patients with hereditary tumor syndromes associated with BCCs is vital. This includes on the one hand advice as to preventative measures, e.g. the repeated use of sunscreens and regular dermatological screening for cutaneous malignancies already in childhood. On the other hand, genetic screening can be offered to families with BCNS and XP.

It has recently been shown that pathway-based causal therapy is feasible and effective. Von Hoff et al. assessed the safety and pharmacokinetics of GDC-0449, a smallmolecule inhibitor of SMO and the effects of the drug on metastatic or locally advanced BCCs. Of the 33 patients treated, 18 had an objective response to GDC-0449 as demonstrated by both imaging and physical examination. ${ }^{32}$ These promising results suggest that in the future, the development of disease-specific therapeutic strategies based on the underlying pathogenetic mechanisms may gradually replace traditional invasive surgical techniques. 


\section{References}

1. Arits A, Schlangen M, Nelemans P, Kelleners-Smeets $N$. Trends in the incidence of basal cell carcinoma by histopathological subtype. J Eur Acad Dermatol Venereol. 2011;25:565-9.

3. Rippey JJ. Why classify basal cell carcinomas? Histopathology. 1998;32:393-8.

4. Efron PA, Chen MK, Glavind FL, et al. Pediatric basal cell carcinoma: case reports and literature review. J Pediatr Surg. 2008;43:2277-80.

5. Kiiski V, Vries E de, Flohil SC, et al. Risk factors for single and multiple basal cell carcinomas. Arch Dermatol. 2010;146:848-55.

6. Gorlin RJ, Goltz RW. Multiple nevoid basal-cell epithelioma, jaw cysts and bifid rib. A syndrome. N Engl J Med. 1960;262:908-12.

7. de Meij TG, Baars MJ, Gille JJ, et al. [From gene to disease: basal cell nevus syndrome]. Ned Tijdschr Geneeskd. 2005;149:78-81.

8. Gorlin RJ. Nevoid basal cell carcinoma (Gorlin) syndrome. Genet Med. 2004;6:530-9.

9. Jones EA, Imran Sajid M, Shenton A, Gareth Evans D. Basal cell carcinomas in Gorlin syndrome: a review of 202 patients. J Skin Cancer. 2011;2011:217378.

10. Lamon T, Gerard S, Meyer N, et al. Exceptional bone metastasis of basal cell carcinoma in Gorlin-Goltz syndrome. Dermatology. 2010;220:57-9.

11. Johnson RL, Rothman $\mathrm{AL}$, Xie J, et al. Human homolog of patched, a candidate gene for the basal cell nevus syndrome. Science. 1996;272:1668-71.

12. Hahn H, Wicking C, Zaphiropoulos PG, et al. Mutations of the human homolog of drosophila patched in the nevoid basal cell carcinoma syndrome. Cell. 1996;85:841-51.

13. Unden AB, Holmberg E, Lundh-Rozell B, et al. Mutations in the human homologue of Drosophila patched (PTCH) in basal cell carcinomas and the Gorlin syndrome: different in vivo mechanisms of PTCH inactivation. Cancer Res. 1996;56:4562-5.

14. Abuzahra F, Parren LJMT Frank J. Multiple basal cell carcinomas in childhood - Bazex-Dupré-Christol syndrome. J Eur Acad Dermatol Venereol. 2012;26:117-21.

15. Bazex A, Dupre A, and Christol B. Génodermatose complexe de type indéterminé associant une hypotrichose, un état atrophodermique généralisé et des dégénérescences cutanées multiples (épithéliomasbasocellulaires). Bull. Soc. Franc. Derm. Syph. 1964;71:206.

16. Goeteyn M, Geerts ML, Kint A, et al. The Bazex-Dupré-Christol syndrome. Arch Dermatol. 1994;130:337-42.

17. Barcelos AC, Nico MM. Bazex-Dupré-Christol syndrome in a 1-year old boy and his mother. Pediatr Dermatol. 2008;25:112-3

18. Castori M, Castiglia D, Passarelli F, et al. Bazex-Dupré-Christol syndrome: an ectodermal dysplasia with skin appendage neoplasms. Eur J Med Genet. 2009;52:250-5.

19. Vabres P, Lacombe D, Rabinowitz LG, Aubert G, et al. The gene for Bazex-Dupré-Christol syndrome maps to chromosome Xq. J Invest Dermatol. 1995;105:87-91.

20. Parren LIMT, Abuzahra F, van Steensel M, et al. Linkage refinement of Bazex-Dupré-Christol syndrome to an 11.4 Mb interval on chromosome Xq25-27.1. Br J Dermatol. 2011;165:201-3.

21. Michaelsson G, Olsson E, Westermark P. The Rombo syndrome: a familial disorder with vermiculate atrophoderma, milia, hypotrichosis, trichoepitheliomas, basal cell carcinomas and peripheral vasodilation with cyanosis. Acta Derm Venereol. 1981;61:497-503.

22. Ashinoff R, Jacobson M, Belsito DV. Rombo syndrome: a second case report and review. J Am Acad Dermatol. 1993;28:1011-4.

23. Van Steensel MAM, Jaspers NGJ, Steijlen PM. A case of Rombo syndrome. Br J Dermatol. 2001;144:1215-8.

24. Oley AO, Sharpe H, Chenevix-Trench G. New syndrome? Basal cell carcinomas, coarse sparse hair, and milia. Am J Med Genet. 1992;43:799-804.

25. Adreani V, Richard M, Folchetti G, Varennes, et al. Congenital hypotrichosis and milia with spontaneous regression during adolescence or Oley syndrome: a variant of Bazex-Dupré-Christol syndrome. Ann Dermatol Venereol. 2000;127:285-8. 
26. Hebra F, Kaposi M. On disease of the skin including exanthemata. Nwe Sydenham Soc. 1874;61:252-8.

27. Dava-Grosjean L. Xeroderma pigmentosum and skin cancer. Adv Exp Med Biol. 2008;637:19-27.

28. Butt FMA, Moshi JR, Owibingire S, Chindia ML. Xeroderma pigmentosum: a review and case series. J Craniomaxillofac Surg. 2010;38:534-7.

29. Webb S. Xeroderma pigmentosum. BMJ. 2008;336:444-6.

30. Mosterd K, Arits AHMM, Thissen MRT, Kelleners-Smeets NWJ. Histology-based treatment of basal cell carcinoma. Acta Derm Venereol. 2009;89:454-8.

31. Mendenhall WM, Amdur RJ, Hinerman RW, et al. Radiotherapy for cutaneous squamous and basal cell carcinomas of the head and neck. Laryngoscope. 2009;119:1994-9.

32. Von Hoff DD, LoRusso PM, Rudin CM, Reddy JC, et al. Inhibition of the hedgehog pathway in advanced basal-cell carcinoma. N Engl J Med. 2009;361:1164-72. 



\section{Chapter 6}

\section{Basal cell carcinoma and trichoepithelioma: a possible matter of confusion}

Arits AH, Parren LJMT, van Marion AM, Sommer A, Frank J, Kelleners-Smeets NW. Basal cell carcinoma and trichoepithelioma: a possible matter of confusion. Int J Dermatol. 2008;47(Suppl 1):13-7. 


\section{Abstract}

Difficulty in differentiation between a solitary basal cell carcinoma, which is known as a malign skin lesion and a benign trichoepithelioma, is a frequent problem in all day dermatologic practice. Clinically as well as histopathologically there are a lot of resemblances between these skin tumors. By means of two real life cases, we give here an overview of the possible problems and appliances in distinguishing these two entities; at the end we do some recommendation about the policy. 


\section{Introduction}

Basal cell carcinoma (BCC) is the most common skin cancer in the white population. Although it is still unclear from which cell this neoplasm derives, recent evidence has suggested that BCC is a hair follicle tumor. ${ }^{1}$ The World Health Organization has classified it as a "keratinocytic tumor". ${ }^{2}$ With a varying clinical picture, BCC predominantly manifests in the fifth and sixth decades of life in the head and neck region. ${ }^{3}$ Usually, the histopathology is quite typical, showing basophilic cells, which are classically arranged in globule-like clusters with palisading cells at their periphery. Both clinically and histologically, however, solitary BCC may be confused with another epithelial tumor, trichoepithelioma (TE). This benign neoplasm of follicular differentiation occurs mainly in young adults. As in BCC, the sites of predilection are the head and neck region, in particular the nose, upper lip, and cheeks. ${ }^{4}$ In this article, we illustrate the difficulties in the clinical and histopathologic differentiation of BCC from TE, in particular BCC with trichodifferentiation, and briefly review the currently available techniques that might be helpful in making an accurate diagnosis.

\section{Case report}

\section{Case 1}

A 30-year-old woman presented at our outpatient clinic with an easily bleeding skin lesion on the nose that had developed approximately 6 months earlier and had not undergone any changes since. Apart from regular therapy with a selective serotonin reuptake inhibitor, Seroxat ${ }^{\circledR}$, her medical history was unremarkable, and she denied any extraordinary exposure to sunlight. On clinical examination, there was a skin-colored papule of $5 \times 3 \mathrm{~mm}$ with central crusting on the right side of the nose (data not shown). Based on the clinical findings, our differential diagnoses included basal cell carcinoma (BCC) and a sebaceous gland hyperplasia. For clarification, a punch biopsy was taken. Histopathology with hematoxylin and eosin staining showed a proliferation of clustered basaloid cells, sometimes in continuation with a hair follicle. In these clusters, there was peripheral palisading and a few retraction clefts at the contact zones with the surrounding stroma. Furthermore, follicular keratinization and a few mitotic figures were observed. On the basis of these findings, a differential diagnosis of BCC or TE was made. Additional studies by immunohistochemistry with both Bcl-2 and Ber-EP4 showed focal staining of cell nests in the tumor margin, but no staining in the centre. CD10 staining was mainly detectable in the stroma surrounding the basaloid cell clusters. Although the immunohistochemical pattern was suggestive of TE, BCC could not be excluded completely. Subsequently, the tumor was successfully treated with Mohs' micrographic 
surgery. As in the first histological examination, the additional tissue preparation for Mohs' frozen sections was not helpful in differentiating between BCC and TE.

\section{Case 2}

In 2005, a 77-year-old man presented at our outpatient department with an easily bleeding skin lesion on the back. He had an unremarkable medical history and reported an average degree of sunlight exposure. At that time, a 4-mm skin-colored papule with hemorrhagic crusts and telangiectasias was documented (Fig. 1a,b), and a tentative diagnosis of BCC was made. Subsequent histopathological examination of a punch biopsy by routine hematoxylin and eosin staining showed a strong proliferation of basaloid cells with trichoid differentiation in the superficial dermis, without significant peripheral palisading or cleft formation between tumor aggregates and stroma (Fig. 2a,b). Based on these findings, a diagnosis of TE was made and no further treatment was initiated.


Figure 1. Clinical presentation of the lesion in Case 2: (a) overview 2005; (b) close-up 2005; (c) overview 2007; (d) close-up 2007

Two years later, the patient returned for the evaluation of the same tumor that had approximately doubled in size. On clinical examination, there was an 8-mm, shiny, erythematous papule with telangiectasias (Fig. 1C,d). With a tentative diagnosis of BCC, the tumor was radically excised. Histopathological examination showed a nodular tumor with a dermal proliferation of basaloid cells, peripheral palisading, and cleft formation, suspicious of a nodular BCC (Fig. 2c,d). Histopathologic revision of the biopsy specimen 
from 2005 revealed that a differentiation between TE and BCC with trichodifferentiation based on routine histopathologic hematoxylin and eosin evaluation was not possible. Nevertheless, the detection of several mitotic figures and cleft formation, as well as the diffuse positive staining with the immunomarkers Bcl-2 and Ber-EP4 and peripheral staining of basaloid cells with CD10, was suggestive of BCC with trichodifferentiation.


Figure 2. Histopathologic examination of the lesion in Case 2:

$(a, b)$ trichoid keratinization and stromal clefting typical of trichoepithelioma (hematoxylin and eosin: $a, \times 100$; b, $\times 200)$; (c,d) left, compact nests of basaloid cells, typical of basal cell carcinoma; right, smaller fields of basaloid cells, typical of trichoepithelioma (hematoxylin and eosin: c, $\times 25$; d, $\times 100$ ) 


\section{Discussion}

As noted above, BCC is a malignant tumor that is thought to be derived from the basal cell layer of the epidermis and/or the outer root sheath of the hair follicle. ${ }^{4}$ By contrast, TE is a dermal tumor that originates from hair follicles and may reveal focal continuity into the epidermis. ${ }^{4}$

The clinical presentation of BCC is variable. Normally, the tumor presents as a firm, skin-colored, red or brown nodule. A pearly white to translucent and raised peripheral edge is one of the characteristic features. Sometimes, however, BCC manifests as an erythematosquamous macula, resembling eczema, or as a sclerotic plaque, resembling a scar. TE mostly presents as a skin-colored nodule or papule that does not usually exceed $1 \mathrm{~cm}$ in size. Both tumors can be traversed by telangiectasias.

In addition to the clinical differentiation difficulties, histologic differentiation between BCC and TE may sometimes be problematic. Both tumors are composed of nests of basaloid cells with follicular differentiation. TE is characterized by epithelial structures resembling hair papillae, small keratinous cysts which, on rupture, can form stromal foreign-body granulomas, loose stroma, and fibroblast aggregates, referred to as papillary mesenchymal bodies (Table 1). ${ }^{4}$ BCC, by contrast, often shows cleft formation between tumor aggregates and stroma, peripheral palisading of keratinocytes, necrotic tumor cells and ulceration, and mitotic figures (Table 1)., ${ }^{4,5}$ Nevertheless, these characteristics are not always present. Therefore, sometimes it may be impossible to make a histopathologic differentiation on the basis of routine hematoxylin and eosin staining. In these instances, additional immunohistochemical examination may provide further information.

Table 1. Histopathologic criteria used to differentiate between basal cell carcinoma and trichoepithelioma, in order of significance.

\begin{tabular}{llll}
\hline & Histologic characteristic & Basal cell carcinoma & Trichoepithelioma \\
\hline 1 & Tumor-stroma cleft formation & ++ & -- \\
2 & Ulceration & ++ & - \\
3 & Epithelial primitive structures & - & ++ \\
4 & Small keratinous cysts & - & + \\
5 & Inflammatory response & + & - \\
6 & Mitosis & + & - \\
7 & Necrotic tumor cells & + & - \\
8 & Papillary mesenchymal bodies & - & + \\
9 & Granulomatous inflammation & -- & + \\
& (around ruptured keratinous cysts) & & -- \\
10 & Stromal edema & + & - \\
11 & Peritumoral mucin production & + & \\
\hline
\end{tabular}

++ , strongly present; +, mostly present; -, mostly absent; --, absent 
In the past, several antibodies have been used to differentiate between BCC and TE, although most are not specific for one epithelial tumor (Table 2). In line with this, the immunomarkers used in our patients, Bcl-2, Ber-EP4, and CD10, did not allow for a differentiation between BCC or TE. Recently however, increasing evidence has suggested that antibodies directed against androgen receptor and transforming growth factor$ß$ (TGF-ß) may be helpful in overcoming this dilemma.

Table 2. Immunohistochemical markers used to differentiate between basal cell carcinoma and trichoepithelioma. Group 1, different immunostaining patterns for the two tumors. Group 2, positive immunostaining for both tumors, but with a different staining pattern. Group 3, inconsistent immunostaining patterns.

\begin{tabular}{llll}
\hline & Immunomarker & Basal cell carcinoma & Trichoepithelioma \\
\hline Group 1 & Androgen receptor(10) & ++ & - \\
& Transforming growth factor- $\beta(11)$ & - & + \\
Group 2 & Ki67(13) & + & + \\
& Proliferating cell nuclear antigen(13) & + & + \\
& P27kip1(18) & + & ++ \\
& CD10(15) & ++ & $-1+$ \\
Group 3 & Bcl-2(11-13) & ++ & $+/-$ \\
& CD34(19,20) & $-/+$ & $+/-$ \\
\hline
\end{tabular}

+ , positive; ++ , strongly positive; -, negative; $-/+$, mostly negative; sometimes positive; $+/-$, mostly positive, sometimes negative.

Androgen receptor is a nuclear ligand-dependent transcription factor that is activated by binding to androgens, testosterone, or dihydrotestosterone. Androgen receptor is expressed in normal skin, but has also been demonstrated in various cutaneous neoplasms, including BCC. ${ }^{6}$ Izikson et al. found positive androgen receptor immunostaining in approximately $80 \%$ of BCC cells compared with negative staining in TE $(P<0.001){ }^{6}$ TGF-ß plays a key role in controlling cell proliferation and differentiation. Verhaegh et al. showed a diffuse cytoplasmic TGF-ß staining in TE tumor cells, whereas negative staining was observed in BCCs. ${ }^{7}$

$\mathrm{BCl}-2$ is an oncogene associated with apoptosis, and can be over-expressed in some malignancies. A difference in $\mathrm{BCl}-2$ staining distribution between $\mathrm{BCC}$ and TE was found by three independent study groups; ${ }^{7,8}$ however, Abdelsayed et al. could not confirm this finding. ${ }^{9}$ Ber-EP4 is a monoclonal antibody that recognizes two glycopolypeptides found in most human epithelial cells. Krahl and Sellhayer did not find any consistency in the staining pattern of Ber-EP4 in BCC compared with TE. ${ }^{10}$ In contrast, Ber-EP4 has been shown to be an excellent marker in differentiating BCC from squamous cell carcinoma. ${ }^{10}$ CD10 is a cell surface enzyme with neutral metalloendopeptidase activity, and is involved in the inactivation of numerous biologically active peptides. Pham et al. showed strong CD10 immunoreactivity in both TE and BCC, but with significantly different staining patterns. ${ }^{11}$ 
Recently, both germline and somatic mutations in different genes have been implicated in the etiopathogenesis of BCC and TE. There is strong evidence that virtually all BCCs arise from genetic defects affecting components of the Sonic Hedgehog (SHH) pathway. About $80 \%$ of BCCs harbour mutations in the PTCH1 gene, coding for PATCHED, a seven-pass transmembrane protein that serves as a receptor for $\mathrm{SHH}$. The remaining 20\% harbour mutations in either SMOH (coding for the SMOOTHENED protein) or SU(FU) (coding for the protein SUPPRESSOR of FUSED). ${ }^{12}$ TE can occur sporadically or in the context of a hereditary tumor syndrome, known as familial cylindromatosis or Brooke-Spiegler syndrome (BSS). BSS is caused by mutations in the CYLD gene. ${ }^{13}$ The encoded protein, CYLD, is an ubiquitin hydrolase that targets by auto-ubiquitinating tumor necrosis factor receptor-associated factor-2 (TRAF2). Ubiquitinated TRAF2 can activate IkB kinase (IKK), which, in turn, phosphorylates the NF-KB inhibitor IkB $\alpha$, triggering the nuclear translocation of active NF-KB. Thus, the absence of CYLD leads to uncontrolled NF-KB activity. Depending on the exact inputs, NF-KB can induce apoptosis or, rather, its opposite, cell growth. ${ }^{14}$

Because TE and BCC may represent two different landmarks in the spectrum of one single entity, we strongly suggest the excision of every solitary TE with a small margin. Complete excision is also the treatment of choice for BCC. Follow-up of a patient with a solitary TE is not recommended.

In summary, clinical and histologic differentiation between BCC and TE can sometimes be difficult. Histopathologic criteria for the differentiation of these two tumors include the presence or lack of retraction between epithelium and stroma, a lack of ulceration, and the presence of primitive follicles in TE. Immunohistochemistry may provide additional information, in particular immunostaining with androgen receptor and TGF- $\beta$. Nevertheless, routine hematoxylin and eosin staining remains the standard for initial histopathologic examination. In the future, molecular genetic techniques may offer the possibility to differentiate with certainty between the two tumors. 


\section{References}

1. Sellheyer K, Krahl D. Basal cell (trichoblastic) carcinoma common expression pattern for epithelial cell adhesion molecule links basal cell carcinoma to early follicular embryogenesis, secondary hair germ, and outer root sheath of the vellus hair follicle: A clue to the adnexal nature of basal cell carcinoma? J Am Acad Dermatol. 2008;58(1):158-67.

2. LeBoit P, Burg G, Weedon D, Sarasin A, editors. World Health Organization classification of tumours: pathology and genetics of skin tumors. Lyon: IARC Press; 2006.

3. de Vries E, Louwman M, Bastiaens M, de Gruijl F, Coebergh JW. Rapid and continuous increases in incidence rates of basal cell carcinoma in the southeast Netherlands since 1973. J Invest Dermatol. 2004;123(4):634-8.

4. Weedon D. Skin Pathology. Tokyo: Churchill Livingstone; 2001. Chapter 31, page 647-49 and Chapter 33, page 715-16.

5. Kechijian P, Connors RC, Ackerman AB. Trichoepithelioma vs. basal-cell carcinoma: criteria for histologic differentiation. J Dermatol Surg. 1975;1(4):22-3.

6. Izikson L, Bhan A, Zembowicz A. Androgen receptor expression helps to differentiate basal cell carcinoma from benign trichoblastic tumors. Am J Dermatopathol. 2005;27(2):91-5.

7. Verhaegh ME, Arends JW, Majoie IM, Hoekzema R, Neumann HA. Transforming growth factor-beta and bcl-2 distribution patterns distinguish trichoepithelioma from basal cell carcinoma. Dermatol Surg. 1997;23(8):695-700.

8. Poniecka AW, Alexis JB. An immunohistochemical study of basal cell carcinoma and trichoepithelioma. Am J Dermatopathol. 1999;21:332-6.

9. Abdelsayed RA, Guijarro-Rojas M, Ibrahim NA, et al. Immunohistochemical evaluation of basal cell carcinoma and trichoepithelioma using BCl-2, Ki67, PCNA and P53. J Cutan Pathol. 2000;27:169-75.

10. Krahl D, Sellheyer K. Monoclonal antibody Ber-EP4 reliably discriminates between microcystic adnexal carcinoma and basal cell carcinoma. J Cutan Pathol. 2007;34:782-7.

11. Pham TT, Selim MA, Burchette JL, et al. CD10 expression in trichoepithelioma and basal cell carcinoma. J Cutan Pathol. 2006;33:123-8.

12. Reifenberger J, Wolter M, Knobbe CB, et al. Somatic mutations in the PTCH, SMOH, SUFUH and TP53 genes in sporadic basal cell carcinomas. Br J Dermatol. 2005;152:43-51.

13. Bignell GR, Warren W, Seal S, et al. Identification of the familial cylindromatosis tumour-suppressor gene. Nat Genet. 2000;25:160-5.

14. Gilmore TD. Introduction to NF-kappaB: players, pathways, perspectives. Oncogene. 2006;25:6680-4. 



\section{Chapter 7}

\section{Multiple basal cell carcinomas in childhood: Bazex-Dupré-Christol syndrome}

Abuzahra F*, Parren LJMT*, Frank J. Multiple familial and pigmented basal cell carcinomas in early childhood - Bazex-Dupré-Christol syndrome. J Eur Acad Dermatol Venereol. 2012;26(1):117-21.

*These authors contributed equally to this manuscript. 


\section{Abstract}

\section{Background}

Bazex-Dupré-Christol syndrome (BDCS) is an X-linked dominantly inherited disorder affecting hair follicle structures. Currently, hypotrichosis, follicular atrophoderma, and basal cell carcinomas are considered frequent symptoms of the disorder whereas milia are supposed to reflect infrequent clinical signs. Usually, basal cell carcinomas in this disease manifest from the second decade of life onwards.

\section{Case report}

Here, we studied a novel multigeneration family of German origin with BDCS. Interestingly, two family members developed pigmented basal cell carcinomas in early childhood, at the age of 3 and 5 years, respectively. The differentiation from other pigmented lesions was accomplished by both dermoscopy and histopathology. A thorough survey of the current literature revealed that milia were present in almost all patients with BDCS reported, as is the case in our family.

\section{Conclusions}

We suggest that milia should also be considered frequent symptoms in BDCS. For the first time, to the best of our knowledge, we describe the occurrence of pigmented basal cell carcinomas in BDCS during the first decade of life. Our observation emphasizes the importance of screening for cutaneous malignancies in this disorder already at young age. 


\section{Introduction}

In 1964, Bazex, Dupré and Christol for the first time described a hereditary syndrome of the skin in which hair follicle structures are affected. ${ }^{1}$ Since then, not more than 20 families with this disorder, nowadays referred to as Bazex-Dupré-Christol syndrome (BDCS) (OMIM 301845), have been reported.

Affected individuals can manifest a broad range of cutaneous symptoms. Until now, frequently and regularly observed clinical signs comprise the triad of hypotrichosis, follicular atrophoderma, and basal cell carcinomas (BCCs). Infrequent symptoms that have been reported include milia, hypohidrosis, hyperpigmentation of the face, and trichoepitheliomas. ${ }^{1-17}$ Apparently, extracutaneous manifestations are not encountered in BDCS. Hypotrichosis can mostly be appreciated already shortly after birth; follicular atrophoderma may manifest during early childhood; and BCCs commonly develop from the second decade of life onwards. , $7,10-12,14^{-1}$

The differential diagnosis of BDCS includes other hereditary syndromes associated with the development of BCCs at early age, such as basal cell nevus syndrome (OMIM 109400), Rombo syndrome (OMIM 180730), Oley syndrome, and Xeroderma pigmentosum (OMIM 278700). With regard to the pattern of inheritance, male-to-male transmission has not yet been reported in this disease. ${ }^{1-17}$

Here, we present a novel German multigeneration family with BDCS. Interestingly, two individuals developed multiple pigmented BCCs already in the first decade of life.

\section{Report of a family}

The index patient, a then 7-year old girl (individual IV-1 in Fig. 1a) was born to nonconsanguineous parents and is the youngest member of a Caucasian 4-generation family of German origin with four individuals affected by BDCS (Fig. 1a). Shortly after birth, hypotrichosis became evident and at the age of 6 months she developed an increasing reddish-brown hyperpigmentation of the face. Twelve months later, disseminated milia and small papules arose and eventually covered the forehead and the temples. Besides, she also had multiple slight funnel-shaped follicular depressions, so-called "ice pick marks", on both cheeks. Already at the age of 5 years her mother noticed a small nodule on the left cheek that slowly increased in size (Fig. 1b). One year later, a second small nodular tumor appeared under the right lower eyelid. However, at that time she did not present her daughter to a dermatologist. It was only when the girl was 7 years old that she was referred to our outpatient clinic for excision of both tumors. Histopathological examination revealed nodular pigmented BCCs on both cheeks (data not shown). Facial milia and follicular atrophoderma on the cheeks still persisted. The skeletal and psychomotoric development was normal. 
(a) 1

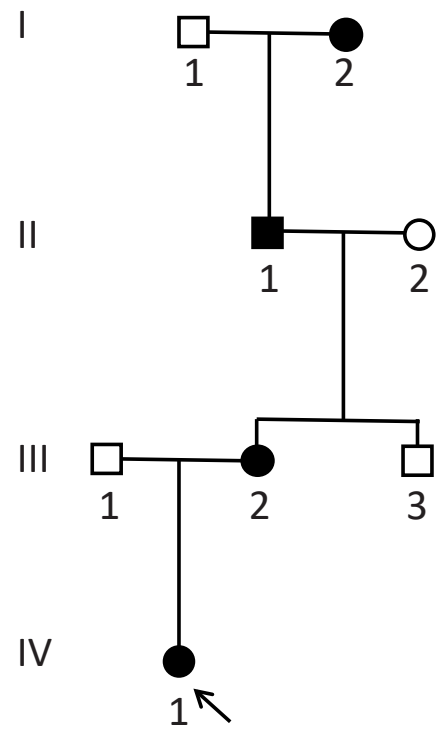



Figure 1. (a) Pedigree of the German multigeneration family with BDCS studied here. The index patient is indicated by an arrow. (b) Index patient at the age of 7 years. Disseminated milia; small papules on redbrownish ground on the cheeks, forehead, and temples; and a pigmented plaque on the left cheek, suspicious of basal cell carcinoma.

Her 37-year old mother (individual III-2 in Fig. 1a) showed similar clinical features. She had a diffuse hypotrichosis and multiple disseminated milia on the forehead, the ears, and the periorbital regions since birth. At the age of 18 months, the milia increased in number and size and covered almost the whole face. Initially, they were skin-colored, afterwards turning to brown. Besides, she developed multiple small and confluent brown macules and papules on her face and forehead. Similar lesions, although less intense, could be seen on the upper extremities, trunk, and in the groins. Excision of a nodule on the left temple and consecutive histological examination revealed a BCC at the age of 3 years. At that time, the erroneous diagnosis of basal cell nevus syndrome with hereditary alopecia was made and she underwent a facial dermabrasion therapy. When we saw her for the first time at the age of 37 years, she showed follicular atrophoderma on the extensor sites of her knees and elbows (Fig. 2a), hypotrichosis of the scalp, two pigmented BCCs on her capilitium (Fig. 2b), and multiple pigmented nodular BCCs on the right lower eyelid (Fig. 2c). Dermoscopy did not show a pigment network although specks of brown pigment were present. Further, we saw linear and branch-like telangiectasia, and leaf-like areas on the periphery of the lesion (Fig. 2d).

Both the grandfather (individual II-1 in Fig. 1a) and grand-grandmother (individual I2 in Fig. 1a) had a medical history of hypotrichosis from birth, recurrent BCCs on the sun-exposed areas of the body, follicular atrophoderma, and milia (data not shown). 
The familial constellation of clinical symptoms and histopathological results in four consecutive generations was suggestive of BDCS.
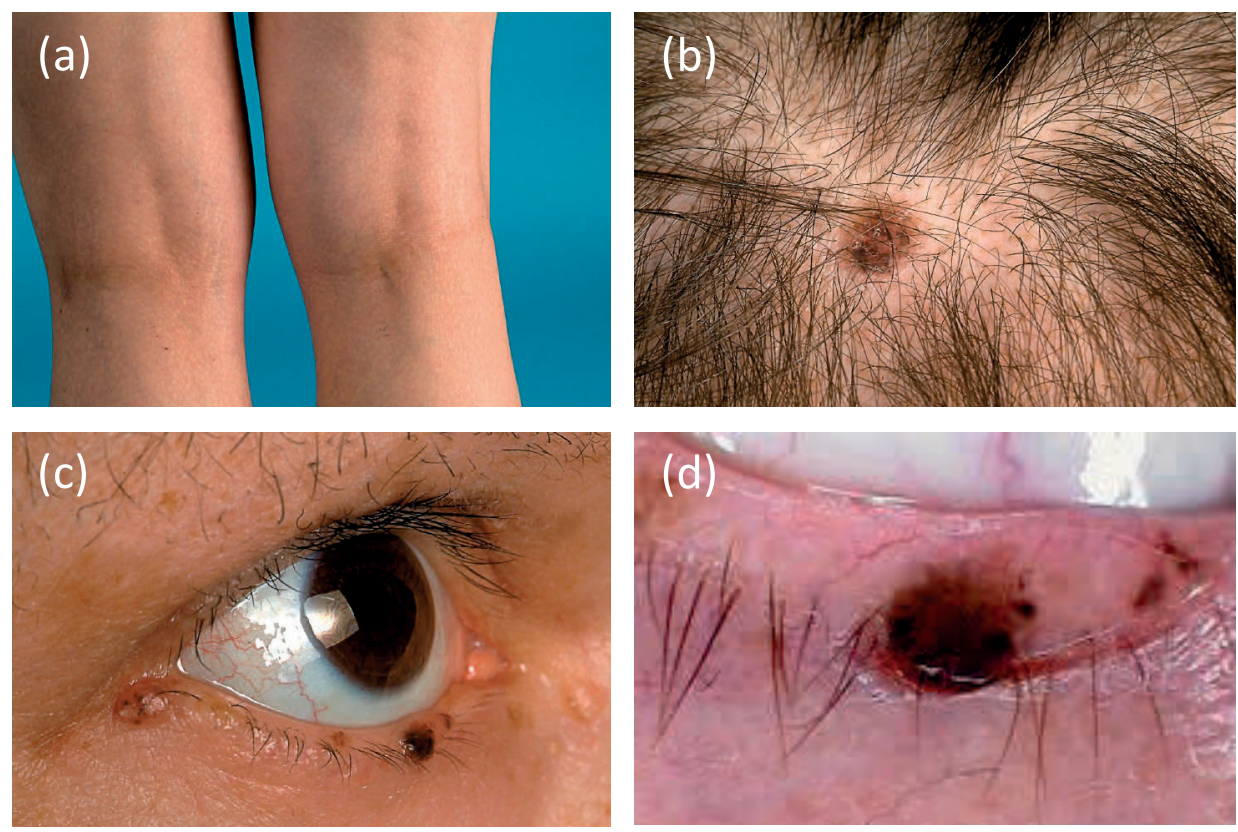

Figure 2. The index patient's mother at the age of 37 years. a) Follicular atrophoderma on the extensor areas of her knees and elbows. b) Hypotrichosis of the scalp with a pigmented BCC. c) Multiple pigmented and nodular BCCs at the right lower eyelid. d) Dermoscopy shows telangiectasia and absence of a pigment network, suggestive for pigmented basal cell carcinoma.

\section{Discussion}

BDCS is a rare hereditary disorder that is characterized by pathologic changes in hair follicle structures. To date, less than 20 sporadic and familial cases have been reported ${ }^{1-}$ 17 , with the youngest patient manifesting a BCC being 16 years old (Table 1). ${ }^{2}$ By contrast, we here describe two females who developed their first BCCs at the very young age of 3 (individual III-2 in Fig. 1a) and 5 years (individual IV-1 in Fig. 1a), respectively. The occurrence of BCCs in children is very rare and in these individuals an underlying genetic disorder should be excluded. ${ }^{18}$ Our findings in the family presented here suggest that when the temptative diagnosis of BDCS is made, screening for BCCs should be initiated during the first decade of life already and, if possible, by an experienced dermatologist since these tumors might be subtle and escape the eyes of an untrained physician. 
Table 1. Clinical characteristics of families with Bazex-Dupré-Christol syndrome reported to date. Note that onset of basal cel carcinomas has not yet been reported during the first decade of life. All patients/families with milia are marked in bold. n.d.: presence of basal cell carcinoma not described.

\begin{tabular}{|c|c|c|}
\hline \multicolumn{2}{|c|}{$\begin{array}{l}\text { Age at onset of first BCC Further symptoms } \\
\text { (in years) }\end{array}$} & \multirow{2}{*}{$\begin{array}{l}\text { Reference } \\
1\end{array}$} \\
\hline Unknown & Hypotrichosis, follicular atrophoderma & \\
\hline n.d. & $\begin{array}{l}\text { Congenital hypotrichosis, follicular atrophoderma, milia, } \\
\text { prolymphocytic leukemia }\end{array}$ & 9 \\
\hline Unknown & Hypotrichosis, follicular atrophoderma & 12 \\
\hline Unknown & Hypotrichosis, milia & 17 \\
\hline Unknown & Hypotrichosis, milia & 5 \\
\hline Unkown & Hypotrichosis, follicular atrophoderma & 15 \\
\hline $21,28,53$ & Hypotrichosis, follicular atrophoderma, milia, hypohidrosis & 14 \\
\hline n.d. & Pigmented follicular atrophoderma, milia, epidermal cysts & 13 \\
\hline 20 & Congenital hypotrichosis, milia & 7 \\
\hline 35 & Hypotrichosis, milia, hypohidrosis. & 4 \\
\hline n.d. & Hypotrichosis, follicular atrophoderma, milia & 8 \\
\hline n.d. & $\begin{array}{l}\text { Hypotrichosis, follicular atrophoderma, milia, brown papules over the } \\
\text { genital area, trichoepithelioma }\end{array}$ & 6 \\
\hline 35 & Hypotrichosis, follicular atrophoderma, milia, hypohidrosis & 11 \\
\hline n.d. & Hypotrichosis, milia, epidermal cysts & 16 \\
\hline Unknown & Hypotrichosis, milia & 10 \\
\hline 16 & Congenital hypotrichosis, follicular atrophoderma, milia, hypohidrosis & 2 \\
\hline n.d. & $\begin{array}{l}\text { Congenital hypotrichosis, follicular atrophoderma, hyperpigmented } \\
\text { papules on head and neck, facial hyperpigmentation, } \\
\text { trichoepithelioma, hypotonia, seizures, mild global developmental } \\
\text { delay }\end{array}$ & 3 \\
\hline 3,5 & $\begin{array}{l}\text { Hypotrichosis, follicular atrophoderma, milia, hyperpigmentation of } \\
\text { the face }\end{array}$ & This study \\
\hline
\end{tabular}

$\mathrm{BCC}$ is the most frequent malignant tumor of the skin with a peak incidence in late adulthood. It usually arises in the sun-exposed areas of the body. A variety of factors have been reported to play an important role in the etiology of BCC, including cumulative exposure to UV-radiation, radiotherapy, immunosuppression, Fitzpatrick skin type 1 and 2 , a positive family history, and genetic defects. ${ }^{18}$

The phenotype in BDCS is variable, both within and between affected families. ${ }^{5}$ Goeteyn and colleagues suggested that females might be less severely affected than males. ${ }^{5}$ In contrast with their findings, we observed that the females in our family had a rather pronounced phenotype, including the manifestation of BCCs in early childhood.

When familial occurrence of BCCs during childhood and adolescence is observed, the differential diagnosis includes hereditary syndromes such as, e.g. Gorlin syndrome, Rombo syndrome, Oley syndrome, and Xeroderma pigmentosum. In contrast to Gorlin syndrome, BDCS does not manifest with palmoplantar pits or skeletal abnormalities. Patients with Rombo syndrome usually have telangiectases and acral erythema. ${ }^{19}$ Still, 
some features overlapping with the phenotype in BDCS may be encountered, mainly atrophoderma vermiculatum and trichoepitheliomas. ${ }^{3,6}$ In this regard, the phenotype observed in our family shows a significant overlap with ROMBO syndrome. In particular, in the index patient we found atrophoderma on the cheeks, where atrophofoderma vermiculatum is usually localized in ROMBO syndrome. In individual II-2, we observed atrophoderma on the knees and elbows, a site that is also affected in ROMBO syndrome. ${ }^{19}$ On the other hand, none of the family members had follicular atrophoderma on the dorsa of the hands, which seems to be the predominant localization in BDCS sites. Furthermore, individual III-2 showed branch-like telangiectases, which can also be observed in ROMBO syndrome. Oley syndrome seems to be a minor form of BDCS, characterized predominantly by congenital hypotrichosis and milia, which show a spontaneous regression during adolescence. Thus, the differential diagnosis may be difficult. In contrast to BDCS, patients with Xeroderma pigmentosum show early onset of freckles in sun-exposed areas, poikiloderma, and premature skin ageing. ${ }^{20}$ Both Gorlin and Rombo syndrome are inherited in an autosomal dominant fashion, whereas Xeroderma pigmentosum is an autosomal recessive disorder.

Until now, the clinical manifestations in BDCS could be subdivided into frequent and infrequent symptoms. The first comprise the classical triade of hypotrichosis, follicular atrophoderma, and BCCs as described in the original report of Bazex and colleagues. ${ }^{1}$ The latter contain, among others, milia. Since a review of all cases and families with BDCS reported to date revealed that milia were present in the vast majority of these patients it is tempting to suggest that milia could also be considered frequent clinical signs rather than infrequent ones, as depicted in Table 2.

Table 2. Suggestion for a revised classification of frequenly and infrequently encountered symptoms in BazexDupré-Christol syndrome. We suggest that milia should be considered a frequent clinical sign.

\begin{tabular}{ll}
\hline Frequent symptoms & Infrequent symptoms \\
\hline Basal cell carcinomas & Epidermal cysts \\
Follicular atrophoderma & Hyperpigmentation of the face \\
Hypotrichosis & Hypohidrosis \\
Milia & Trichoepitheliomas \\
\hline
\end{tabular}

Many of the BCCs detected in individuals III-2 and IV-1 were pigmented (Figures 1b, 2b, and $2 \mathrm{c}$ ). To the best of our knowledge, pigmented BCCs have not yet been described in BDCS. Clinically, a deeply pigmented BCC may be difficult to differentiate from a malignant melanoma. Although the manifestation of malignant melanoma in children is uncommon, too, they tend to occur more frequently than BCCs. ${ }^{21}$ In these cases, dermoscopy might be helpful, as in our patients (Figure $2 \mathrm{~d}$ ).

Preventive measures in BDCS such as predictive genetic testing are mainly hampered by the fact that the causative gene is unknown. Pujol and colleagues sought to prevent tumor development with 13 cis-retinoid, topical retinoid acid, and etretinate 


\section{Chapter 7}

but this prophylactic treatment failed. ${ }^{22}$ In clinically overt and histopathologically confirmed BCCs the first choice therapy is surgical excision.

Since our report shows that in BDCS there is an apparent risk for the manifestation of BCCs at very young age we consider it very important to offer a regular tumor screening to affected families, e.g. once to twice a year, dependent on the individual dynamics of the disease. In children with BCCs, the differential diagnosis of BDCS should always be considered. 


\section{References}

1. Bazex A, Dupre A, and Christol B. Génodermatose complexe de type indéterminé associant une hypotrichose, un état atrophodermique généralisé et des dégénérescences cutanées multiples (épithéliomasbasocellulaires). Bull. Soc. Franc. Derm. Syph. 1964;71:206.

2. Barcelos AC, Nico MM. Bazex-Dupré-Christol syndrome in a 1-year old boy and his mother. Pediatr Dermatol. 2008;25:112-3.

3. Castori M, Castiglia D, PAssarelli F, et al. Bazex-Dupré-Christol syndrome: an ectodermal dysplasia with skin appendage neoplasms. Eur J Med Genet. 2009;52:250-5.

4. Glaessl A, Hohenlautner U, Landthaler M, et al. Sporadic Bazex-Dupré-Christol-like syndrome: Early onset basal cell carcinoma, hypohidrosis, hypotrichosis, and prominent milia. Dermatol Surg. 2001;26:152-4.

5. Goeteyn M, Geerts ML, Kint A, et al. The Bazex-Dupré-Christol syndrome. Arch Dermatol. 1994;130:33742.

6. Yung A, Newton-Bishop JA. A case of Bazex-Dupré-Christol syndrome associated with multiple genital trichoepitheliomas. Br J Dermatol. 2005;153:682-4.

7. Adreani V, Richard M, Folchetti G, et al. Congenital hypotrichosis and milia with spontaneous regression during adolescence or Oley syndrome: a variant of Bazex-Dupré-Christol syndrome. Ann Dermatol Venereol. 2000;127:285-8.

8. Beljan G and Mezte D. Miliaria and follicular atrophodermia as an early sign of Bazex-Dupré-Christol syndrome. J Dtsch Dermatol Ges. 2004;2:602-4.

9. Colomb D, Ducros B, Boussuge N. Bazex-Dupré-Christol syndrome. A propos of a case with prolymhocytic leukemia. Ann Dermatol Venereol. 1989;116:381-7.

10. Gamblicher T, Hoffjan S, Altmeyer $P$, et al. A case of sporadic Bazex-Dupré-Christol syndrome presenting with scarring folliculitis of the scalp. Br J Dermatol. 2007;156:184-6.

11. Greco M, Bessaguet-Kupfer I, Bourrigan M, et al. Diffuse milia in an infant indicative of Bazex-DupréChristol syndrome. Ann Dermatol Venereol. 2006;133:697-9.

12. Herges A, Stieler W, Stadler R. Bazex-Dupré-Christol syndrome. Follicular atrophoderma, multiple basal cell carcinomas and hypotrichosis. Hautarzt. 1993;44:385-91.

13. Inoue $\mathrm{Y}$, Ono T, Kayashima K, et al. Hereditary perioral pigmented follicular atrophoderma associated with milia and epidermoid cysts. Br J Dermatol. 1998;139:713-8.

14. Kidd A, Carson L, Gregory DW, et al. A Scottish family with Bazex-Dupré-Christol syndrome: follicular atrophoderma, congenital hypotrichosis, and basal cell carcinoma. J Med Genet. 1996;33:493-7.

15. Moreau-Cabarrot A, Bonafe JL, Hachich N, et al. Follicular atrophoderma, basal cell proliferation and hypotrichosis (Bazex-Dupré-Christol syndrome). A study in 2 families. Ann Dermatol Venereol. 1994;121:297-301.

16. Torrelo A, Sprecher E, Imelda G, et al. What syndrome is this? Pediatr Dermatol. 2006;23:286-90.

17. Vabres $P$, de Prost $Y$. Bazex-Dupré-Christol syndrome: a possible diagnosis for basal cell carcinomas, coarse sparse hair, and milia. Am J Med Genet. 1993;45:786.

18. Efron PA, Chen MK, Glavind FL, et al. Pediatric basal cell carcinoma: case reports and literature review. J Pediatr Surg. 2008;43:2277-80.

19. van Steensel MAM, Jaspers NG, and Steijlen PM. A case of Rombo syndrome. Br J Dermatol. 2001;144:1215-8.

20. Butt FM, Moshi JR, Owibingire S, et al. Xeroderma pigmentosum: a review and case series. J Craniomaxillofac Surg. 2010;38:534-7.

21. Tatiana KSC, Somers GR, Pope E, et al. Predisposing factors and outcomes of malignant skin tumors in children. Plast Reconstr Surg. 2010;126:508-14.

22. Pujol RM, Nadal C, Matia-Guju S, et al. Multiple follicular hamartomas with sweat gland and sebaceous differentiation, vermiculate atrophoderma, milia, hypotrichosis, and late development of multiple basal cell carcinomas. J Am Acad Dermatol. 1998;39:853-7. 



\section{Chapter 8}

\section{Linkage refinement of Bazex-Dupré-Christol syndrome to an $11.4 \mathrm{Mb}$ interval on chromosome Xq25-27.1}

Parren LJMT, Abuzahra F, Wagenvoort T, Koene F, van Steensel MAM, Steijlen PM, van Geel M, Frank J. Linkage refinement of Bazex-Dupré-Christol syndrome to an 11.4-Mb interval on chromosome Xq25-27.1. Br J Dermatol. 2011;165(1):201-3. 

MADAM, Bazex-Dupré-Christol syndrome (BDCS) (OMIM 301845) is a hereditary tumor disorder that was first recognized in 1964 by Bazex and colleagues. ${ }^{1}$ The disease is characterized by a triad of congenital hypotrichosis; early development of basal cell carcinomas (BCCs) from the first decade onwards; and follicular atrophoderma, most frequently localized on the dorsa of the hands and feet, extensor surfaces of the elbows and knees, and the face. Follicular atrophoderma presents as follicular funnels (socalled "ice-pick-marks") due to deep and lax follicular ostia. ${ }^{2}$ Further symptoms described in patients with BDCS comprise disseminated milia, hyperpigmentation of the forehead, localized hypohidrosis, and hair shaft abnormalities. ${ }^{3,4}$

The diagnosis of this rare genodermatosis can be difficult because the clinical symptoms can develop at different age with intra- and interfamilial phenotypic variation. ${ }^{5}$ Usually, hypotrichosis is the earliest sign. ${ }^{6}$ Consequently, the disease has to be differentiated from other genetic disorders manifesting with congenital or early-onset hair loss such as hypotrichosis simplex, and hypohidrotic ectodermal dysplasia. ${ }^{7}$ Further differential diagnoses of BDCS on the one hand include hereditary tumor syndromes associated with early onset of BCCs such as Gorlin syndrome (OMIM 109400) and Rombo syndrome (OMIM 180730), and on the other hand rare ectodermal dysplasias with proneness to skin tumor development such as, e.g., generalized basaloid follicular hamartoma syndrome (OMIM 605827), odonto-onycho-dermal dysplasia (OMIM 257980), and Schöpf-Schulz-Passarge syndrome (OMIM 224750). ${ }^{8}$

To date, not more than twenty families with BDCS have been reported. Since none of these families showed male-to-male transmission, 5,6,8 an X-linked dominant inheritance mode was proposed. Indeed, Vabres et al. in 1995 reported linkage of three French BDCS families to a $23.3 \mathrm{Mb}$ region on chromosome Xq24-27.1, suggesting that the disorder might be caused by a single gene defect only. ${ }^{9}$

Recently, we ascertained a novel family with BDCS. This six-generation family of German origin comprised 9 living affected members from four generations (Fig. 1a). To ascertain familials who fulfilled the clinical criteria of BDCS outlined above, all living individuals outlined in the pedigree were examined by a dermatologist from our group (either F.A. and/or J.F.). In line with previous clinical reports, we noted in affected family members some degree of phenotypic variation with, e.g. individual VI-2 developing multiple and progressive BCCs already at the age of 5 years (Fig. 1b), whereas individual $\mathrm{V}-5$ in Fig. 1a manifested few BCCs only, starting in the $3^{\text {rd }}$ decade of life.

Informed consent was obtained from all participants in accordance with local ethics committee guidelines and genomic DNA was isolated from peripheral blood samples according to standard techniques. ${ }^{10}$ We ascertained linkage to the long arm of chromosome X with 11 microsatellite markers, in the order centromere, DXS424, DXS8059, DXS8057, DXS8038, DXS8068, DXS8033, DXS994, DXS1062, DXS1211, DXS1192, DXS102, telomere (primer sequences and amplification conditions available from the authors upon request). After thereby confirming linkage to the same chromosomal region pre- 
viously identified by Vabres and colleagues, we sought to narrow down the critical interval and screen putative candidate genes for mutations.
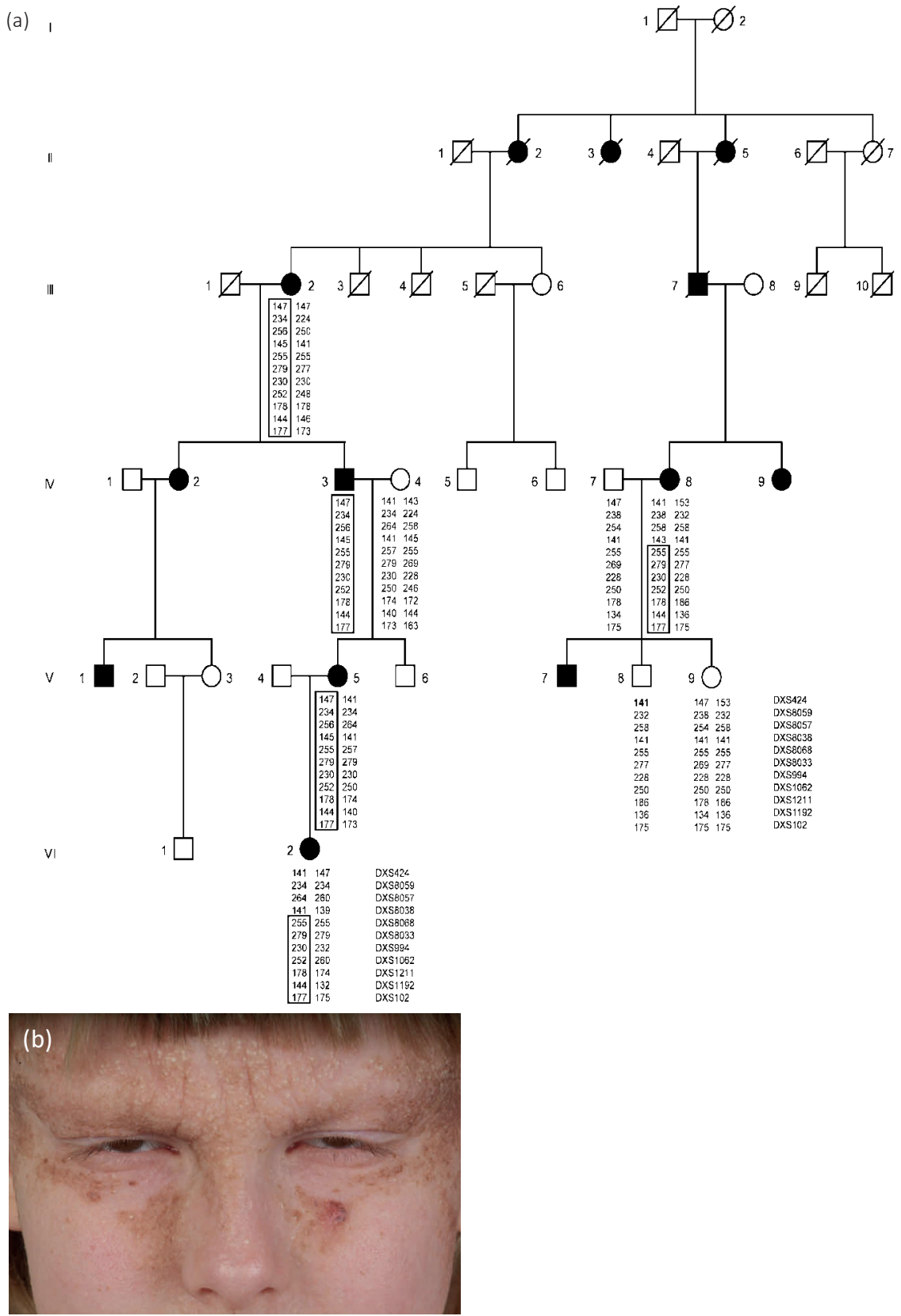

Figure 1. a) Pedigree and haplotype analysis. Affected individuals are marked by filled black symbols. The haplotype co-segregating with the disease is marked by a square box. b) Clinical manifestation of BDCS in individual VI-2. 
Haplotype analysis revealed a recombination event proximal of marker DXS8038 in individual VI-2. A similar recombination event also occurred in individual IV-8. Whereas in individual VI-2 this recombination certainly has occurred de novo, we cannot be sure for individual IV-8 because we do not have information about her parents (Fig. 1a). Considering the original linkage report from Vabres et al., we have now narrowed down the critical region of BDCS to be located between DXS8038 and DXS984. Thus, we could refine the candidate region for BDCS to an 11.4 Mb interval on chromosome Xq25-27.1, according to the physical map of the USCS Genome Browser, version February 2009, GRCh37/ hg19 (www.genome.ucsc.edu).

The newly defined region contains 101 genes. Considering the clinical symptoms encountered in BDCS we hypothesized that the gene mutated in this disorder might play an important role in regulating cell proliferation and differentiation in the hair follicle. Based on this assumption, we screened the coding regions and adjacent splice sites of 12 candidate genes for mutations: ACTRT1, AIFM1, RAB33a, SUHW3, ENOX2, MST4, RAP2C/ TFPD3, HS6ST2, ZNF449, ZNF75D, GPR112, ARHGEF6 (Table 1; primer sequences and amplification conditions available from the authors upon request). However, we did not find a pathogenic mutation.

Although we were not able to find the causative genetic defect for BDCS we narrowed down the critical interval considerably and excluded several candidate genes. Additional families with this disorder will have to be studied to further refine the candidate region. Elucidation of the genetic defect underlying BDCS is expected to provide new insights into the pathophysiology of hair follicle development and growth as well as the molecular mechanisms governing formation of hair follicle tumors, in particular trichoepithelioma and BCC.

Table 1. Candidate genes excluded.

\begin{tabular}{|c|c|c|}
\hline Gene & Locus & Function \\
\hline ACTRT1 & ChrX:127,012,624-127,014,063 & Plays a role in cell growth and/or maintenance. \\
\hline AIFM1 & ChrX:129,091,019-129,127,489 & $\begin{array}{l}\text { Caspase-independent mitochondrial effector of } \\
\text { apoptotic cell death. }\end{array}$ \\
\hline$R A B 33 a$ & ChrX:129,133,454-129,146,525 & $\begin{array}{l}\text { GTP-binding protein that may be involved in } \\
\text { vesicle transport. }\end{array}$ \\
\hline SUHW3 & ChrX:129,164,368-129,230,554 & Involved in cell growth and cell differentiation \\
\hline ENOX2 & ChrX:129,585,038-129,864,889 & Growth-related cell surface protein \\
\hline MST4 & ChrX:130,985,317-131,037,652 & Functions in the apoptotic pathway \\
\hline RAP2C/TFPD3 & ChrX:131,164,734-131,179,870 & Involved in SRE-mediated gene transcription \\
\hline HS6ST2 & ChrX:131,587,719-131,923,093 & $\begin{array}{l}\text { Interacts with various ligands to influence cell } \\
\text { growth, differentiation, adhesion, and } \\
\text { migration. }\end{array}$ \\
\hline ZNF449 & ChrX:134,306,362-134,325,004 & Involved in cell growth and cell differentiation. \\
\hline ZNF75D & ChrX:134,247,385-134,305,623 & Involved in cell growth and cell differentiation. \\
\hline GPR112 & ChrX:135,210,788-135,326,713 & $\begin{array}{l}\text { Transmembrane receptor that activates } \\
\text { different signal transduction pathways. }\end{array}$ \\
\hline ARHGEF6 & ChrX:135,575,377-135,691,169 & $\begin{array}{l}\text { Forms a complex with G proteins and } \\
\text { stimulates Rho-dependent signals. }\end{array}$ \\
\hline
\end{tabular}




\section{References}

1. Bazex A, Dupre A, and Christol B. Genodermose complexe de type indetermine associant une hypotrichose, un etat atrophodermique generalise et des degenerescences cutanees multiples (epitheliomasbasocellulaires). Bull. Soc. Franc. Derm. Syph. 1964;71:206.

2. Kidd A, Carson L, Gregory DW, et al. A Scottish family with Bazex-Dupré-Christol syndrome: follicular atrophoderma, congenital hypotrichosis, and basal cell carcinoma. J Med Genet. 1996;33:493-7.

3. Yung A, Newton-Bishop JA. A case of Bazex-Dupré-Christol syndrome associated with multiple genital trichoepitheliomas. Br J Dermatol. 2005;153:682-4.

4. Glaessl A, Hohenlautner U, Landthaler M, et al. Sporadic Bazex-Dupré-Christol-like syndrome: Early onset basal cell carcinoma, hypohidrosis, hypotrichosis, and prominent milia. Dermatol Surg. 2001;26:152-4.

5. Goeteyn M, Geerts ML, Kint A, et al. The Bazex-Dupré-Christol syndrome. Arch Dermatol. 1994;130:33742.

6. Barcelos AC, Nico MM. Bazex-Dupré-Christol syndrome in a 1-year old boy and his mother. Pediatr Dermatol. 2008;25:112-3.

7. Raamsdonk van CD. Hereditary hair loss and the ancient signaling pathways that regulate ectodermal appendage formation. Clin Genet. 2009;76:332-40.

8. Castori M, Castiglia D, PAssarelli F, et al. Bazex-Dupré-Christol syndrome: an ectodermal dysplasia with skin appendage neoplasms. Eur J Med Genet. 2009;52:250-5.

9. Vabres $P$, Lacombe $D$, Rabinowitz LG, et al. The gene for Bazex-Dupré-Christol syndrome maps to chromosome Xq. J Invest Dermatol. 1995;105:87-91.

10. Miller SA, Dykes DD, and Polesky HF. A simple salting out procedure for extracting DNA from human nucleated cells. Nucleic Acids Res. 1988;16:1215. 


\section{Chapter 9}

Discussion and valorisation 
Skin adnexal tumors show a broad range of phenotypic variability and usually distinct, but sometimes also overlapping histopathological characteristics. To date, different genes and signaling routes have been implicated in the development and growth of these tumors, including the hedgehog and the NF-kB signaling pathway, as in BDCS and $\mathrm{BSS}$, respectively. A better understanding of the specific molecular defects giving rise to rare hereditary disorders associated with cutaneous adnexal tumors might pave the way to the development of targeted topical and systemic therapies for these tumors when occurring as sporadic and solitary lesions or in a non-syndromic setting.

Both BSS and BDCS might be underdiagnosed or can even go undiagnosed for years. This is mainly due to the reason that i) both disorders are rare or, in the case of BDCS, even very rare and, thus, possibly unfamiliar to most physicians, ii) their clinical symptoms may be mild and subtle, iii) disease onset can occur at different age, and iv) patients and families with both BSS and BDCS show inter- and intrafamilial phenotypic variability.

Here, we sought to delineate more comprehensively different aspects of these cutaneous tumor disorders, in particular the variable clinical manifestation of apparently allelic diseases, the molecular genetic background and mutational spectrum of BSS and BDCS, as well as established and novel treatment options.

\section{Brooke-Spiegler syndrome}

\section{Clinical spectrum}

In BSS, the extent and size of individual tumors may vary from a few, subtle and barely noticeable translucent to skin-colored facial papules of 2-3 $\mathrm{mm}$ in diameter to the formation of an enormous tumor mass that can cover the entire circumference of the scalp, a so-called turban tumor. Such phenotypic differences can even be observed within the same family with an identical $C Y L D$ mutation. ${ }^{1}$ Albeit the full-blown picture of turban tumor is very rare, this severe and most dramatic clinical manifestation of BSS is associated more frequently with complications such as secondary infection, fetor, and ulceration. In such cases, the psychological burden impaled on affected individuals should not be underestimated. In about $6 \%$ of BSS patients, cylindromas can grow into the external auditory channel, thereby leading to hearing impairment or even loss due to obstruction and occlusion of the auditory channel, as in the individual described in chapter 2. Apart from hearing impairment, also calvarian defects and intracranial invasion have been reported. ${ }^{2-4}$

Intriguingly, some patients with BSS may manifest cylindromas or trichoepitheliomas only. These disorders, referred to as familial cylindromatosis and multiple familial trichoepithelioma, respectively, are allelic with BSS. This can be proven by molecular genetic diagnosis and identification of an underlying CYLD mutation. However, there is 
evidence that the occurrence of familial trichoepitheliomas can also be due to an as of yet unknown genetic defect located on chromosome 9p21, as shown by Harada and colleagues in $1996 .^{5}$

\section{Molecular genetic background}

Currently, more than 100 CYLD mutations have been detected. The spectrum of CYLD mutations reported to date comprises missense (12\%), nonsense (30\%), frameshift (50\%), splice site (15\%) mutations, and large genomic deletions (3\%). Through molecular studies we added 9 novel and 2 recurrent CYLD germline mutations in Dutch, German and Turkish patients and families, as demonstrated in chapters 3.1 and 3.2.

Until recently, there were no studies on the structural and functional consequences of CYLD splice site mutations. Therefore, we evaluated the effects of three splice site mutations on the cellular and RNA genetic level, as shown in chapter 3.1.

First, we demonstrated equal CYLD expression in normal human epidermal keratinocytes, leukocytes and peripheral blood mononuclear cells. Knowledge on the cell-type specific expression of CYLD should facilitate the functional assessment of splice site mutations in the future.

Generally, splice site mutations can cause intron retention, exon skipping, cryptic splicing and combinations thereof, resulting in in-frame or out-of-frame translation. Out-of-frame translation and nonsense mutations generally lead to the occurrence of a premature stop codon (PTC). ${ }^{6}$ Such PTCs can either result in the formation of a truncated protein ${ }^{7}$ or lead to degradation and elimination of mutated transcripts by nonsensemediated mRNA decay. ${ }^{6}$ By reverse transcriptase (RT-)PCR, we ascertained that two of the splice site mutations (c.2108+1G>A and c.2242-2A>G) result in skipping of exons 15 and 17 , respectively, leading to putative out-of-frame translation and generation of a PTC. By contrast, splice site mutation c.2109-2A $>C$ did not show an aberrant splicing pattern. This finding suggested that the transcript of the mutated allele is subject to nonsense-mediated mRNA decay. CYLD mRNA expression was measured in peripheral blood leukocytes by quantitative RT-PCR. This confirmed the outcome of our RT-PCR, since only mutation c.2109-2A $>C$ is associated with evident mRNA decay. Clinically, the patient carrying mutation c.2109-2A>C presented with cylindromas only. As opposed to this, mutations c. $2108+1 G>A$ and c.2242-2A $>G$ only lead to negligible mRNA decay, indicating that transcription from these mutant alleles might result in the formation of truncated and dysfunctional proteins. Clinically, both patients carrying these mutations showed cylindromas and trichoepitheliomas. Although these data could indicate a certain genotype-phenotype-correlation, the residual amounts of mRNA seem to be unrelated to the distinct phenotypes in patients with CYLD splice site mutations, because mutation c.2109-2A>C has already been described in a patient with trichoepithelioma only. ${ }^{8}$ This finding currently largely excludes a genotype-phenotype correlation in BSS. 
Since a single CYLD mutation can give rise to different phenotypes, even within one family, the question arises whether other mechanisms are involved in the development of BSS, multiple familial trichoepithelioma and familial cylindromatosis. Such factors may include as of yet unknown environmental factors, modifier genes or epigenetic events. ${ }^{9}$

\section{Mosaicism in BSS}

A segmental or linear presentation of cylindromas, trichoepitheliomas or spiradenomas has been described on few occasions only. ${ }^{10-17}$

Here, we studied a female patient with trichoepitheliomas in a segmental distribution on her shoulder, as described in chapter 3.3. Clinically, we considered a type 1 segmental mosaicism since i) the tumors occurred at the same age as one would expect the common and diffuse phenotype to manifest, and ii) disease severity was equal as in the symmetric phenotype caused by a heterozygous germline mutation. After extracting DNA from the segmentally aligned trichoepitheliomas, direct sequencing of the CYLD gene did not reveal a mutation. This, however, does not completely rule out the possibility of a postzygotic somatic CYLD mutation as underlying genetic cause. For instance, it would be conceivable that we missed a CYLD mutation located in the promoter or deep intronic regions. Likewise, epigenetic events could be responsible for the phenotype, as could be the involvement of other, hitherto unknown genes. As to the latter, one possible candidate gene could be located within the linkage interval for multiple familial trichoepitheliomas on chromosome 9p21, as previously reported. ${ }^{5}$ In this context, it would be challenging and interesting to study more patients with mosaic manifestation of cylindromas, trichoepitheliomas or spiradenomas, to elucidate the underlying pathogenetic mechanisms.

\section{Treatment}

To date, no curative therapy is available for BSS. The treatment of first choice in affected patients with BSS is surgical excision of the tumors. However, in individuals with a turban tumor this can be challenging, mainly due to two reasons. First, the possible extent of the tumors masses; and second, due to the fact that cylindromas and trichoepitheliomas are hair follicle tumors, which results in the necessity to excise the entire skin to prevent tumor recurrence. Furthermore, the functional outcome of a subsequent reconstruction is very important because affected individuals often want to wear a wig post surgery. The use of artificial dermis to establish a solid outcome is well established in the management of acute burns and oncological resections with fullthickness calvarial defects. ${ }^{18,19}$ In cooperation with our colleagues from the Department of Plastic and Reconstructive Surgery of the Maastricht University Medical Center+ we for the first time treated a female patient with extensive tumor manifestation on the scalp with this therapeutic regimen, as described in chapter 4 . 
Since the treatment of turban tumors is very complex, we generally recommend a multidisciplinary approach in which dermatologists, plastic surgeons, psychologists, and otorhinolaryngologists can bundle their expertise.

Theoretically, a targeted, pathway-based therapy would be desirable. This could be achieved, e.g. by interference with the NF-KB signaling route. Although Brummelkamp and colleagues ${ }^{20}$ as well as other groups have explored such therapeutic approaches, they altogether have been unsuccessful, as of yet. Still, such causal therapeutic attempts could eventually lead to improved treatment options for affected individuals. Salicylic acid inhibits IKK-gamma, and thereby it interferes with the canonical NF-KB pathway. However, its inhibitory potential is weak and, thus, a possible solution could be the use of more potent pathway inhibitors. We also applied this treatment to the patient described in chapter 2. Unfortunately though, this therapy likewise was not successful. Therefore, more insights into the underlying genetic mechanisms governing tumor formation will be needed to improve targeted therapeutic approaches in BSS.

\section{Part 2. Bazex-Dupré-Christol syndrome}

\section{Clinical spectrum}

Besides the characteristic clinical triad of hypotrichosis, follicular atrophoderma and basal cell carcinomas that was described in the original report of Bazex, Dupré and Christol, ${ }^{21}$ other symptoms can be encountered less frequently. These symptoms features comprise milia, hypohidrosis, hair shaft abnormalities, such as pili torti and trichorrhexis nodosa, facial hyperpigmentation, pinched nose with hypoplastic nasal alae and prominent columella, and trichoepitheliomas.

In an attempt to delineate more precisely the frequency of milia, we revisited all reports on BDCS. Thereby, we found that milia occur more often than, e.g. follicular atrophoderma, namely in $81 \%$ of patients and families with BDCS, as described in chapter 7. ${ }^{22-24}$ Therefore, we suggest that milia should be added to the triad of hypotrichosis, follicular atrophoderma and basal cell carcinomas, as a frequent clinical manifestation of the disorder.

To date, the manifestation of basal cell carcinomas in BDCS was described from the second decade onwards. In chapter 7, however, we show for the first time these tumors may also occur in children at the age of three and five years, respectively. Whenever basal cell carcinomas occur in young individuals, an underlying genetic disorder, such as BDCS, should be excluded. Other hereditary tumor disorders to be excluded in such cases include basal cell nevus syndrome, Rombo syndrome, Oley syndrome and Xeroderma pigmentosum, as described in chapter 5.

The differential diagnosis between BDCS and these other disorders may be difficult since there are overlapping clinical features. Patients with basal cell nevus syndrome 
develop basal cell carcinomas and facial milia, but, most importantly, also extracutaneous manifestations such as macrocephaly, jaw cysts and skeletal abnormalities, which are not encountered in BDCS. Rombo syndrome is an autosomal dominant disorder characterized by vermiculate atrophoderma on the elbows and cheeks, development of basal cell carcinomas, hypotrichosis, trichoepitheliomas and reddening of the skin. Both vermiculate atrophoderma on the elbows and cheeks as well as peripheral vasodilatation have not yet been described in BDCS. Oley syndrome manifests with congenital hypotrichosis, milia and basal cell carcinomas. However, it is not clear if it reflects an own entity or merely a milder variant of BDCS. Individuals with Xeroderma pigmentosum can also develop basal cell carcinomas. However, this disorder can also manifest with other malignant skin tumors, e.g. malignant melanoma, and is characterized by severe early-onset photosensitivity, premature skin ageing, photophobia, and poikiloderma.

In approximately one third of families with BDCS, trichoepitheliomas are observed. ${ }^{22,25-28}$ Both clinically and histologically, it can be difficult to differentiate between basal cell carcinomas and trichoepitheliomas. The predilection sites of basal cell carcinomas and trichoepitheliomas are similar and include the head and neck region as well as the trunk. Histologically, both trichoepitheliomas and basal cell carcinomas show nests of basaloid cells with follicular differentiation. Trichoepitheliomas show trabecular nests surrounded by stroma containing fibroblasts, while basal cell carcinomas manifest peripheral palisading of basaloid keratinocytes, cleft formation between tumor nests and stroma, ulceration and mitotic figures. However, not all characteristics may be present, and therefore it can be challenging to distinct a trichoepithelioma from a basal cell carcinoma histologically. Additional immunohistochemistry can offer diagnostic support in these cases. In previous studies, several immunohistochemical markers have been applied, albeit with ambiguous results. Here, we studied the potential of androgen receptor and TGF- $\beta$ as histological biomarkers for the differentiation between these two tumors, as described in chapter 6 .

Androgen receptor is a nuclear ligand-dependent transcription factor that is activated by binding to androgens, testosterone, of dihydrotestosterone. It is expressed in $80 \%$ of basal cell carcinomas, but not in trichoepitheliomas, as confirmed by Mostafa et al. and Arits et al. ${ }^{29,30}$ Whereas a positive staining confirms the diagnosis of basal cell carcinoma, a negative staining does not exclude it.

TGF- $\beta$ plays a key role in controlling cell proliferation and differentiation. TGF- $\beta$ shows a positive staining in trichoepitheliomas, but is negative in basal cell carcinomas. Other useful markers to differentiate between basal cell carcinomas and trichoepitheliomas include CD10, Ki-67, and PHLDA1. ${ }^{29}$ 


\section{Molecular genetic background}

Until recently, the underlying genetic defect of BDCS was unknown. An X-linked inheritance pattern was suspected since none of the affected families showed male-to-male transmission. In 1995, Vabres and colleagues mapped the gene of BDCS to chromosome Xq24-27.1. ${ }^{31}$ In chapter 8, we studied a German family with BDCS and performed haplotype analysis. We were able to refine the candidate region to an $11.4 \mathrm{Mb}$ interval on chromosome Xq25-27.1, which contained 101 genes. Since we hypothesized that the causing gene would play a role in hair follicle differentiation and regulating cell proliferation, we selected 12 candidate genes: ACTRT1, AIFM1, RAB33A, SUHW3/ZNF280C, ENOX2, MST4, RAP2C/TFPD3, HS6ST2, ZNF449, ZNF75D, GPR112, and ARHGEF6. We performed mutation analysis of the coding regions and adjacent splice sites, but were not able to detect a pathogenic mutation. Interestingly, Bal and colleagues reported in 2017 that they found mutations in the ACTRT1 gene in two families with BDCS, and germline mutations in transcribed sequences encoding enhancer RNAs (eRNAs), located in the non-coding sequences surrounding the ACTRT1 gene in 4 other families with BDCS. $^{32}$ Intriguingly, the ACTRT1 gene is located outside our candidate region in a 2.6 $\mathrm{Mb}$ gene desert, and we did not detect a mutation in the ACTRT1 gene in our family. One explanation could be that the underlying genetic defect in our family is located in non-coding sequences of the ACTRT1 gene that we did not sequence. Other possible explanations for not detecting disease-causing sequence alterations in the ACTRT1 gene in our family could be either mutations in the promoter region or eRNAs; or the involvement of other hitherto unknown genes in disease pathogenesis. Likewise, epigenetic events could silence the function of ACTRT1, e.g. DNA methylation or histone modification.

The ACTRT1 gene encodes for actin-related protein T1 (ARP-T1), which plays a role in cell growth and/or maintenance. ARP-T1 inhibits the transcription factor GLI1 expression by binding to the GLI1 promoter, which leads to activation of the Hedgehog signaling pathway. The hedgehog signaling pathway is also involved in the development of sporadic basal cell carcinomas and basal cell nevus syndrome. ${ }^{33}$ Further studies will be required to elucidate possible other pathogenetic mechanisms involved in BDCS.

In summary, our studies on BSS and BDCS show that several facets of these disorders are still not well understood and require in depth molecular studies to better understand the underlying pathogenetic mechanisms. This, eventually, should also lead to the development of better treatment modalities with less necessity for repeated surgical interventions and, thus, to an increased quality of life for affected individuals. 


\section{References}

1. Poblete Guriérrez PP, Eggermann T, Höller D, Jugert FK, Beermann T, Grussendorf-Conen EI, Zerres K, Merk HF, Frank J. Phenotype diversity in familial cylindromatosis: a frameshift mutation in the tumor suppressor gene CYLD underlies different tumors of skin appendages. J Inverst Dermatol. 2002;119(2):527-31.

2. Lauritzen E, Ibrahim RM, Schmidt G. Turban tumour with intracranial invasion. Ugeskr Laeger. 2018;180(23).pii:V11170856.

3. Friedrich RE. Dermal cylindroma of the scalp (turban tumour) and subjacent calvarian defects. Anticancer Res. 2010;30(5):1793-7.

4. Gildea JH, Lillehei KO, Golitz LE, Kleinschmidt-DeMasters BK. Benign cylindroma causing transcalvarial invasion in a patient with familial cylindromatosis. Clin Neuropathol. 2007;26(3):125-30.

5. Harada H, Hashimoto K, Ko MS. The gene for multiple familial trichoepithelioma maps to chromosome 9p21. J Invest Dermatol. 1996;107(1):41-3.

6. Hentze MW, Kulozik AE. A perfect message: RNA surveillance and nonsense-mediated decay. Cell. 1999;96:307-10.

7. Frio TR, Civic N, Ransijn A, Beckmann JS, and Rivolta C. Two trans-acting eQTLs modulate the penetrance of PRPF31 mutations. Hum Mol Genet. 2008;17:3154-65.

8. Duparc A, Lasek-Duriez A, Wiart T, Duban-Bedu B, Gosset P, Modiano P. Multiple familia trichoepithelioma: a new CYLD gene mutation. Ann Dermatol Venereol. 2013;140:274-7.

9. Iliopulos D, Jaeger SA, Hirsch HA, Bulyk ML, Struhl K. STAT3 activation of miR-21 and miR-181b-1 via PTEN and CYLD are part of the epigenetic switch linking inflammation to cancer. Moll Cell. 2010;39:493-506.

10. Rosales Santillan M, Atajnert K, Swaby MG, Migden MR, Silapunt S. Multiple eccrine spiradenomas in a zosteriform pattern. Dermatol Online J. 2017;23:13.

11. Gordon S, Styron BT, Haggstrom A. Pediatric segmental eccrine spiradenomas: a case report and review of the literature. Pediatric Dermatol. 2013;30:e285-6.

12. Englander L, Emer JJ, McClain D, Amin B, Turner RB. A rare case of multiple segmental eccrine spiradenomas. J Clin Aesthet Dermatol. 2011;4:38-44.

13. Geffner RE, Boslen B, Santa Cruz DJ. Linear and dermatomal trichoepitheliomas. J Am Acad Dermatol. 1986;14:927-30.

14. Chang YC, Colome-Grimmer M, Kelly E. Multiple trichoepitheliomas in the lines of Blaschko. Pediatr Dermatol. 2006;23:149-51.

15. Schirren CG, Worle B, Kind P, Plewig G. A nevoid plaque with histological changes of trichoepithelioma and cylindroma in Brooke-Spiegler syndrome. An immunohistochemical study with cytokeratins. J Cutan Pathol. 1995;22:563-9.

16. Oh DH, Lane AT, Turk AE, Kohler S. A young boy with a large hemifacial plaque with histopathologic features of trichoepithelioma. J Am Acad Dermatol. 1997;37:881-3.

17. Furuichi M, Makino T, Yamakoshi T, Matsui K, Shimizu T. Blaschkoid distribution of cylindromas in a germline CYLD mutation carrier. Br J Dermatol. 2012;166(6):1376-8.

18. Dantzer E, Braye FM. Reconstructive surgery using an artificial dermis (Integra): results with 39 grafts. Br J Plast Surg. 2001;54(8):659-64.

19. Wain RA, Shah SH, Senarath-Yapa K, Laitung JK. Dermal substitutes doe well on dura: comparison of split skin grafting +/- artificial dermis for reconstruction of full-thickness calvarial defects. J Plast Reconstr Aesthet Surg. 2010;63:e286-8.

20. Brummelkamp TR, Nijman AMB, Dirac AMG, Bernards R. Loss of the cylindromatosis tumour suppressor inhibits apoptosis by activating NF-kB. Nature. 2003:424:797-801.

21. Bazex A, Dupre A, Christol B. Génodermatose complexe de type indéterminé associant une hypotrichose, un état atrophodermique généralisé et des dégénérescences cutanées multiples (épithéliomasbasocellulaires). Bull Soc Franc Derm Syph. 1964;71:206. 
22. Gonfiantini MV, Armando M, Pucciarini ML, Macchiaiolo M, Buonuomo PS, Diociaiuti A, Lepri FR, Sirleto P, Vicari S, Bartuli A. Borderline cognitive level in a family with Bazex-Dupré-Christol syndrome. Am J Med Genet A. 2015;167:1637-43.

23. Chauhan P, Meena D, Dhanta A, Kansal NK, Durgapal P. Bazex-Dupré-Christol syndrome: first report in an Indian familiy. Indian J Dermatol Venereol Leprol. 2018;84:451-6.

24. Yesenia Arévalo N, Buján MM, Cervini AB, Pierini AM. Bazex-Dupré-Christol syndrome: Case series. Arch Argent Pediatr. 2015;113:e256-9.

25. Yung A, Newton-Bishop JA. A case of Bazex-Dupré-Christol syndrome associated with multiple genital trichoepitheliomas. Br J Dermatol. 2005;153:682-4.

26. Castori M, Castiglia D, Passarelli F, Paradisi M. Bazex-Dupré-Christol syndrome: an ectodermal dysplasia with skin appendage neoplasms. Eur J Med Genet. 2009;52:250-5.

27. Goeteyn M, Geerts ML, Kint A, De Weert J. The Bazex-Dupré-Christol syndrome. Arch Dermatol. 1994;130:337-42.

28. Kidd A, Carson L, Gregory DW, de Silva D, Holmes J, Dean JC, Haites N. A Scottish family with BazexDupré-Christol syndrome: follicular atrophoderma, congenital hypotrichosis, and basal cell carcinoma. J Med Genet. 1996;33:493-7.

29. Mostafa NA, Assaf M, Elhakim S, Abdel-Halim MRE, El-Nabarawy E, Ghareeb K. Diagnostic accuracy of immunohistochemical markers in differentiation between basal cell carcinoma and trichoepithelioma in small biopsy specimens. J Cutan Pathol. 2018; epub ahead of print.

30. Arits AH, van Marion AM, Lohman BG, Thissen MR, Steijlen PM, Nelemans PJ, Kelleners-Smeets NW. Differentiation between basal cell carcinoma and trichoepithelioma by immunohistochemical staining of the androgen receptor: an overview. Eur J Dermatol. 2011;21(6):870-3.

31. Vabres P, Lacombe D, Rabinowitz LG, Aubert G, Anderson CE, Taieb A, Bonafe JL, Hors-Cayla MC. The gene for Bazex-Dupré-Christol syndrome maps to chromosome Xq. J Invest Dermatol. 1995;105:87-91.

32. Bal E, Park HS, Belaid-Choucair Z, Kayserili H, Naville M, MAdrange M, Chiticariu E, HAjd-Rabia S, Cagnard N, Kuonen F, Bachmann D, Huber M, Le Gall C, Cote F, Hanein S, Rosti RO, Aslanger AD, Waisfisz Q, Bodemer C, Hermine O, Morice-Picard F, Labeille B, Caux F, Mazereeuw-Hautier J, Philip N, Levy N, Taieb A, Avril MF, Headon DJ, Gyapay G, Magnaldo T, Fraitag S, Crollius HR, Vabres P, Hohl D, Munnich A, Smahi A. Mutations in ACTRT1 and its enhancer RNA elements lead to aberrant activation of Hedgehog signalling in inherited and sporadic basal cell carcinomas. Nat Med. 2017;23:1226-33.

33. Abe Y, Tanaka N. Roles of the Hedgehog signaling pathway in epidermal and hair follicle development, homeostasis, and cancer. J Dev Biol. 2017;5:E12. 

Summary 
In this thesis, two rare genetic disorders are discussed, both of which are characterized by the development of skin adnexal tumors.

In the first part, we shed light on Brooke-Spiegler syndrome, an autosomal dominant genodermatosis. Patients with Brooke-Spiegler syndrome develop cylindromas, trichoepitheliomas, and/or spiradenomas. The diseases familial cylindromatosis and multiple familial trichoepitheliomas show a huge degree of clinical overlap. Both Brooke-Spiegler syndrome, familial cylindromatosis and multiple familial trichoepitheliomas are caused by mutations in the CYLD gene, thereby representing different ends of genetically allelic diseases.

In the second part of this thesis, we illustrate Bazex-Dupré-Christol syndrome. This very rare $\mathrm{X}$-linked disorder is characterized by congenital hypotrichosis, follicular atrophoderma and the occurrence of basal cell carcinomas at young age. In some patients and families previously reported, mutations in the ACTRT1 gene have been reported. However, to date, the genetic alterations underlying the disease in several more affected families have not yet been unraveled.

In chapter 1, we provide a general introduction on Brooke-Spiegler syndrome and Bazex-Dupré-Christol syndrome. We describe the different tumors that can arise in these disorders and review the current knowledge regarding the molecular background and therapeutic options.

In chapter 2, we describe a 37-year-old patient with a turban tumor. He developed progressive hearing loss over approximately four years and presented with pain in the right external acoustic meatus since four weeks. Physical examination showed a cylindroma with a diameter of one centimeter in the right meatus externus that caused an obstruction. After radical excision of the tumor the hearing defect resolved completely.

Chapter 3 is subdivided in three sections, in which we present the results of mutation analysis in the CYLD gene in patients with a tentative diagnosis of Brooke-Spiegler syndrome.

In 3.1 we studied three unrelated Caucasian patients with Brooke-Spiegler syndrome. The diagnosis was based on the characteristic clinical manifestations and histopathological examination. We performed mutation analysis in the CYLD gene, which showed two novel pathogenic splice site mutations, designated c.2108+1G>A and c.2242-2A>G and a recurrent pathogenic mutation, designated c.2109-2A>C. Of note, the mutation identified in the first patient, c.2108+1G>A, was not detectable in either parent. This is the first de novo mutation reported in Brooke-Spiegler syndrome. The consequences of splices site mutations in the CYLD gene had not yet been studied before. To select the appropriate tissue for RNA studies, we showed that CYLD is almost equally expressed in normal human keratinocytes, leukocytes and peripheral blood mononuclear cells. Mutations c. $2108+1 \mathrm{G}>\mathrm{A}$ and c.2242A $>\mathrm{G}$ resulted in exon skipping of exon 15 and 17, respectively, while we did not find an aberrant splicing pattern for 
c. $2109-2 A>C$. By qRT-PCR, we showed that mutations c. $2108+1 G>A$ and c. $2242-2 A>C$ did not result in a significant decrease of mRNA levels whereas mutation c.2109-2A>C is associated with approximately 60\% mRNA decay when compared to a control. However, no genotype-phenotype correlations could be deduced from these results.

In 3.2, we sought to elucidate the molecular genetic basis in 7 German and 1 Turkish patients with multiple cylindromas, trichoepitheliomas and/or spiradenomas. Mutation analysis showed two missense, two nonsense, two deletion, and two duplication mutations in the CYLD gene, respectively c.2261T>G, c.2581T>G, c.2409C>A, c.2540G >A, c.2081del, c.822del, c.2649dup and c.588_591dup. Seven of these mutations had not been reported previously. We give an overview on all mutations in the CYLD gene described earlier.

In 3.3, we present a 24-year-old patient with a segmental manifestation of trichoepitheliomas on her right shoulder, following the lines of Blaschko. The clinical presentation was suggestive of a segmental type 1 somatic mosaicism, according to Happle. Segmental manifestations of Brooke-Spiegler syndrome are rare and had not been analyzed on the molecular genetic level previously. We performed mutation analysis in the CYLD gene on peripheral blood mononuclear cells and tumor tissue but could not detect any pathogenic mutations.

In chapter 4, we describe a novel therapeutic regimen for turban tumor. A 47-year-old woman with a turban tumor suffered from depression and felt secluded from social life due to her appearance. The purpose of treatment was creating a robust skin to enable her wearing a wig. We performed a total scalp excision down to the periosteum, followed by coverage of the periosteum with an artificial dermis. Three weeks thereafter, we successfully covered the artificial dermis with split skin grafts. Four months after the surgery, she was able to wear a wig, which resulted in an increased self-esteem.

In chapter 5, we provide an overview on hereditary diseases featuring basal cell carcinomas. We discuss basal cell nevus syndrome, Bazex-Dupré-Christol syndrome, Rombo syndrome, Oley syndrome and Xeroderma pigmentosum.

Chapter 6 delineates the difficulties in differentiating between trichoepitheliomas and basal cell carcinomas, both clinically and histopathologically. Immunohistochemical examination can provide additional information, and we show that immunostaining with androgen receptor and TGF- $\beta$ can be helpful to differentiate these two tumors.

In chapter 7, we present a German family with Bazex-Dupré-Christol syndrome. The index patient and her mother developed a basal cell carcinoma at the age of three and five years, respectively. They also manifested hypotrichosis, milia in the face and on the ears and follicular atrophoderma. Both her grandfather and grand-grandmother had a medical history of similar clinical symptoms. Since the basal cell carcinomas occurred in early childhood, we advise that screening for basal cell carcinomas should already be initiated from the first decade of life onwards by an experienced dermatologist when 
the tentative diagnosis of Bazex-Dupré-Christol syndrome is made because the tumor manifestation might be subtle at onset. We also revised all cases of Bazex-DupréChristol syndrome and showed that $80 \%$ of the patients develop milia. We therefore suggest that milia should be added as an additional cutaneous symptom to the primordially clinical triad of hypotrichosis, follicular atrophoderma and basal cell carcinomas.

In chapter 8, we describe a six-generation pedigree of German origin with Bazex-DupréChristol syndrome. Up to that point, the disorder was linked to a $23.3 \mathrm{Mb}$ interval on the long arm of chromosome X (Xq24-27.1) but the underlying genetic defect was unknown. By performing haplotype analysis, we were able to refine the candidate region to an 11.4 Mb interval (Xq25-27.1). Subsequently, we screened 12 candidate genes for mutations, namely ACTRT1, AIFM1, RAB33A, SUHW3/ANF280C, ENOX2, MST4, RAP2C/TFPD3, HS6ST2, ZNF449, ZNF75D, GPR112, and ARHGEF6. However, we did not find a pathogenic mutation although mutations in the ACTRT1 gene were recently described in a subset of patients with Bazex-Dupré-Christol syndrome. 


\section{Samenvatting}


Dit proefschrift richt zich op twee zeldzame genetische aandoeningen die gekenmerkt worden door het ontstaan van huidadnextumoren.

In het eerste deel wordt gekeken naar het Brooke-Spiegler syndroom, een autosomaal dominante genodermatose. Patiënten met Brooke-Spiegler syndroom ontwikkelen cylindromen, trichoepitheliomen en/of spiradenomen. De ziektes familiaire cylindromatose en multipele familiaire trichoepitheliomen tonen grote klinische overlap. Zowel Brooke-Spiegler syndroom als familiaire cylindromatose en multipele familiaire trichoepitheliomen worden veroorzaakt door mutaties in het CYLD gen en representeren verschillende eindes van genetisch allelische aandoeningen.

In het tweede deel van dit proefschrift wordt het Bazex-Dupré-Christol syndroom belicht. Dit is een zeer zeldzame X-gebonden ziekte, gekenmerkt door congenitale hypotrichose, folliculaire atrophoderma en het ontstaan van basaalcelcarcinomen op jonge leeftijd. In enkele eerder beschreven patienten en families zijn mutaties in het ACTRT1 gen gerapporteerd. Echter, tot op heden zijn in verschillende andere families de genetische veranderingen die ten grondslag liggen aan de ziekte nog niet opgehelderd.

In hoofdstuk 1 wordt een algemene introductie gegeven over het Brooke-Spiegler en Bazex-Dupré-Christol syndroom. Hierin wordt aandacht gegeven aan de verschillende tumoren die kunnen ontstaan in deze ziekten, en er wordt een overzicht gegeven over de huidige kennis van de moleculaire achtergrond en de therapeutische opties.

In hoofdstuk 2 beschrijven we een 37-jarige patiënt met een turban tumor. Hij had sinds 4 jaar progressieve gehoorverlies aan het rechter oor en sinds 4 weken pijn in de rechter gehoorgang. Lichamelijk onderzoek toonde een 1 centimeter groot cylindroom in de rechter gehoorgang waardoor er een obstructie van de gehoorgang was ontstaan. Het cylindroom werd verwijderd waarna de gehoorsproblemen verdwenen. Nadien werd hij behandeld met topicaal 20\% salicylzuur in elastic collodion basis, echter zonder effect.

Hoofdstuk 3 is onderverdeeld in drie delen. Hierin worden de resultaten weergegeven van de mutatieanalyse van het CYLD gen bij patiënten met een klinische verdenking op Brooke-Spiegler syndroom.

In 3.1 beschrijven we 3 niet-gerelateerde Caucasische patiënten met BrookeSpiegler syndroom. De diagnose was gesteld op basis van het klinisch beeld en histopathologie. We hebben mutatie-analyse van het CYLD gen uitgevoerd en dit toonde twee niet-eerder beschreven pathogene splice site mutaties, te weten c.2108+1G $>A$ en c.2242-2A>G, en een reeds bekende pathogene splice site mutatie c.2109-2A>C. Opvallend was dat de ouders van de eerste patiënte met mutatie c.2108+1G>A geen drager waren van deze mutatie. Dit is de eerste gerapporteerde de novo mutatie in BrookeSpiegler syndroom. De consequenties van splice site mutaties in het CYLD gen waren nooit eerder beschreven. Om het goede weefsel te selecteren voor RNA studies, toonden we aan dat de expressie van CYLD in humane epidermale keratinocyten, leukocyten en perifere bloed mononucleaire cellen nagenoeg gelijk is. Mutaties c. $2108+1 \mathrm{G}>\mathrm{A}$ en 
c.2242-2A>G resulteerden in exon skipping van respectievelijk exon 15 en 17, terwijl er geen splicing patroon werd gevonden voor c.2109-2A>C. qRT-PCR toonde overeenkomstig deze resultaten dat mutaties c.2108+1G $>A$ en c.2242-2A $>G$ geen significante verlaging lieten zien van mRNA levels, terwijl mutatie c.2109-2A>C is geassocieerd met ongeveer $60 \%$ mRNA decay vergeleken met een controle. Deze uitkomsten leidden echter niet tot een genotype-phenotype correlatie.

In 3.2 hebben we 7 Duitse patiënten en 1 Turkse patiënte onderzocht met multipele cylindromen, trichoepitheliomen en/of spiradenomen. Mutatie-analyse toonde twee missense, twee nonsense, twee deletie en twee duplicatie mutaties in het CYLD gen, te weten c.2261T>G, c.2581T>G, c.2409C>A, c.2540G>A, c.2081del, c.822del, c.2649dup en c.588_591dup, waarvan er zeven niet eerder gerapporteerd waren. We geven een overzicht van de eerder beschreven CYLD mutaties.

In 3.3 presenteren we een 24-jarige patiënte met segmentale trichoepitheliomen volgens de lijnen van Blaschko op haar rechter schouder. Klinisch paste het beeld bij een type 1 segmentale vorm van mosaïcisme. Segmentale varianten van BrookeSpiegler syndroom zijn zeldzaam, en waren niet eerder genetisch geanalyseerd. We hebben mutatie-analyse verricht van het CYLD gen in het perifere bloed en in het aangedane weefsel. Dit liet echter geen mutaties zien.

In hoofdstuk 4 beschrijven we een nieuwe therapeutische optie voor een turban tumor. We rapporteren een 47-jarige vrouw met een turban tumor, die zich depressief en sociaal geïsoleerd voelde door haar uiterlijk. Doel van de behandeling was het creëren van een robuuste huid waardoor ze een pruik kon gaan dragen. We voerden excisie van de huid uit tot op het periost, gevolgd door het aanbrengen van een artificiële dermis. Drie weken later konden er split skin transplantaten geplaatst worden met zeer goed resultaat. Vier maanden na de ingreep kon ze een pruik dragen met een positief effect op haar zelfbeeld.

In hoofdstuk 5 geven we een overzicht van erfelijke ziekten met basaalcelcarcinomen. Hierin worden het basaalcel naevus syndroom, Bazex-Dupré-Christol syndroom, Rombo syndroom, Oley syndroom en Xeroderma pigmentosum beschreven.

Hoofdstuk 6 laat zien dat het moeilijk kan zijn om zowel klinisch als histopathologisch onderscheid te maken tussen trichoepitheliomen en basaalcelcarcinomen. Immunohistochemisch onderzoek kan hierbij helpen. In deze sectie tonen we dat de immunokleuringen met de androgene receptor en TGF- $\beta$ kunnen helpen bij het differentiëren tussen deze twee tumoren.

In hoofdstuk 7 wordt een Duitse familie beschreven met Bazex-Dupré-Christol syndroom waarbij de index patiënte en haar moeder op respectievelijk drie- en vijfjarige leeftijd een basaalcelcarcinoom ontwikkelden. Daarnaast toonden zij hypotrichose, milia in het gezicht en op de oren en folliculaire atrophoderma. Grootvader en anamnestisch ook overgrootmoeder hadden vergelijkbare klinische symptomen. Gezien de 
jonge leeftijd waarop de basaalcelcarcinomen zijn ontstaan adviseren we om bij patiënten bij wie klinisch gedacht wordt aan Bazex-Dupré-Christol syndroom vanaf de eerste decade van het leven al te screenen op basaalcelcarcinomen door een ervaren dermatoloog aangezien de afwijkingen subtiel kunnen zijn. Daarnaast hebben we alle beschreven patiënten van Bazex-Dupré-Christol syndroom gereviseerd en daaruit blijkt dat ruim $80 \%$ van de patiënten milia ontwikkelt. We suggereren daarom dat milia toegevoegd moeten worden aan de oorspronkelijke triade van hypotrichose, folliculaire atrophoderma en basaalcelcarcinomen.

In hoofdstuk 8 hebben we een Duitse familie van zes generaties beschreven met BazexDupré-Christol syndroom. Tot dan toe was de aandoening gelinkt aan een 23.3 Mb interval op het X-chromosoom (Xq24-27.1), maar het onderliggende genetische defect was niet bekend. We hebben door middel van haplotype analyse het interval op chromosoom X kunnen verkleinen naar een 11,4 Mb interval (Xq25-27.1). Daarnaast hebben we 12 kandidaatgenen gescreend middels mutatie-analyse, te weten ACTRT1, AIFM1, RAB33A, SUHW3/ANF280C, ENOX2, MST4, RAP2C/TFPD3, HS6ST2, ZNF449, ZNF75D, GPR112, en ARHGEF6. We konden echter geen mutatie aantonen in deze genen, hoewel recent mutaties in het ACTRT1 gen in enkele patiënten met Bazex-Dupré-Christol syndroom zijn beschreven. 


\section{List of abbreviations}

aa

ARP-T1

$\mathrm{BCC}$

BCNS

BDCS

bp

BSS

CAP-GLY

DUB

eRNA

EXAC

FC

GLI

HGVS

IKK

K48

K63

LPS

MFT

NEMO

NF-KB

NHEK

NIK

PBMC

PCR

PTC

PTCH1

RT-PCR

qRT

$\mathrm{SHH}$

SMO

TE

TGF-ß

TLR

TRAF-2

$\mathrm{UCH}$

USP

$X P$ amino acids

actin-related protein $\mathrm{T} 1$

basal cell carcinoma

Basal cell nevus syndrome

Bazex-Dupré-Christol syndrome

base pairs

Brooke-Spiegler syndrome

cytoskeleton-associated protein glycine-rich

deubiquitinating enzyme

enhancer RNA

Exome Aggregation Consortium

familial cylindromatosis

glioma-associated oncogene

Human Genome Variation Society

IKappaB-kinase

lysine-48

lysine-63

lipopolysaccharide

multiple familial trichoepithelioma

NF-kB essential modulator

nuclear factor-kappa B

normal human epidermal keratinocytes

NF-kB-inducing kinase

peripheral blood mononuclear cells

polymerase chain reaction

premature termination codon

patched1

reverse transcriptase PCR

quantitative reverse transcriptase

Sonic hedgehog

smoothened

trichoepithelioma

transforming growth factor- $§$

Toll-like receptor

tumor necrosis factor associated receptor 2

ubiquitin C-terminal hydrolase

ubiquitin-specific protease

Xeroderma pigmentosum 



\section{Curriculum vitae}

Lizelotte Johanna Maria Theresia Parren is geboren op 7 augustus 1983 te Sittard. Zij groeide op in Papenhoven in een gezin met een broer en een zusje. Na het doorlopen van het gymnasium op scholengemeenschap Trevianum te Sittard van 1995 tot en met 2001, startte ze aansluitend met de studie geneeskunde aan de Universiteit Maastricht. Tijdens het co-schap dermatologie ontstond interesse voor dit vakgebied. De wetenschappelijke stage in de laatste 4 maanden van haar geneeskunde-opleiding werd ingevuld door een onderzoek naar de klinische en genetische aspecten van huidadnextumoren onder begeleiding van Jorge Frank. Na het behalen van haar arts-examen in 2007 werd ze direct aangenomen voor de opleiding tot dermatoloog in het Academisch Ziekenhuis Maastricht (nu geheten Maastricht Universitair Medisch Centrum+) en kon haar onderzoek worden voortgezet in de vorm van een promotietraject naast de opleiding. In deze tijd was zij actief betrokken bij het opzetten van het inloopspreekuur en lymfoomspreekuur en het schrijven van het vernieuwde opleidingsplan. Daarnaast zette zij zich in als vertegenwoordiger van de arts-assistentengroep als algemeen bestuurslid van de Vereniging voor Arts-assistenten Dermatologie en Venereologie van 2008 tot 2012 en was zij in deze periode lid van het Concilium Dermatologicum et Venereologicum. Op 1 augustus 2012 rondde zij haar opleiding tot dermatoloog af, waarna ze toetrad tot de vakgroep dermatologie van het Jeroen Bosch Ziekenhuis te 'sHertogenbosch. 



\section{List of publications}


Zweegers J, Weppner-Parren LMT. Bleomycine-geïnduceerde flagellate dermatitis. NTVDV. 2018; accepted.

Parren LMT, Giehl K, van Geel M, Frank J. Phenotype variability in tumor disorders of the skin appendages. Arch Dermatol Res. 2018;310(7):599-606.

Parren LIMT, Baron JM, Joussen S, Marquardt Y, Hanneken S, van Steensel MAM, Steijlen PM, van Geel M, Frank J. CYLD mutations differentially affect splicing and mRNA decay in Brooke-Spiegler syndrome. J Eur Acad Dermatol Venereol. 2018; Epub ahead of print.

Zweegers J, Roosenboom B, van de Kerkhof PC, van den Reek JM, Otero ME, Atalay S, Kuijpers AL, Koetsier MI, Arnold WP, Berends MA, Weppner-Parren LMT, Bijen M, Njoo MD, Mommers JM, van Lümig PP, Driessen RJ, Kievit W, de Jong EM. Frequency and predictors of a high clinical response in patients with psoriasis on biological therapy in daily practice: results from the prospective, multicenter BioCAPTURE cohort. Br J Dermatol. 2017;176(3):786-93.

Zweegers J, van den Reek JM, van de Kerkhof PC, Otero ME, Kuijpers AL, Koetsier MI, Arnold WP, Berends MA, Weppner-Parren LMT, Ossenkoppele PM, Njoo MD, Mommers JM, van Lümig PP, Driessen RJ, Kievit W, de Jong EM. Body mass index predicts discontinuation due to ineffectiveness and female sex predicts discontinuation due to side-effects in patients with psoriasis treated with adalimumab, etanercept or ustekinumab in daily practice: a prospective, comparative, long-term drug-survival study from the BioCAPTURE registry. Br J Dermatol. 2016;175(2):340-7.

Parren LMT, Munte K, Winnepenninckx V, van Geel M, Steijlen PM, Frank J, van Steensel MAM. Clustered unilateral trichoepitheliomas indicate Type 1 segmental manifestation of multiple familial trichoepithelioma. Clin Exp Dermatol. 2016;41(6):682-4.

Sezgi P, Weppner-Parren LMT, Greebe RJ, Mol SJJ, Mutsaers ER, van Geest AJ. Kaposisarcoom bij 3 hiv-negatieve patienten. Een zeldzaam fenomeen. NTvDV. 2015;25:321-4.

Parren LMT, Ferdinandus P, van der Hulst R, Frank J, Tuinder S. A novel therapeutic strategy for turban tumor: scalp excision and combined reconstruction with artificial dermis and split skin graft. Int J Dermatol. 2014;53(2):246-9.

Otters EFM, Tebbe-Gholami T, Weppner-Parren LMT. Trigeminal trophic syndrome. NTvDV. 2014;24(7):444-5.

Abuzahra F, Parren LMT, Frank J. Multiple familial and pigmented basal cell carcinomas in early childhood - Bazex-Dupré-Christol syndrome. J Eur Acad Dermatol Venereol. 2012;26(1):117-21. 
Pi Van de Venne SJA, Stegmann APA, Parren LMT, Steijlen PM, Herbergs J, van LentAlbrechts JA, van Geel M, van Steensel MAM, Nagtzaam IF. X-gebonden recessieve ichthyosis bij een vrouw. NTVDV. 2012;22:389-90.

Martens H, Westers-Attema A, Parren LMT, Winnepennickx VJL, Nagtzaam IF. Een aandoening met twee gezichten. NTVDV. 2012;22:364-7.

Parren LMT, Frank J. Hereditary tumour syndromes featuring basal cell carcinomas. Br J Dermatol. 2011;165(1):30-4.

Parren LMT, Abuzahra F, Wagenvoort T, Koene F, van Steensel MAM, Steijlen PM, van Geel M, Frank J. Linkage refinement of Bazex-Dupré-Christol syndrome to an 11.4-Mb interval on chromosome Xq25-27.1. Br J Dermatol. 2011;165(1):201-3.

Parren LMT, van Marion AM, Frank J. Sarcoidose in een litteken. NTVDV. 2010;20:126128.

Parren LMT, van Pelt J. Diagnose in beeld: een jongetje met bultjes op de schouder. NTvG. 2010;154:A1083.

Parren LMT, Bauer B, Hamm H, Frank J. Brooke-Spiegler syndrome complicated by unilateral hearing loss. Int J Dermatol. 2008;47(Suppl 1):56-9.

Arits AH, Parren LMT, van Marion AM, Sommer A, Frank J, Kelleners-Smeets NW. Basal cell carcinoma and trichoepithelioma: a possible matter of confusion. Int J Dermatol. 2008;47 (Suppl 1):13-7.

Parren LMT, Nellen RG, van Marion AM, Henquet CJ, Frank J, Poblete-Gutiérrez P. Penile pyoderma gangrenosum: successful treatment with colchicine. Int J Dermatol. 2008;47(Suppl 1):7-9.

Van Steensel MAM, van Geel M, Parren LMT, Schrander-Stumpel CT, MarcusSoekarman D. Shprintzen-Goldberg syndrome associated with a novel missense mutation in TGFBR2. Exp Dermatol. 2008;17(4):362-5.

Parren LMT, van Steensel MAM, van Geel M, van Marion AMW, Steijlen PM, PobleteGutiérrez P, Frank J. Brooke-Spiegler syndroom: kliniek en moleculaire achtergrond. NTvDV. 2007;17:291-4. 

Dankwoord 
En toen was het eindelijk dan toch zover... Gestart in 2007 en met verschillende tussenpozen is mijn proefschrift dan toch afgerond. Dank aan iedereen die me op welke manier dan ook geholpen heeft bij het tot stand laten komen van dit proefschrift. Daarbij wil ik enkele personen specifiek bedanken:

Professor Steijlen, u heeft me in 2007 aangenomen voor de opleiding terwijl ik net uit de schoolbanken kwam. Daarnaast heeft u me de mogelijkheid geboden om naast mijn opleiding dit wetenschappelijk onderzoek uit te voeren. Hartelijk dank voor dit vertrouwen.

Jorge, in 2007 heeft u me onder uw hoede genomen tijdens mijn wetenschappelijke stage in het laatste half jaar van mijn geneeskundestudie. $U$ heeft me met uw liefde voor de wetenschap geënthousiasmeerd voor het verrichten van onderzoek. Ik ben blij dat het ons uiteindelijk toch gelukt is om het promotietraject af te ronden. Hartelijk dank voor alle energie die $u$ in de begeleiding van mij gestoken heeft.

Michel, je hebt me wegwijs gemaakt in het laboratorium en me vaak geholpen als ik door de bomen het bos niet meer zag. Wat was het fijn dat ik met elke vraag bij je terecht kon. Hartelijk dank voor de begeleiding en steun.

Dank aan alle patiënten en families die hebben geparticipeerd in het onderzoek. Zonder jullie bijdrage was dit proefschrift er niet geweest.

Annet en Ivo, jullie zijn vandaag mijn paranimfen.

Annet, ik ken je al vanaf onze eerste onderwijsgroep in 2001. Toevallig kwamen we elkaar aan het eind van de geneeskundestudie weer tegen omdat we beiden interesse in dermatologie hadden. Tijdens de opleiding was jij mijn maatje.

Ivo, tijdens het begin van de opleiding bleek al snel dat we het goed met elkaar konden vinden. Ik heb genoten van de wandelingen in het heuvelland, het bezoeken van congressen in San Diego en Denver en jouw heerlijke pastagerechten.

Hoewel we elkaar niet dagelijks spreken waardeer ik onze vriendschap enorm. Dank voor al jullie positiviteit en dat jullie aan mijn zijde willen staan op dit belangrijke moment.

Alle collega's uit het lab, met name Reno en Miriam: hartelijk dank voor de begeleiding en gezelligheid.

Alle co-auteurs, dank voor het aanmelden van patiënten en de hulp bij het uitvoeren van enkele onderzoeken en de bijdrages voor artikels.

Dames van het secretariaat in Maastricht: dank voor de ondersteuning en alle gezellige gesprekken. Jullie hulp is enorm belangrijk geweest om vooruit te komen.

Annelieske, ik vond het erg fijn dat ik aan het eind van het traject voor elke vraag bij je terecht kon. Leuk dat we ook na mijn tijd in Maastricht contact hebben gehouden. 
Oud-collega's uit Maastricht, ik heb genoten van mijn assistententijd. Hartelijk dank voor alle gezellige momenten en de mooie tijd. Stafleden, dank voor het opleiden en de interesse.

Collega's uit het Jeroen Bosch Ziekenhuis, ik ben in 2012 heel fijn ontvangen in 'sHertogenbosch. We hebben een leuk team van secretaresses, doksterassistenten, verpleegkundigen en artsen waarin ik me gewaardeerd voel. Dank voor de steun en de fijne samenwerking! Adrienne, Denise, Mitra, Monique, Rens en Robert Jan, dank dat jullie me de ruimte hebben gegeven om deze promotie af te kunnen ronden.

Beste leden van de beoordelingscommissie en corona, dank voor het lezen en beoordelen van mijn proefschrift.

Lieve (schoon)familie en vrienden, bedankt voor jullie vriendschap, steun en interesse. De leuke gesprekken en gezelligheid maakten dat ik weer energie had om verder te kunnen werken. Ik hoop vanaf nu meer tijd voor jullie te hebben.

Ineke, je staat altijd voor ons klaar en we kunnen altijd op je terugvallen. Dat waardeer ik enorm. Hartelijk dank voor alles!

George, wat had ik graag gehad dat je er vandaag bij was geweest.. Ik mis je.

Clim en Nicolette, ik ben dankbaar dat jullie er altijd voor me zijn en dat we zo'n sterke band hebben. Ik zeg het misschien niet vaak, maar ik ben heel blij met jullie!

Lieve pap en mam, zonder jullie had ik hier niet gestaan. Dank voor de fijne jeugd die jullie ons gegeven hebben. Jullie hebben me laten zien dat je met hard werken bijna alles kunt bereiken. Jullie staan altijd voor ons klaar en hebben altijd een luisterend oor. Ik hou van jullie.

Jeroen, met jouw optimisme en nuchterheid weet je me altijd aan het lachen te maken en kan je me weer laten relativeren. Je bent de liefde van mijn leven en ben enorm dankbaar voor het feit dat je er altijd voor onze kleine wondertjes en mij bent... Ik hou van je.

Thomas, Rosalie en $\boldsymbol{\bullet}$. Met jullie aanwezigheid is het leven veel mooier. Jullie zijn mijn alles, mijn wondertjes. Ik hou enorm veel van jullie! 
